\title{
U.S. Geological Survey Ecosystems Science Strategy- Advancing Discovery and Application through Collaboration
}

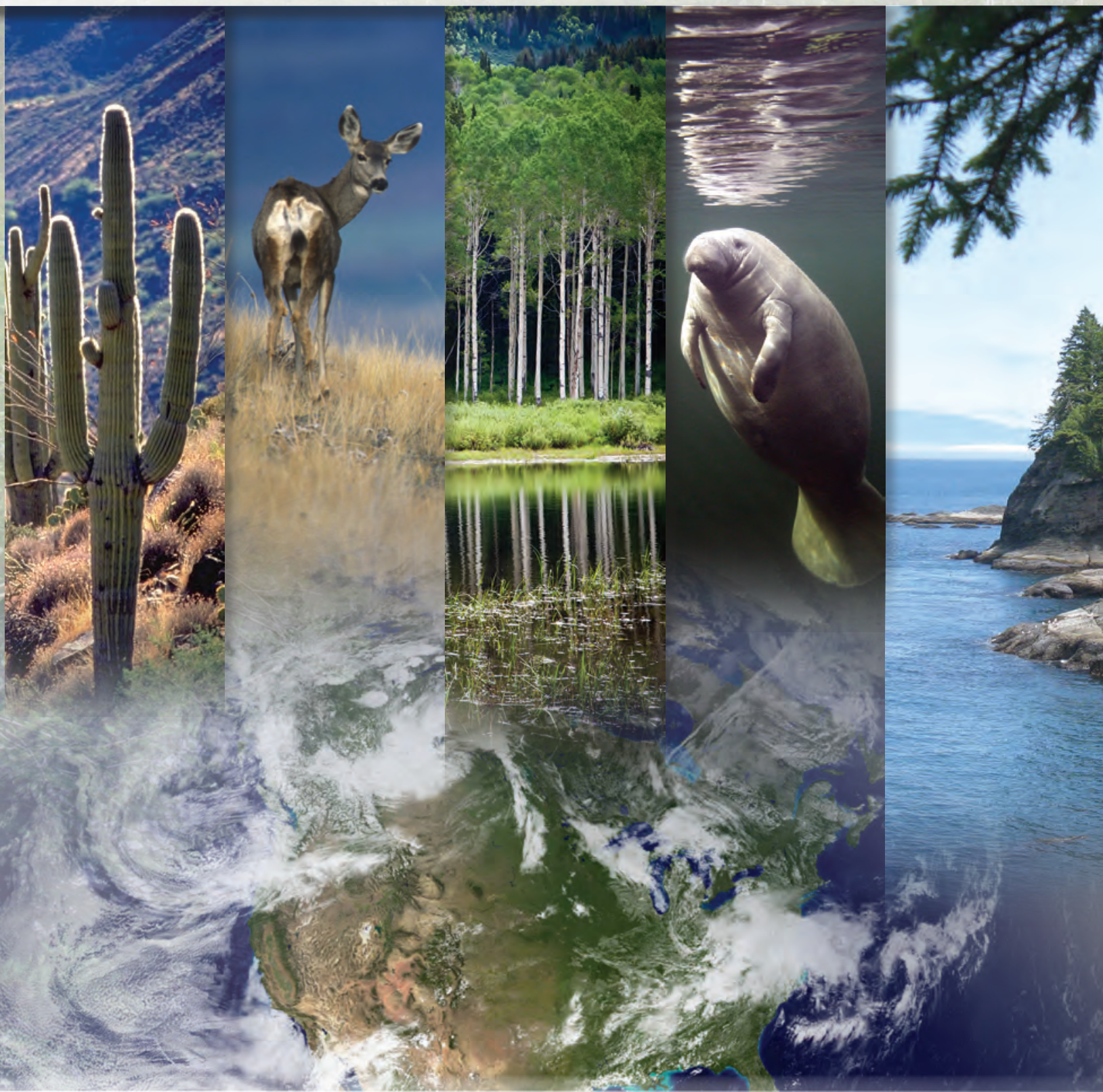

Circular 1383-C

U.S. Department of the Interior U.S. Geological Survey 



\section{U.S. Geological Survey Ecosystems Science Strategy-Advancing Discovery and Application through Collaboration}

By Byron K. Williams, G. Lynn Wingard, Gary Brewer, James E. Cloern, Guy Gelfenbaum, Robert B. Jacobson, Jeffrey L. Kershner, Anthony D. McGuire, James D. Nichols, Carl D. Shapiro, Charles van Riper III, and Robin P. White

Circular 1383-C 


\section{U.S. Department of the Interior \\ KEN SALAZAR, Secretary \\ U.S. Geological Survey \\ Marcia K. McNutt, Director}

U.S. Geological Survey, Reston, Virginia: 2013

For more information on the USGS — the Federal source for science about the Earth, its natural and living resources, natural hazards, and the environment, visit http://www.usgs.gov or call 1-888-ASK-USGS.

For an overview of USGS information products, including maps, imagery, and publications, visit http://www.usgs.gov/pubprod

To order this and other USGS information products, visit http://store.usgs.gov

Any use of trade, firm, or product names is for descriptive purposes only and does not imply endorsement by the U.S. Government.

Although this information product, for the most part, is in the public domain, it also may contain copyrighted materials as noted in the text. Permission to reproduce copyrighted items must be secured from the copyright owner.

Suggested citation:

Williams, B.K., Wingard, G.L., Brewer, Gary, Cloern, J.E., Gelfenbaum, Guy, Jacobson, R.B., Kershner, J.L., McGuire, A.D., Nichols, J.D., Shapiro, C.D., van Riper III, Charles, and White, R.P., 2013, U.S. Geological Survey ecosystems science strategy —Advancing discovery and application through collaboration:

U.S. Geological Survey Circular 1383-C, 43 p. 


\section{Foreword}

In 2007, the U.S. Geological Survey (USGS) published a Bureau Science Strategy Facing Tomorrow's Challenges - U.S. Geological Survey Science in the Decade 2007-2017. It provided a view of the future, establishing science goals that reflected the USGS's fundamental mission in areas of societal impact such as energy and minerals, climate and land use change, ecosystems, natural hazards, environmental health, and water. Intended to inform long-term program planning, the strategy emphasizes how USGS science can make substantial contributions to the well-being of the Nation and the world.

In 2010, I realigned the USGS management and budget structure, changing it from a structure associated with scientific disciplines — Geography, Geology, Biology and Hydrology — to an issue-based organization along the lines of the Science Strategy. My aim was to align our management structure with our mission, our science priorities, our metrics for success, and our budget. An added benefit was that the USGS immediately appeared relevant to more Americans, and it became easier for those outside the agency to navigate our organizational structure to find where within the USGS they would find the solution to their problem. External partners rarely approached us with a problem in "geology," but they might need help with an issue in climate change or energy research.

The new organization is focused on seven science mission areas:

- Climate and Land Use Change

- Core Science Systems

- Ecosystems

- Energy and Minerals

- Environmental Health

- Natural Hazards

- Water

The scope of each of these new mission areas is broader than the science directions outlined in the USGS Science Strategy and together cover the scope of USGS science activities.

In 2010, I also commissioned seven Science Strategy Planning Teams (SSPTs) to draft science strategies for each USGS mission area. Although the existing Bureau Science Strategy could be a starting point for this exercise, the SSPTs had to go well beyond the scope of the existing document. What is of value and enduring from the work of the programs that existed under the former science disciplines needed to be reframed and reinterpreted under the new organization of the science mission areas. In addition, new opportunities for research directions have emerged in the five years since the Bureau Science Strategy was drafted, and exciting possibilities for cooperating and collaborating in new ways are enabled by the new mission focus of the organization.

Scientists from across the Bureau were selected for these SSPTs for their experience in strategic planning, broad range of experience and expertise, and knowledge of stakeholder needs and relationships. Each SSPT was charged with developing a long-term (10-year) science strategy that encompasses the portfolio of USGS science in the respective mission area. Each science strategy will reinforce others because scientific knowledge inherently has significance to multiple issues. Leadership of the USGS and the Department of the Interior will use the science vision and priorities developed in these strategies for program guidance, implementation planning, accountability reporting, and resource allocation. These strategies will guide science and technology investment and workforce and human capital strategies. They will inform our partners regarding opportunities for communication, collaboration, and coordination.

The USGS has taken a significant step toward demonstrating that we are ready to collaborate on the most pressing natural science issues of our day and the future. I believe a leadership aligned to support these issue-based science directions and equipped with the guidance provided in these new science strategies in the capable hands of our scientists will create a new era for USGS of which we can all be proud.

Marcia McNutt

Director 


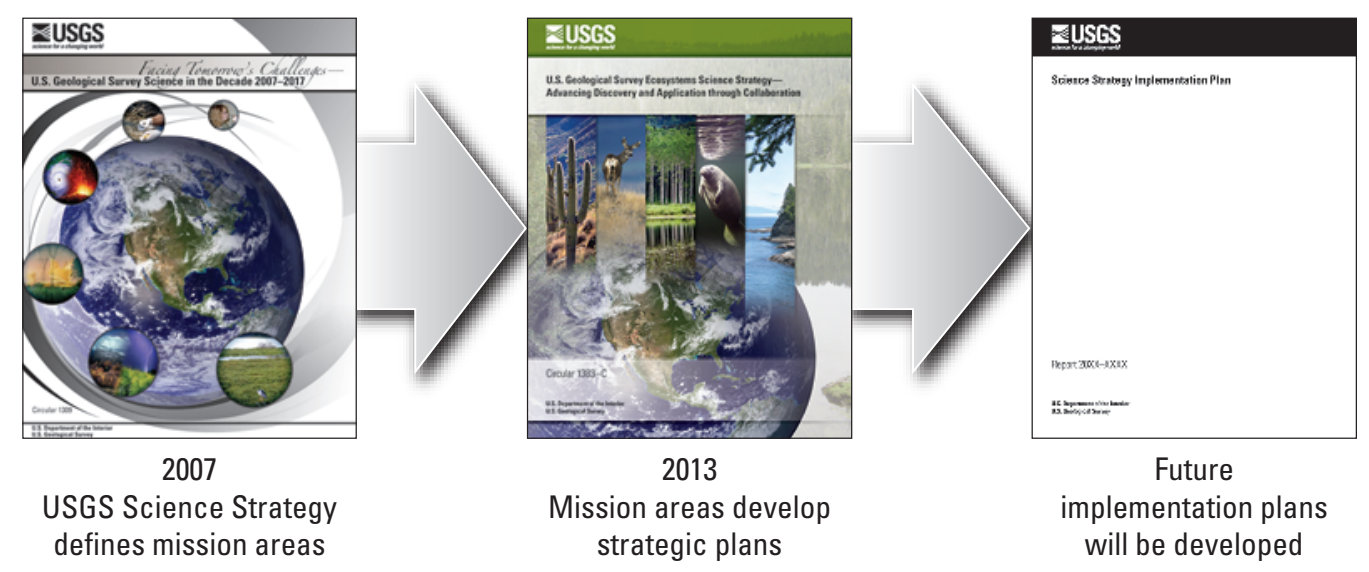

\section{About this Report}

This document describes a 10-year strategy to address priority environmental and resource management challenges for the U.S. Geological Survey (USGS) Ecosystems Mission Area. The strategy articulates a vision to improve understanding of how and why ecosystems change and explains how USGS ecosystem science can help inform managers and policy-makers to sustain and restore natural resources, protect vital ecosystem services, and secure the long-term health and economic well-being of U.S. citizens. Ecosystem science is by nature a collaborative process involving many scientific disciplines and expertise, and though the USGS has a strong, interdisciplinary science workforce, it is not the only agency involved in ecosystem research. We recognize that many Federal, State, and nongovernmental agencies and universities are actively involved in ecosystem science, and we hope that the strategy articulated in this document will provide a framework to build on interdisciplinary partnerships for future collaboration.

Fundamental to the ongoing development of the Ecosystems Strategy has been the engagement of external partners and USGS scientists and managers across USGS mission areas. Team members have participated in more than 25 listening sessions, including sessions held for USGS regional offices, science centers, offices of other Department of the Interior (DOI) bureaus, and participants at regional science workshops and national conferences. Input has been received verbally and in writing from many USGS colleagues, partners, and stakeholders who addressed the team by way of teleconferences, during listening sessions, and through the USGS Science Strategy Planning Team (SSPT) Web site. The team compiled, categorized, and evaluated verbal and written input from all of these sources and the resulting plan was released for public comment in June 2012 as USGS Open-File Report 2012-1092. This Circular represents a final compilation of the input we have received toward developing this science strategy. Future implementation will involve a collaborative process among USGS associate directors, program coordinators, science center directors, and DOI partners. 

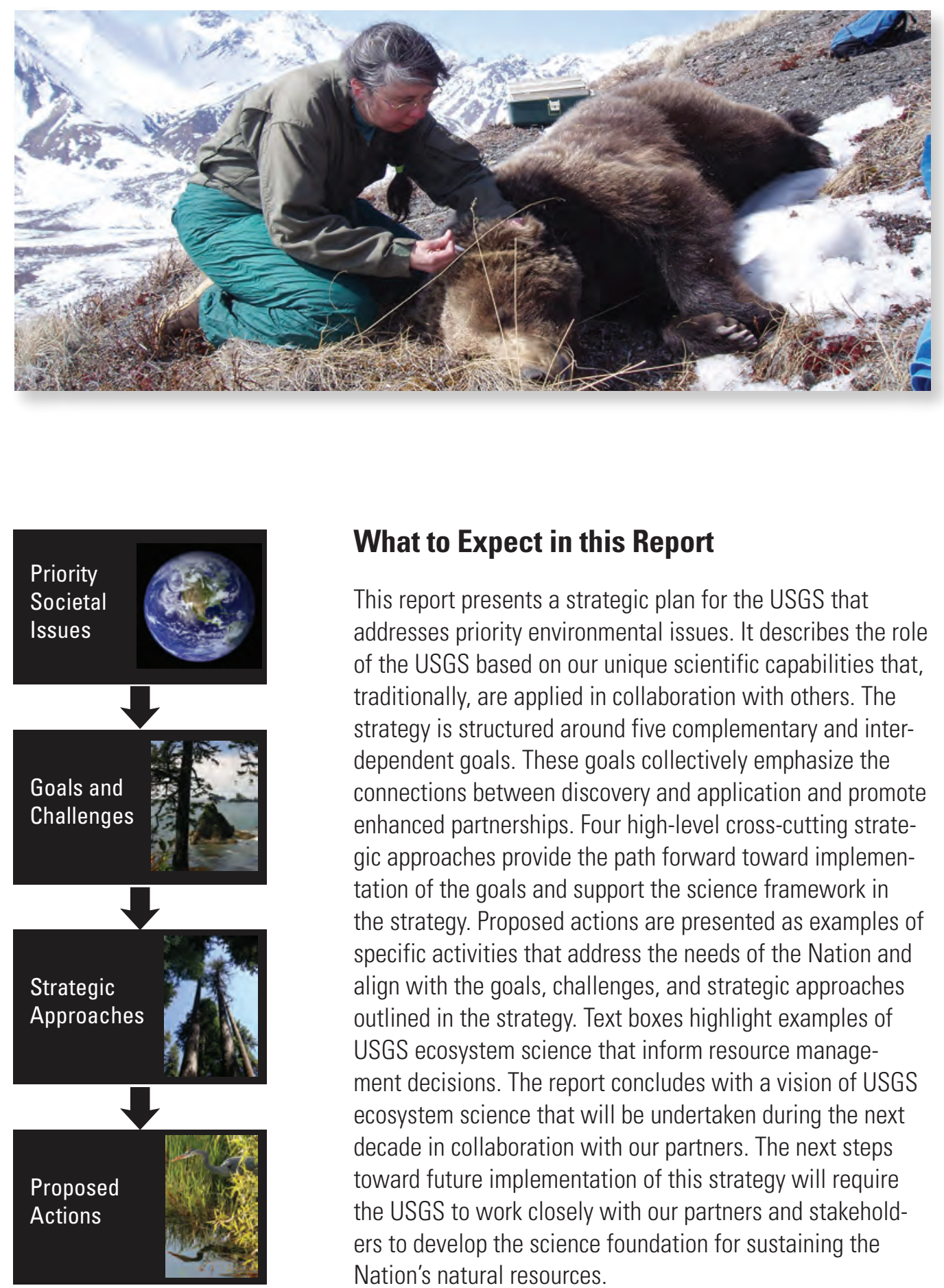

\section{What to Expect in this Report}

This report presents a strategic plan for the USGS that addresses priority environmental issues. It describes the role of the USGS based on our unique scientific capabilities that, traditionally, are applied in collaboration with others. The strategy is structured around five complementary and interdependent goals. These goals collectively emphasize the connections between discovery and application and promote enhanced partnerships. Four high-level cross-cutting strategic approaches provide the path forward toward implementation of the goals and support the science framework in the strategy. Proposed actions are presented as examples of specific activities that address the needs of the Nation and align with the goals, challenges, and strategic approaches outlined in the strategy. Text boxes highlight examples of USGS ecosystem science that inform resource management decisions. The report concludes with a vision of USGS ecosystem science that will be undertaken during the next decade in collaboration with our partners. The next steps toward future implementation of this strategy will require the USGS to work closely with our partners and stakeholders to develop the science foundation for sustaining the Nation's natural resources. 


\section{Contents}

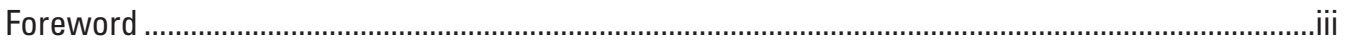

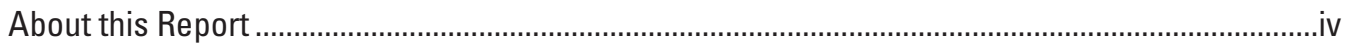

What to Expect in this Report .....................................................................................................

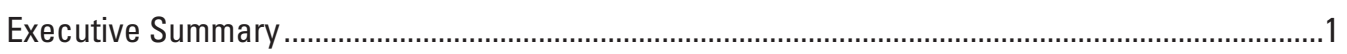

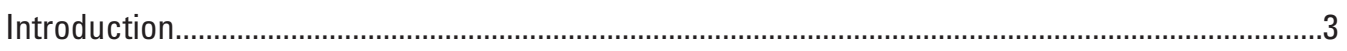

Why Does the Nation Need Ecosystem Science? ..............................................................

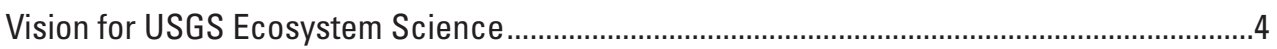

Roles of Scientific Discovery and Application......................................................................

Building on USGS Foundations and Strengths ……...........................................................

Holistic, Cross-Scale Science Capabilities ........................................................................

Monitoring, Assessment, and Modeling .....................................................................

Interdisciplinary Science .................................................................................................

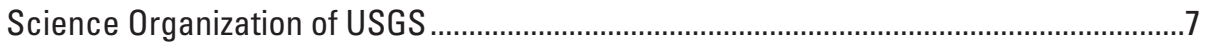

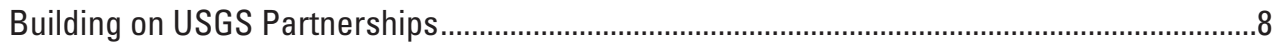

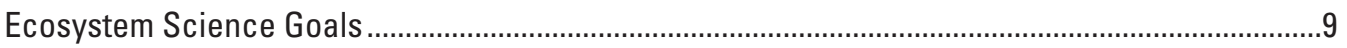

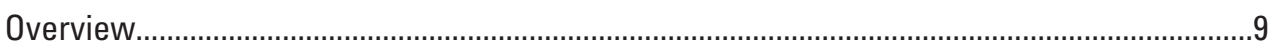

Goal 1: Improve Understanding of Ecosystem Structure, Function, and Processes..............12

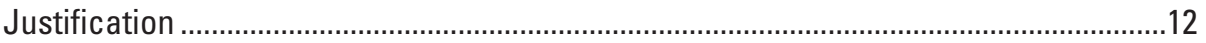

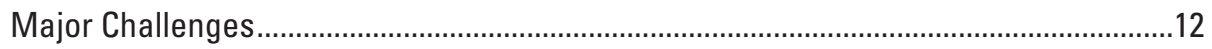

Goal 2: Advance Understanding of How Drivers Influence Ecosystem Change.....................14

Justification .............................................................................................................

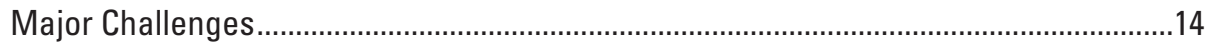

Goal 3: Improve Understanding of the Services that Ecosystems Provide to Society............16

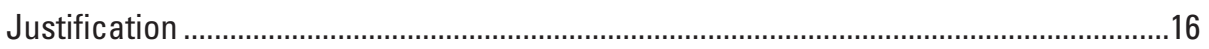

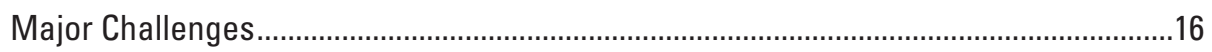

Goal 4: Develop Tools, Technologies, and Capacities to Inform Decisionmaking about

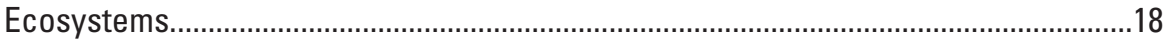

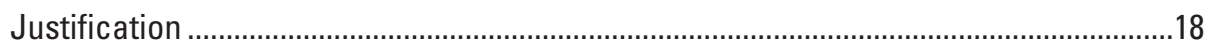

Major Challenges............................................................................................................18

Goal 5: Apply Science to Enhance Strategies for Management, Conservation, and

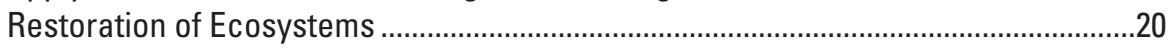

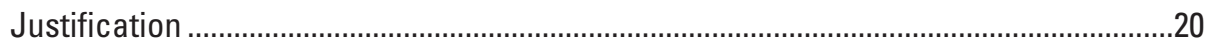

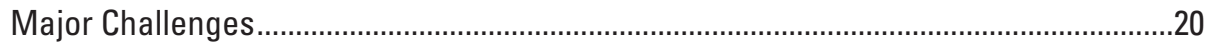

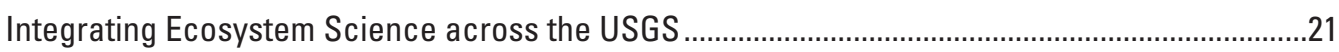

Climate and Land Use Change................................................................................24

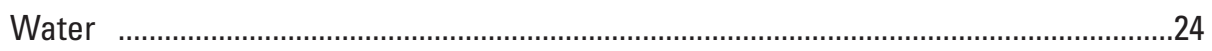

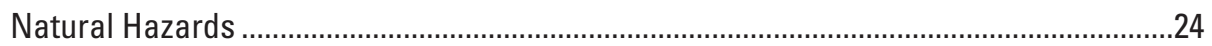

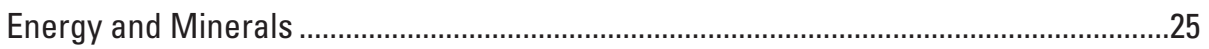

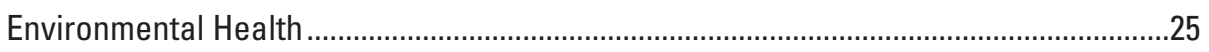

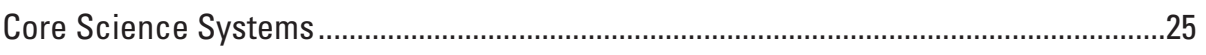

Strategic Approaches and Outcomes: The Path Forward ..............................................................26 
Strategic Approach 1. Assess Information Needs for Ecosystem Science through Enhanced Partnerships

Strategic Approach 2. Promote the Use of Interdisciplinary Ecosystem Science ..................28

Strategic Approach 3. Enhance Modeling and Forecasting ...............................................29

Strategic Approach 4. Support Decisionmaking ................................................................30

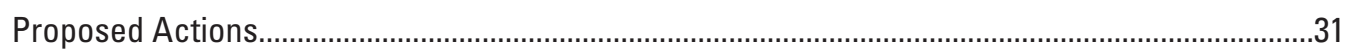

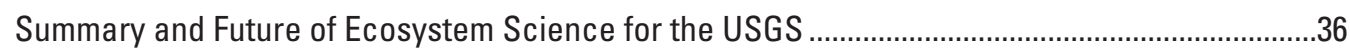

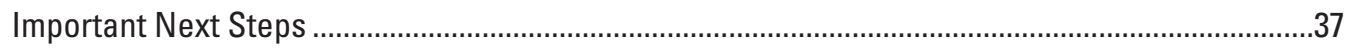

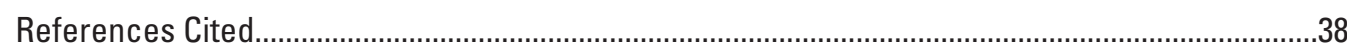

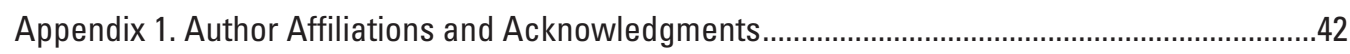

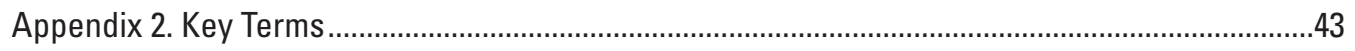

\section{Figures}

1. Diagram showing the interconnections between goals, USGS mission areas, discovery and application, and resource management..

2. Diagram showing the study of an ecosystem and the drivers influencing the system while fully engaging and integrating resource management in the process

Highlights

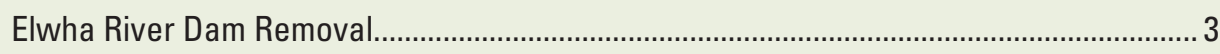

Lake Drying in Alaska ....................................................................................................... 4

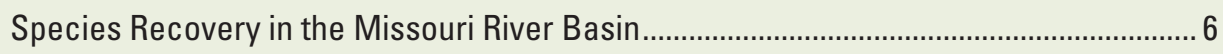

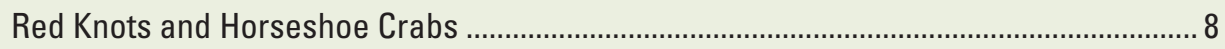

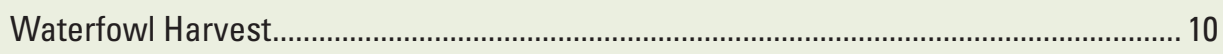

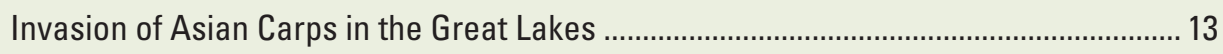

Stressors to the Sacramento—San Joaquin Delta ......................................................... 15

Valuing Ecosystem and Economic Services across Land-Use Scenarios in the

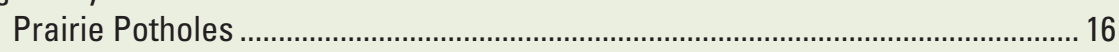

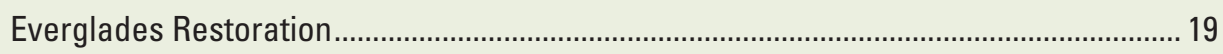

Science to Enhance Management of the Chesapeake Bay.............................................. 20

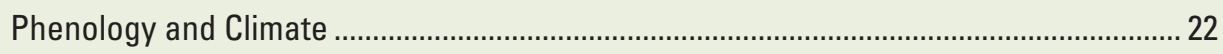

United States-Mexico Border ........................................................................................... 27

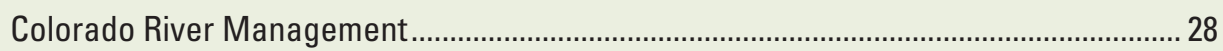

Golden Eagles in Denali Park................................................................................... 30

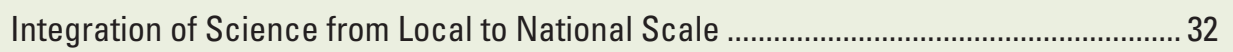




\title{
U.S. Geological Survey Strategy for Ecosystems Science-Advancing Discovery and Application Through Collaboration
}

\author{
Byron K. Williams, G. Lynn Wingard, Gary Brewer, James E. Cloern, Guy Gelfenbaum, Robert B. Jacobson, \\ Jeffrey L. Kershner, Anthony D. McGuire, James D. Nichols, Carl D. Shapiro, Charles van Riper III, and \\ Robin P. White
}

\section{Executive Summary}

Ecosystem science is critical to making informed decisions about natural resources that can sustain our Nation's economic and environmental well-being. Resource managers and policymakers are faced with countless decisions each year at local, regional, and national levels on issues as diverse as renewable and nonrenewable energy development, agriculture, forestry, water supply, and resource allocations at the urbanrural interface. The urgency for sound decisionmaking is increasing dramatically as the world is being transformed at an unprecedented pace and in uncertain directions. Environmental changes are associated with natural hazards, greenhouse gas emissions, and increasing demands for water, land, food, energy, mineral, and living resources. At risk is the Nation's environmental capital, the goods and services provided by resilient ecosystems that are vital to the health and wellbeing of human societies. Ecosystem science - the study of systems of organisms interacting with their environment and the consequences of natural and human-induced change on these systems - is necessary to inform decisionmakers as they develop policies to adapt to these changes.

This Ecosystems Science Strategy is built on a framework that includes basic and applied science. It highlights the critical roles that U.S. Geological Survey (USGS) scientists and partners can play in building scientific understanding and providing timely information to decisionmakers. The strategy underscores the connection between scientific discoveries and the application of new knowledge, and it integrates ecosystem science and decisionmaking, producing new scientific outcomes to assist resource managers and providing public benefits. We envision the USGS as a leader in integrating scientific information into decisionmaking processes that affect the Nation's natural resources and human well-being.
The USGS is uniquely positioned to play a pivotal role in ecosystem science. With its wide range of expertise, the Bureau can bring holistic, cross-scale, interdisciplinary capabilities to the design and conduct of monitoring, research, and modeling and to new technologies for data collection, management, and visualization. Collectively, these capabilities can be used to reveal ecological patterns and processes, explain how and why ecosystems change, and forecast change over different spatial and temporal scales. USGS science can provide managers with options and decision-support tools to use resources sustainably. The USGS has long-standing, collaborative relationships with the Department of the Interior (DOI) and other partners in the natural sciences, in both conducting science and applying the results. The USGS engages these partners in cooperative investigations that otherwise would lack the necessary support or be too expensive for a single bureau to conduct.

The heart of this strategy is a framework for USGS ecosystems science that focuses on five long-term goals, which are seen as interconnected components that reinforce our vision of the USGS providing science that is at the forefront of decisionmaking:

- Improve understanding of ecosystem structure, function, and processes. The focus for this goal is an understanding of how ecosystems work, including the dynamics of species, their populations, interactions, and genetics, and how they change across spatial and temporal scales.

- Advance understanding of how drivers influence ecosystem change. The challenges here are explaining the drivers of ecosystem change, their spatio-temporal 
patterns, their uncertainties and interactions, and their influence on ecosystem processes and dynamics.

- Improve understanding of the services that ecosystems provide to society. Here the emphasis is on the measurement of environmental capital and ecosystem services, and the identification of sources and patterns of change in space and time.

- Develop tools, technologies, and capacities to inform decisionmaking about ecosystems. This includes developing new technologies and approaches for conducting applications-oriented ecosystem science. A principal challenge will be how to quantify uncertainty and incorporate it in decision analysis.

- Apply science to enhance strategies for management, conservation, and restoration of ecosystems. These challenges include development of novel approaches to monitoring, assessment, and restoration of ecosystems; new methods to address species of concern and communities at risk; and innovations in decision analysis and support to address imminent ecosystem changes or those that are underway.

Closely integrated with the five goals are four strategic approaches that provide the path forward for the USGS Ecosystems Mission Area. These approaches cross-cut all of the goals and are seen as essential to the implementation of this strategy:

- Assess information needs for ecosystem science through enhanced partnerships. Work with the DOI and other agencies and institutions to identify, design, and implement priority decision-driven ecological research.

- Promote the use of interdisciplinary ecosystem science. Design and conduct interdisciplinary process-oriented research in ecosystem science.
- Enhance modeling and forecasting. Build models to forecast ecosystem change, assess future management scenarios, and reduce uncertainties through an adaptive learning process.

- Support decisionmaking. Use quantitative approaches to assess the vulnerabilities of ecosystems, habitats, and species, and evaluate strategies for adaptation, restoration, and sustainable management.

Following the four strategic approaches are a set of proposed actions that represent a sampling of specific USGS activities that align with this strategy and that address the Nation's most pressing environmental needs.

The strategy emphasizes coordination of activities across the USGS mission areas pursuant to these goals. Ecosystem science is inherently interdisciplinary and requires a broad perspective that incorporates the biological and physical sciences, climate science, information technology, and scientific capacity in mission areas across the Bureau. With its emphasis on coordination, this strategy can provide a critical underpinning for integrated science efforts with scientists from multiple mission areas of the USGS working together. Of course, the USGS will continue to conduct discipline-specific and interdisciplinary investigations, and both will continue to be vital parts of the ecosystem science portfolio.

Finally, the strategy stresses the importance of coordination with other Federal agencies and organizations in the natural resources community. The USGS collaborates with resource agencies in the DOI and other organizations throughout the world to meet societal needs for species and ecosystem management. Working with these agencies and organizations, the USGS will play a key role in guiding sound decisionmaking during the next decade by advancing the scientific foundation for sustaining the natural resources that diverse, productive, resilient ecosystems provide.

Site of former Lake Aldwell after removal of Elwha Dam, Washington, 2012. Photograph by Robin White, USGS. 
Ecosystem science is the study of systems of organisms interacting with their environment and the consequences of natural and human-induced change on those systems.

\section{Introduction}

\section{Why Does the Nation Need Ecosystem Science?}

The Nation's social and economic development hinges on healthy ecosystems that support living things and natural processes. Ecosystems produce food and fiber, sequester carbon, purify water, detoxify pollutants, sustain and retain soil, pollinate crops, and dampen the destructive forces of coastal storms and other natural disasters (President's Council on Science and Technology, 2011). In 1997, the global value of these services was estimated between $\$ 16$ trillion and $\$ 54$ trillion annually (Costanza and others, 1997). To ensure human health and safety and sustain a vibrant economy for present and future generations, the USGS must provide the credible, unbiased, and relevant science information that resource managers need to maintain and restore the health of the Nation's ecosystems in what is undeniably a fast-changing world. The pace of human population growth and environmental change is far-reaching and unprecedented, affecting water availability and quality, distribution and extinction rates for plants and animals, the stability of marine and terrestrial ecosystems, rates and magnitudes of disturbances, and cycling of lifesustaining elements (carbon, nitrogen, phosphorus). Human actions have placed three of Earth's life-support processesbiodiversity, climate, and the nitrogen cycle (Rockstrom and others, 2009) - beyond the operating range judged safe for humanity (Vitousek and others, 1997). In the future, environmental changes and their impacts are expected to accelerate and interact with sources of natural variability to produce unknown outcomes.

Land and resource managers are facing decisions of increasing complexity and urgency to conserve biological diversity, restore and rehabilitate damaged ecosystems, adapt to climate change, resolve conflicts of resource allocation, and assess the changing condition of living resources and their habitats. This document provides a strategy for USGS ecosystem science that will better enable society to understand how and why ecosystems change, to predict and forecast future changes, and to guide actions that restore and sustain ecosystems and their life-support functions.

\section{Elwha River Dam Removal}

The removal of the Glines Canyon Dam in Olympic National Park, and the Elwha Dam downstream, is the largest dam-removal project in the United States. The restoration of the river will enable onceproductive native salmon runs to return, restoring the vital marine-derived nutrients and food sources for terrestrial and aquatic communities in the watershed. In cooperation with local, State, Federal, and tribal partners, the USGS is developing new ecological information on fish and wildlife populations, vegetation patterns and dynamics, sediment transport and storage in the reservoirs, river channel and coastal evolution, hydrological processes, coastal habitats, and beach erosion. Understanding changes to river and coastal habitats, fate of sediment, and salmon recolonization in the upper watershed provides critical information for restoration of the Elwha River and comparable dam removal projects across the country.
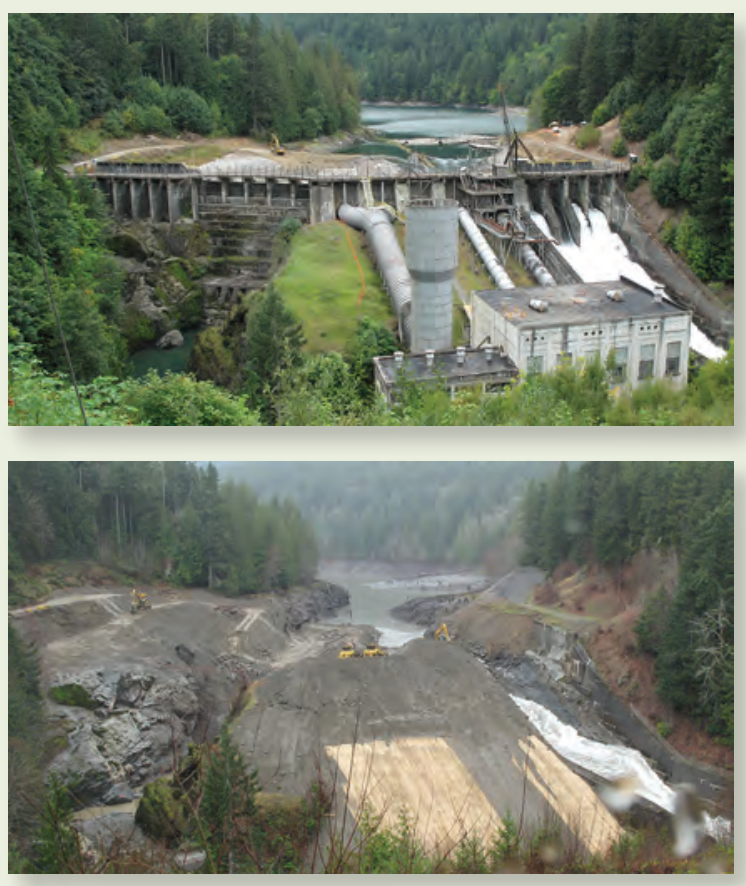

Top: photograph of the Elwha Dam before removal, September 15, 2011. Bottom: Elwha River after removal of dam, March 12, 2012. 


\section{Vision for USGS Ecosystem Science}

Ecosystems are changing rapidly and the integration of scientific discovery and application will be necessary to address problems that increasingly affect the welfare of American citizens and people around the world. Our vision is as follows:

USGS will be a leader in Ecosystem Science by

bringing unbiased scientific information to the

forefront of decisionmaking processes that affect the

Nation's natural resources and human well-being.

Ecosystem Science encompasses studies of organisms and their environments at scales from genes to populations to biomes and entails understanding the effects of ecosystem change. It requires studies across a spectrum of spatial scales to better understand how local-scale features of landscapes (such as water diversions) interact with global- and continental-scale processes (such as climate oscillations) to drive changes in biological communities, ecosystem processes, and social change. Ecosystem science also includes investigations across temporal scales from short term to millennial (geologic). Exploration of how humans function as integral parts of ecosystems and how they act as drivers of ecosystem change is an important component of the science portfolio.
The motivation for USGS ecosystem science is to understand complex systems of living and nonliving components and their interactions and to apply that understanding to better support the management of the Nation's natural resources.

During the next decade, ecosystem science will be challenged to integrate system responses to climate variability and other drivers of ecosystem change such as landscape alterations, introductions of nonnative species, pollutant discharges, and effects of water and energy development. Effective ecosystem management requires the integration of scientific discovery and application to solve problems that will increasingly affect the welfare of American citizens and global populations. Because humans are a substantial and growing force of ecosystem change, the integration of natural and social sciences will be essential for effective application of ecosystem science.

This strategy proposes new directions for interdisciplinary and integrated science to understand how multiple forces interact to bring about ecological changes. The USGS will apply a range of scientific approaches including experimentation, process measurements, remote sensing, analyses of the geologic record, long-term observations, natural history studies, and modeling to develop and test hypotheses about ecosystem functions and management. The ultimate goal is to inform policy and guide sustainable use while reducing uncertainty about the future.

\section{Lake Drying in Alaska}

Northern latitude lakes are drying in concert with climate warming. These lakes provide substantial and essential ecosystem services that range from national waterfowl production to global carbon storage. This ongoing interdisciplinary project relies on collaborations among the science mission areas of Ecosystems, Climate and Land Use Change, and Water to address the following research questions: How variable are the rates and magnitudes of change in lake surface area in National Wildlife Refuges in Alaska? What landscape characteristics are associated with these changes? What fine-scale mechanisms are affecting lake area change? What lake characteristics affect species richness and diversity of biological communities associated with lakes? What are the projected effects of continued lake drying on biodiversity in National Wildlife Refuges in Alaska? How can projected climate-related trends in biodiversity be used to enhance the management of these refuges?

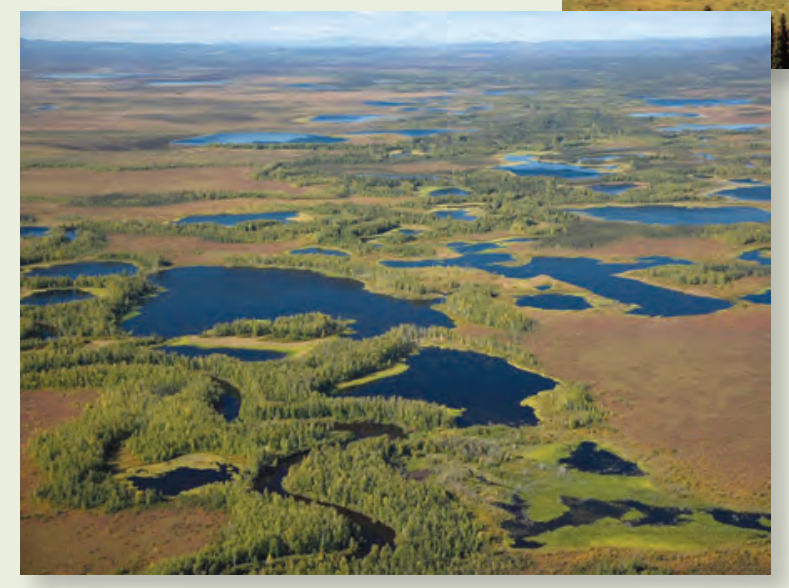

Above: An example of progressive lake drying in boreal forest wetlands within Yukon Flats National Wildlife Refuge, Alaska, August 2011. Photograph by May-Le Ng, University of Alaska Fairbanks. Left: Boreal forest wetlands within Yukon Flats National Wildlife Refuge, Alaska, with examples of floating mat encroachment in the foreground. Photograph from http:// www.marysrosaries.com/collaboration/index.php?title=Category:Images . 


\section{Roles of Scientific Discovery and Application}

USGS ecosystem science is an integrated effort of discovering ecosystem function and change and then applying these discoveries to inform the increasingly complex decisions faced by policymakers and resource managers (fig. 1). Science produces new knowledge that is available for application to address problems of social importance. In turn, the process of applying knowledge to address problems can highlight additional science needs, which can help to focus scientific investigations to discover additional knowledge (fig. 1A).

The framework for the association between science and application shown in figure $1 A$ has proven to be successful for many decades (Stokes, 1997). However, as society moves well into the 21 st century, this framework is gradually being supplanted by an enhanced association between discovery and application in which new knowledge is seen as originating from the application of existing knowledge by practitioners, as well as from basic and applied research conducted by scientists. Thus, learning not only can inform but also can be informed by resource management, with "application" itself becoming a way to discover new knowledge along with a more traditional science approach to discovery. Both forms of investigation can be recognized as part of the discovery process, with discovery and application seen as overlapping rather than separate activities (fig. 1B). The overlap corresponds to simultaneous application of knowledge and discovery of new knowledge, such that applications (for example, science-based interventions) are used to pursue management goals as well as obtain new knowledge.

Examples of applications-based learning are especially prevalent in investigations of ecological systems. An example of the use of interventions to manage and to learn is the management of nonnative species, in which different interventions are used in the field to simultaneously control invasives and understand the mechanisms of their establishment and spread. Other examples include (1) management of grazing lands, in which different pasturing strategies simultaneously provide grazing benefits and determine the conditions for sustainable pastoral landscapes and (2) the regulation of fish and wildlife harvests, in which harvest strategies are implemented, their consequences are tracked, and the data are used to improve understanding about population ecology. In these, and many other instances, management actions taken by practitioners offer opportunities to advance knowledge about how ecosystems respond to change.

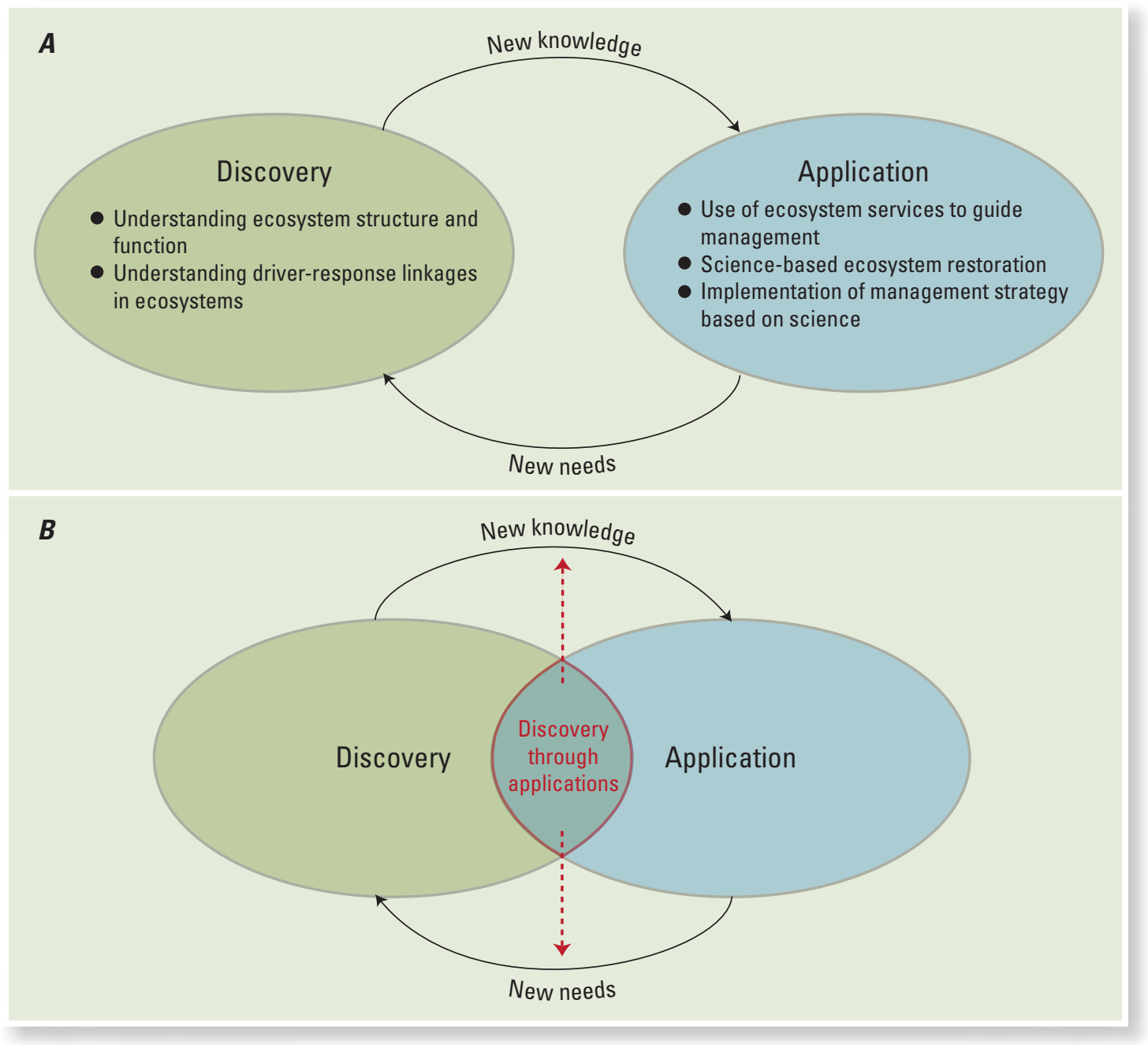

Figure 1. Ecosystem science builds on the interaction between new knowledge from scientific discovery and applications of that knowledge. $A$, Discovery of new knowledge by scientists informs applications, and applications, in turn, uncover new needs that lead to additional discovery. $B$, The application of knowledge can itself be used to generate new knowledge. 


\section{Species Recovery in the Missouri River Basin}

Along the Missouri River, reservoir management, channelization, and bank stabilization have been associated with declines of three threatened or endangered species: the pallid sturgeon, interior least tern, and piping plover. Since 1990, the USGS has been working collaboratively with conservation agencies to understand these species and link and quantify population responses to management and restoration actions. For the pallid sturgeon, this has required investigation of food-web productivity and energetic requirements, larval dispersal, and meta-population dynamics in reproductive ecology of the species. USGS scientists are actively engaged with stakeholders and managers who rely on the USGS to provide and interpret relevant, credible, unbiased, and timely interdisciplinary information on the river ecosystem and species and to apply this information in structured decision processes.

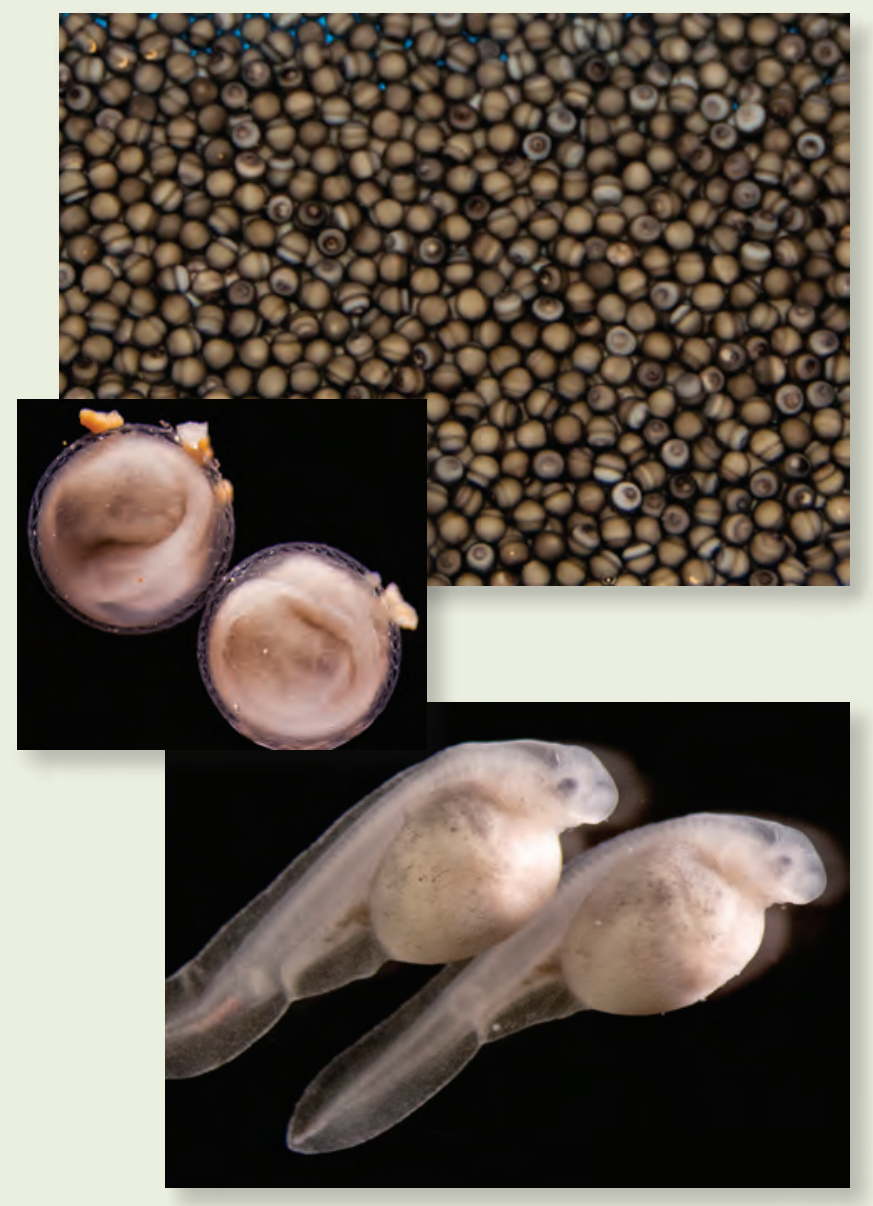

Top: Unfertilized pallid sturgeon eggs expressed from a female induced to spawn in the laboratory.

Center: Developing pallid sturgeon embryos.

Bottom: Recently hatched pallid sturgeon free-embryos. Photographs taken June 2011, by Aaron DeLonay, USGS.
Engagement of people who live and work on landscapes offers novel opportunities for learning through application. Native peoples, farmers, commercial fishermen, loggers, and others who make a living from the land are practitioners of ecosystem management. As such, they can provide distinct perspectives on how ecosystems function as working landscapes. The insights of local people can be used to focus investigations, develop and constrain hypotheses, and, in some cases, provide observations and interpretations that would otherwise not be available to scientists and managers.

The framework described here extends the context for scientific investigation to include science that targets specific applications, science that is guided by needs identified through applications, and science that is generated by the process of science application itself. It ties the USGS more closely and effectively to the DOI management agencies and other partners by encouraging an active engagement of scientists and managers in scientific discovery and its application to real problems. The framework promotes an enhanced relevance of USGS science to the partners who use and ultimately must support the science.

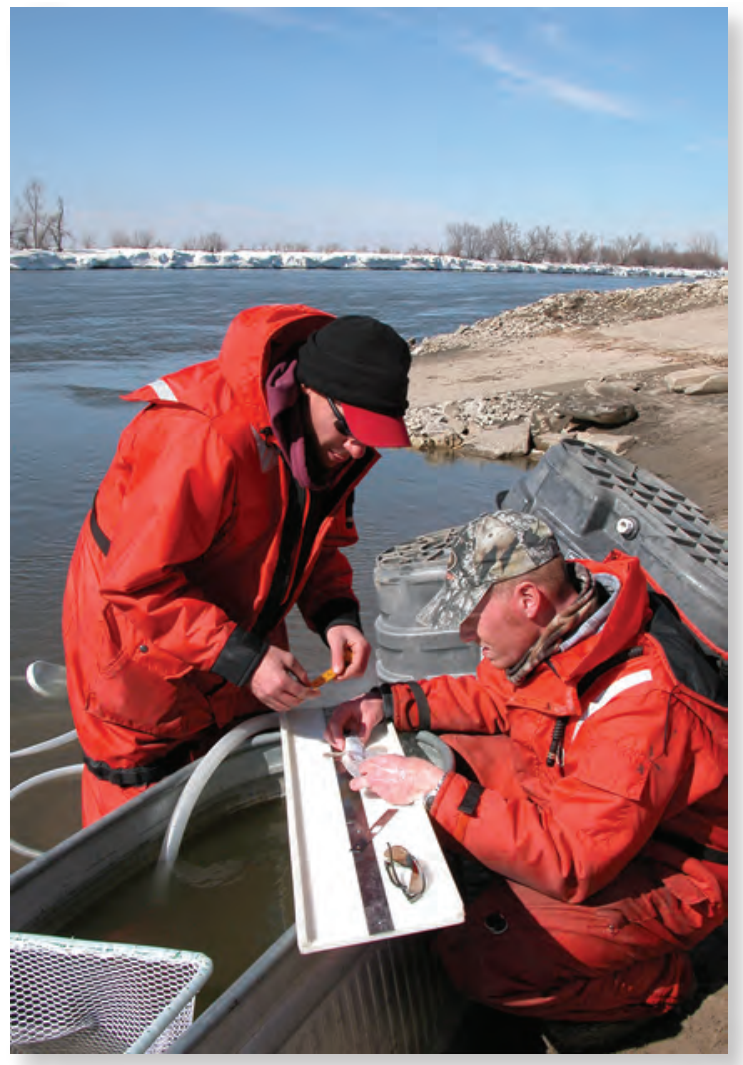

USGS researchers measure a pallid sturgeon (Scaphirhynchus albus) on the Missouri River near Mondamin, lowa, March 2007. Photograph by Janice Albers, USGS. 


\section{Building on USGS Foundations and Strengths}

The USGS is known for its multidisciplinary expertise and comprehensive, integrative research. In what follows, we describe some Bureau strengths that provide a foundation for moving ecosystem science forward during the next decade.

\section{Holistic, Cross-Scale Science Capabilities}

The Bureau's mission is to conduct science that supports decisionmaking for the benefit of society. The USGS conducts scientific investigations across a variety of administrative, geographic, and ecological scales in cooperation with many research and management partners. Because the USGS does not have jurisdictional boundaries or regulatory authorities, our science can be conducted across local, State, tribal, regional, and national jurisdictions. This breadth allows for the comprehensive investigation of ecosystem components and their interactions. The interdisciplinary capability of the USGS workforce can be utilized for addressing complex ecological problems.

\section{Monitoring, Assessment, and Modeling}

The USGS supports regional and nationwide monitoring of key indicators of the environmental health of terrestrial, freshwater, and marine habitats, along with assessments of the abundance and distribution of biota, invasive species, wildlife disease, and other ecological characteristics. USGS data holdings and observation networks are unparalleled and vital for understanding the status, trends, and health of our Nation's ecosystems and natural resources. Many of these datasets include decades-long records of observations with corresponding Geographic Information System (GIS) data layers, collected under strict standards of quality assurance and quality control. USGS scientists are widely recognized as leaders in developing methods for estimating ecological attributes from monitoring data. Such estimates can be used in forecasting models and in discriminating among competing models of system dynamics. This combination of monitoring programs, knowledge of inference methods, and modeling capability is truly unique and distinguishes the USGS from other agencies and groups.

"Ecological history will be indispensable in meeting the environmental challenges of the coming decades. We can't know where we are, or where we're going, without knowing where we've been."

(S.T. Jackson, 2007)

\section{Interdisciplinary Science}

The USGS includes biologists, hydrologists, geologists, geographers, social scientists, and many other specialists who collaborate to understand the interactions among the biological, physical, chemical, and social components of ecosystems. USGS research ranges across multiple spatial scales, from the genes of individual species to biomes and oceans. The research also ranges across temporal scales, from seconds to geologic epochs. The broad array of disciplinary expertise in the USGS allows the Bureau to examine ecosystem responses to large-scale and long-term drivers, by both hindcasting and forecasting beyond the scientific records of the 19th-21st centuries. These capabilities contribute to improved understanding of system responses to environmental forces that may act on decadal to millennial timeframes. Long-term data, linked to the understanding derived from recent studies of living systems, provide the basis for forecasting human-induced and natural change into the next century. The USGS is a leader in investigating and documenting ecosystem changes that have occurred throughout the Earth's history.

\section{Science Organization of USGS}

The USGS mission areas include a focus on key ecosystem processes that promotes the incorporation of broad-ranging expertise into interdisciplinary ecosystem investigations. Thus, ecosystems are linked to climatic, land-use, and hydrological patterns. Natural hazards such as flooding and fire drive ecosystem change, and changes within ecosystems, in turn, can affect the impact and scope of natural disasters. For example, loss of vegetation can lead to landslides or greater impacts from coastal storm surges and tsunamis; flood hazard zonation can reduce flood damages while increasing biodiversity of floodplains; and fuel buildup and treatments can amplify or mitigate wildfire intensity. The extraction of energy and mineral resources may degrade ecosystems, while biogeochemical cycling within ecosystems creates and alters energy and mineral resources. Environmental health is influenced by the physical and biological quality of the environment, which can include contaminants, toxicants, and pathogens that result in disease in wildlife and humans and alter the structure and functioning of ecosystems. USGS core science systems provide the tools and technologies for characterizing the human dimensions and social drivers of ecosystem science and for observing, analyzing, and utilizing GIS to visualize ecosystem status and change. Each of the mission areas in the USGS can play a critical role in the Bureau's strategy for ecosystem science. 


\section{Building on USGS Partnerships}

USGS ecosystem science can build on the Bureau's ongoing collaborations and partnerships to leverage science resources and to support partner agency information needs. USGS science centers and cooperative research units are broadly distributed across the country, and many are colocated with university or other collaborators. This geographic structure facilitates the ability of USGS scientists to work in diverse ecosystems with other local, territorial, State, tribal, Federal $^{1}$, and nongovernmental organizational partners. Collaborative efforts often include USGS centers and sister agencies within the DOI. Cooperative ventures such as the DOI Landscape Conservation Cooperatives, Cooperative Research Units, Cooperative Ecosystem Studies Units, and Climate Science Centers that promote ecosystem-based adaptive management are anticipated to grow. In addition, the USGS will need to collaborate closely with resource agencies in the DOI to

'Primary USGS Federal partners include Department of the Interior Bureaus (U.S. Fish and Wildlife Service, National Park Service, Bureau of Indian Affairs, Bureau of Ocean Energy Management, Regulation and Enforcement, Bureau of Land Management, Bureau of Reclamation) as well as the U.S. Army Corps of Engineers, the U.S. Environmental Protection Agency, National Oceanic and Atmospheric Administration, Department of Agriculture, Department of Energy, Department of Defense, Department of Homeland Security, Department of Transportation, National Institute of Health, and National Aeronautics and Space Administration. address their needs for species and ecosystem management. One way to do this is through the establishment of a USGS science forum that works closely with our DOI partners (see first proposed action, p. 35).

The USGS will need to coordinate closely with other mission areas, agencies, and organizations in the science community to determine where USGS efforts can provide added value to existing research efforts and identify promising new directions related to the goals and approaches outlined in this strategy. In an era of declining budgets it will be more important than ever for the USGS to develop complementary research approaches that build on the research strengths of other agencies, universities, and nongovernmental research organizations. Some examples of existing USGS collaborations with other science agencies include the Priority Ecosystems Science initiatives that are highlighted throughout the strategy. Other examples of USGS contributions to hypothesis-driven, integrated research and monitoring include the National Ecological Observatory Network, Critical Zone Observatories, the Consortium of Universities for the Advancement of Hydrologic Sciences, and the Long Term Ecological Research Network. As the USGS moves toward implementation of this strategy, additional communication and research forums will be necessary to ensure that the USGS works with our partners to address the most pressing ecosystem science needs of the Nation.

\section{Red Knots and Horseshoe Crabs}

The management of horseshoe crab harvests in Delaware Bay represents a large-scale decision problem with respect to geographic area, animal population sizes, and diversity of the stakeholder community. The key tradeoff is between the horseshoe crab fishery and migrating red knots, which require crab eggs to attain mass levels that enable the birds to complete their migration to the Arctic and successfully reproduce. The diverse stakeholder community includes the U.S. Fish and Wildlife Service, State resource agencies, and nongovernmental conservation organizations, with the Atlantic States Marine Fisheries Commission (ASMFC) designated as the legal decisionmaker. An adaptive management program was developed by USGS scientists and the stakeholder community for deriving horseshoe crab harvest regulations and was endorsed in 2010 and formally adopted by the ASMFC in 2011.
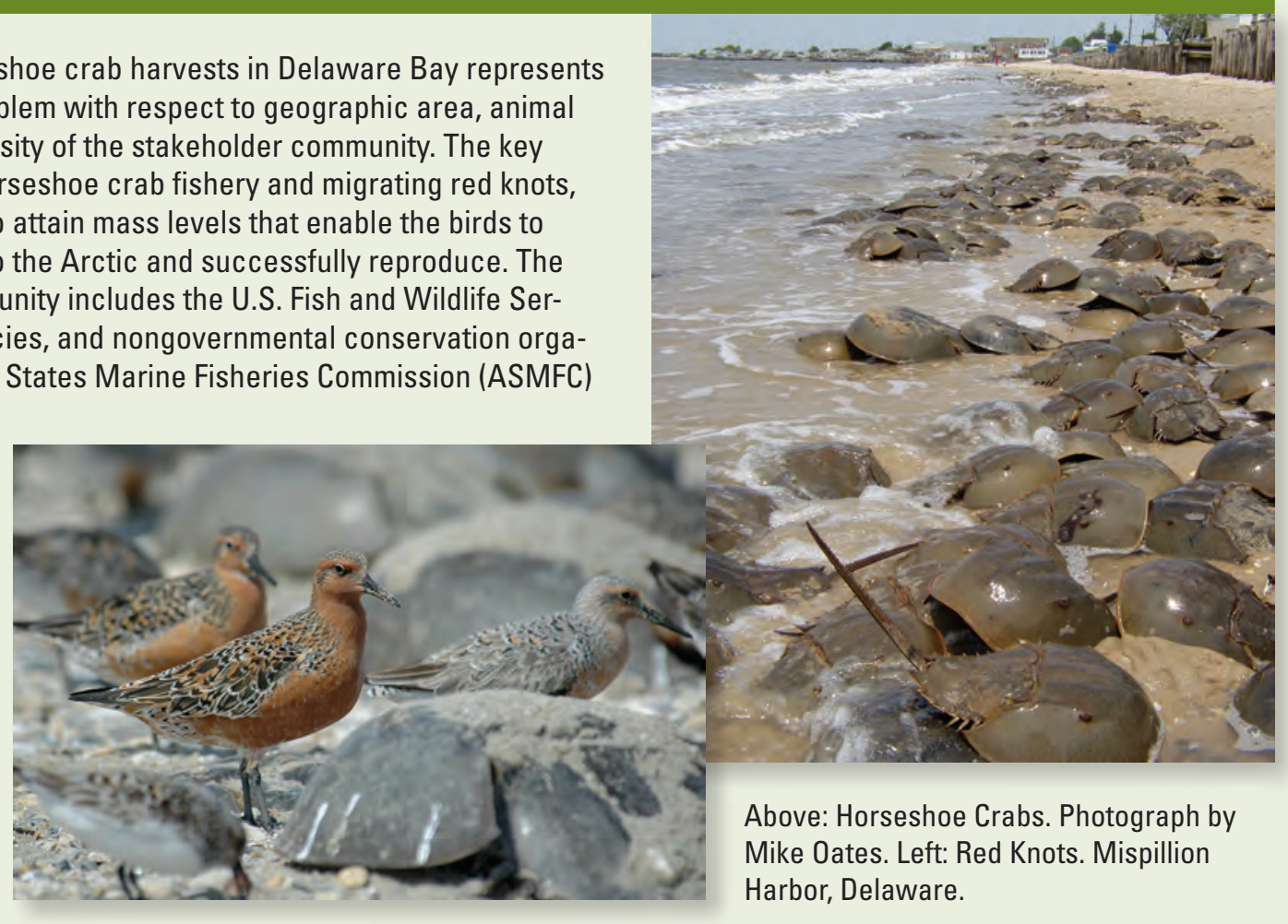

Above: Horseshoe Crabs. Photograph by Mike Oates. Left: Red Knots. Mispillion Harbor, Delaware. 


\section{Ecosystem Science Goals}

\section{Overview}

In the next 10 years, the population of the United States is projected to grow by more than 30 million people (U.S. Census Bureau, 2008). Over 50 percent of U.S. citizens reside in coastal watershed counties that comprise only 17 percent of U.S. land area, and the trend of migration to the coasts and warmer regions is expected to continue. The country shares extensive borders with Canada and Mexico, where cross-border issues in resource use will continue to draw attention (for example see highlight, p. 30). Pressures on ecosystem resources will vary widely across the landscape. The demand for new energy will increase by 20 percent beyond the current demand (National Energy Policy Development Group, 2001), and basic services such as clean water and sustainable food supplies will have to increase to meet the needs of an increasing human population. Climate change likely will alter the geographic distribution of species, test the capacity of plants and animals to adapt, increase the spread of disease, and alter the duration and intensity of storms and drought (Intergovernmental Panel on Climate Change, 2007).

These natural and human-induced changes will lead to tradeoffs between increasing use of natural resources and long-term sustainability. Society needs new insight into ecosystems and new ways to integrate science into the process of making decisions about these ecosystems. The need to make smart choices involving stewardship, human well-being, and prosperity has never been more urgent. Resource management issues of broad importance to society provide the context for the goals and challenges presented in this plan. These cross-cutting priority societal issues include the following:

- Recovery and management of threatened and endangered species.

- Detection and control of invasive species, pathogens, and wildlife disease.

- Evaluation of tradeoffs between ecological and economic uses of land and water.

- Adaptation to and mitigation of ecological effects of climate change, sea-level rise, nitrogen deposition, and the acidification of soils, freshwaters, and oceans.

- Design of strategies for sustaining and restoring ecosystem functions and services of resilient landscapes and seascapes.
- Identification of strategies to mitigate the harmful effects of contaminants and pollutants on vital ecosystem processes and human health.

These issues transcend the development of any strategic plan in that they are long-standing, increasing in importance, and broadly recognized as influencing ecosystems and the services they provide to society. As such, they provide the context for framing this science strategy and its goals and challenges.

A common theme that emerges from the priority societal issues is a general sense of urgency in expanding our understanding of ecosystem processes. With increasing human demands on natural resources, the Nation needs to take bold steps to move ecosystem science and management forward. At its most fundamental level, scientific understanding of ecosystems, particularly understanding of ecosystem structure, function, and processes, is incomplete and will need to be expanded. The need to understand how ecosystems work, how they vary over space and time, and how physical and ecological processes influence ecosystem services, biodiversity, threatened and endangered species, and other ecosystem attributes that society values is fundamental.

At the same time, the Nation is faced with the challenge of unprecedented ecosystem changes driven by a variety of sources, including climate change, increasing demand for energy, food, and water, and biological invasives. To anticipate and predict the potential changes that may occur to ecosystems, it is important to advance understanding of how drivers influence ecosystem change. For example, the sustainability of future water supplies for ecosystems will be influenced by climate and human use, and a key need will be to predict the consequences of actions to increase water supplies for society while accounting for the effects on aquatic ecosystems.

The services that ecosystems provide to society include clean water and air; healthy forests, rangelands, and croplands; and diverse plant and animal communities that enhance the environment and support economic, social, and cultural systems. Although ecologists understand the benefits of some ecosystem outputs, there is a need to expand understanding of the services that ecosystems provide to society. Key questions are as follows: What services do different ecosystems provide? How do they interact with one another? Are there critical thresholds that, when reached, result in the decline or possible elimination of those services? How can 


\section{Waterfowl Harvest}

The management of waterfowl harvests for some populations in North America has been based on an adaptive management framework since 1995. The resource management problem is large in geographic scale, number and abundances of managed species, and size and diversity of the stakeholder community, which includes multiple Federal, State, and provincial management agencies as well as nongovernmental hunting and conservation organizations. The central tradeoff is between the legal mandate to maintain healthy migratory bird populations and the secondary objective of permitting sport hunting. USGS scientists were instrumental in developing a science-based adaptive approach to hunting regulations for the U.S. Fish and Wildlife Service. Its adoption has led to a reduction of uncertainty about population responses to hunting and has resulted in transparent and defensible hunting regulations for nearly 20 years.

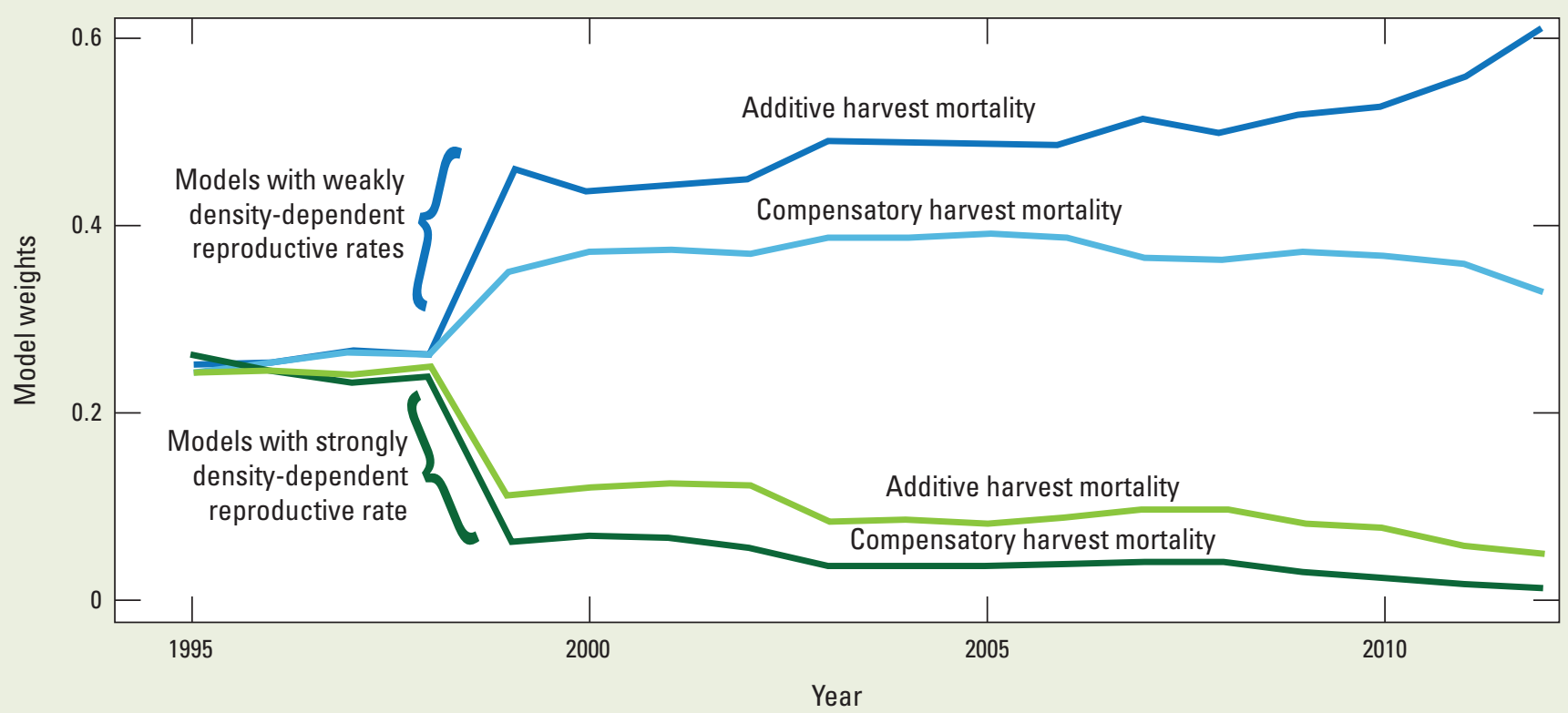

Models of mid-continent mallards have been developed to help predict changes in populations. These models are used by U.S. Fish \& Wildlife Service as a basis for developing regulatory strategies for wildlife management. Assumptions about reproduction and annual mortality are incorporated into the models and the linkage between reproduction and population density is incorporated in two forms - weak and strong density dependence in reproduction rate. In addition, two forms of the linkage between annual mortality rate and hunting are considered (additive mortality, in which harvest mortality is added to other non-hunting mortality factors, and compensatory mortality, in which harvest mortality is compensated by reductions in non-hunting mortality sources). In combination these forms describe 4 different models, each with its own predictions about population changes over time. The models, and measures of confidence in them, are based on monitoring data. (Adapted from U.S. Fish \& Wildlife Service, 2012; see this publication for details of the model development.)

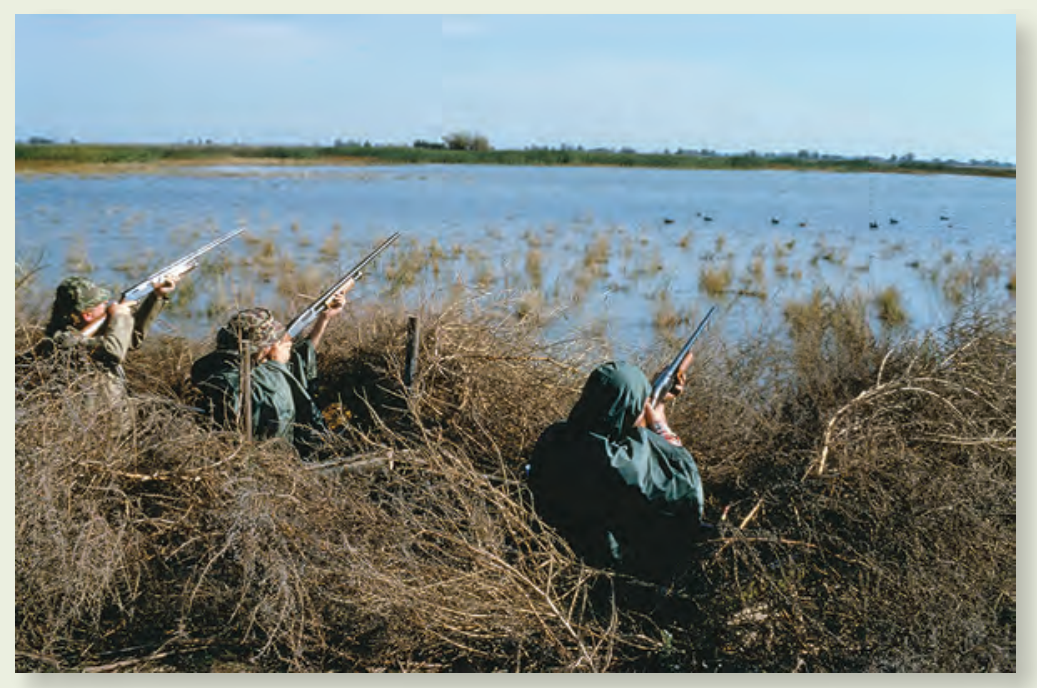


decisionmakers weigh tradeoffs among the various services to make the best informed decisions?

Managing natural resources for ecosystem services and tradeoffs is increasingly difficult given the multiple needs and priorities of society at local to national levels. As the complexity of decisionmaking increases, so does the need to develop tools, technologies, and capacities to inform decisionmaking about ecosystems. During the past 20 years, new satellite and mapping technologies, the evolution of geographic mapping systems, and new technologies to describe the genetic makeup of organisms have emerged. Telephones have evolved from simple communication devices into tools that can instantly communicate scientific information through social media and applications. Computational resources have evolved from handheld calculators to high performance computing systems capable of trillions of calculations per second. The USGS must find ways to use these technologies to assess the ecological consequences of decisions, particularly given the uncertainty of future climate and land-use changes. What tools can be developed to help managers better support their decisions with the right information at the right time? What new technologies will be needed to examine ecosystem vulnerability, threshold identification, and other ecosystem attributes? The emergence of new tools and approaches that allow ecologists to look at broad landscapes and variability at multiple scales will provide new capabilities in USGS scientific investigations.

Finally, one of the basic strengths of ecosystem science in the USGS has been our connection with resource management agencies and our ability to work with land managers in addressing their needs. Agency needs will include large-scale as well as site-specific studies to help a refuge, park, or district manager with a specific issue. For example, priority ecosystem studies in the Everglades, Puget Sound, Colorado River, Chesapeake Bay, and San Francisco Bay are addressing spatially large and complex issues related to water management and ecosystem restoration. In addition, polar bear studies in the Arctic and grizzly bear studies in Yellowstone and Glacier National Parks focus on key species in complex environments. As the complexity of these problems grows, the USGS will need to work with our conservation partners to provide the science needed to enhance strategies for management, conservation, and restoration of ecosystems. An important growth area for the USGS and other natural resource agencies alike is the application of adaptive management (Williams and others, 2007; Williams and Brown, 2012) to learn about the effects of management actions while exploiting that learning to make better decisions in the future. The science provided by the USGS will help managers better understand the consequences of their decisions and, in turn, guide subsequent management and future research.

The goals and challenges in this strategy were developed to be complementary and interdependent, rather than independent, stand-alone research needs. Collectively, they emphasize ecosystem science that links discovery with application and promotes enhanced research and management partnerships (fig. $1 B$ ). Below, we attempt to convey both urgency and optimism: urgency in providing science to assist resourcemanagement agencies in finding the right balance between natural resource conservation and economic development and optimism that the Nation has the capacity in its science and institutions to address and resolve these complex environmental issues.

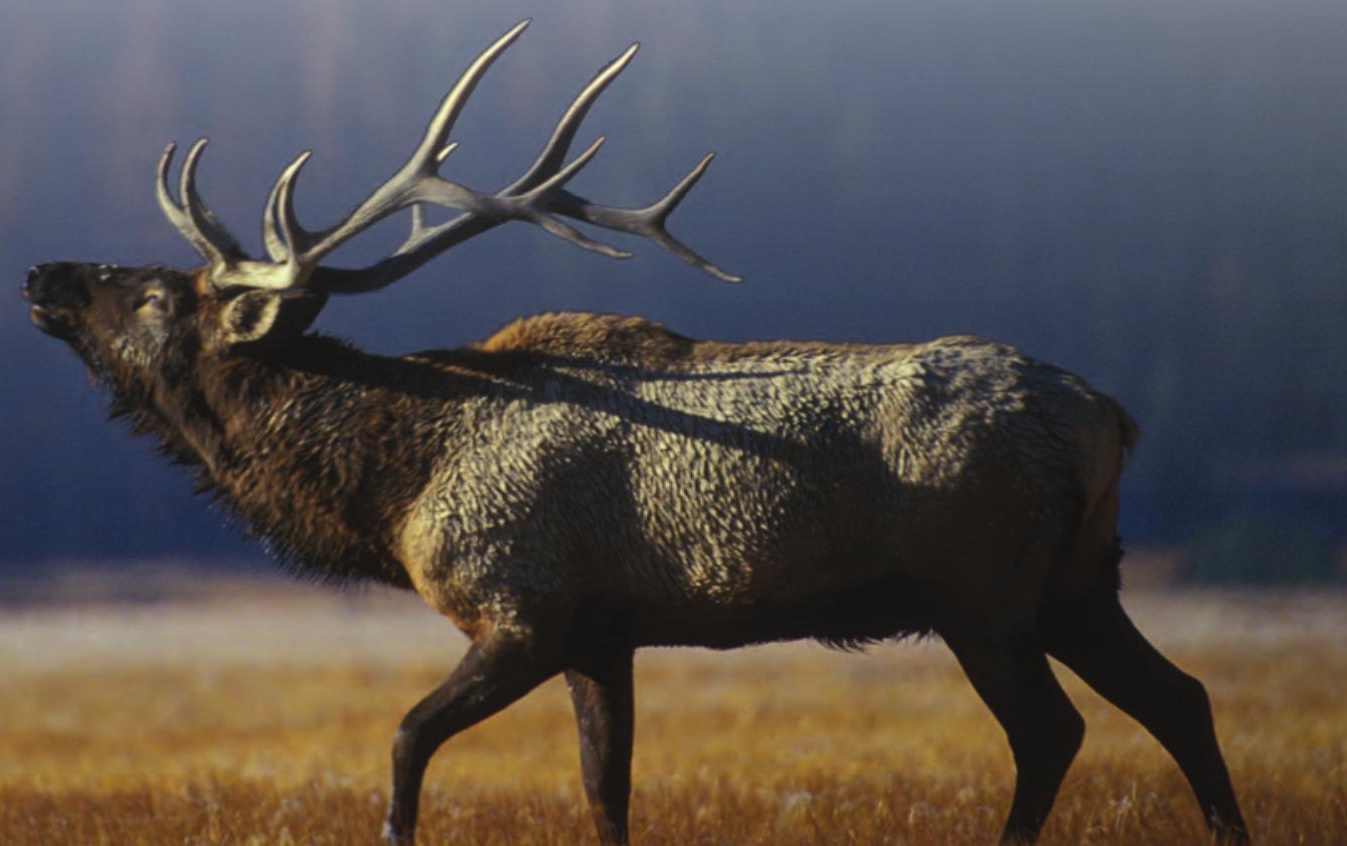




\section{Goal 1: Improve Understanding of Ecosystem Structure, Function, and Processes}

\section{Justification}

Along with the production and use of energy, minerals, water, food, and fiber, the protection and sustainability of natural resources and their ecosystems is a national priority. Scientific and social information, and particularly inventory and monitoring information, are essential for developing and implementing policies to meet these priorities (Fleishman and others, 2011). However, the current pace of scientific discoveries, including the acquisition of basic monitoring data, is insufficient to adequately inform U.S. resource management policy in the next decade (Fleishman and others, 2011). The rapid changes now taking place in all ecosystems make it imperative to understand ecosystem structure, function, and processes and how ecosystems directly or indirectly support human populations and security of the country. Understanding of the condition and trends of ecosystems

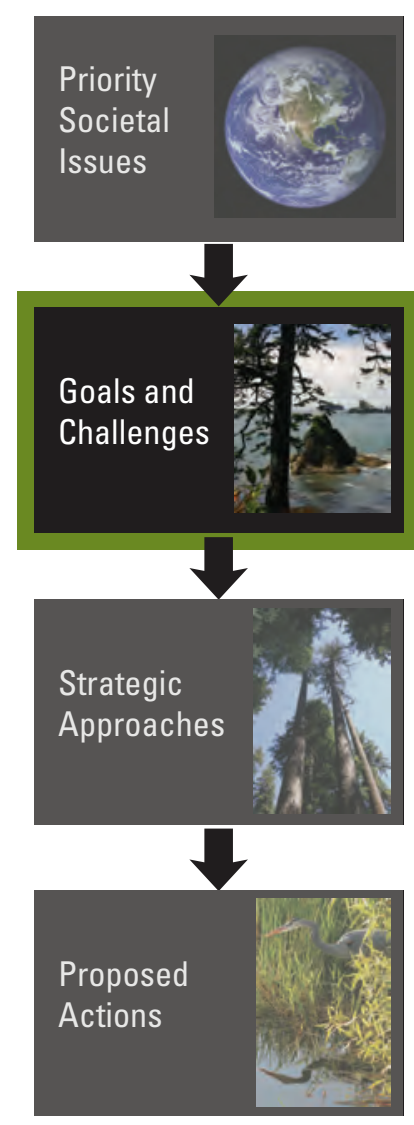
benefits from both discipline-based and multidisciplinary science, along with collaboration with resource managers and policymakers. Although much has been learned, current knowledge often is insufficient to resolve managers' questions about the causes and consequences of change, the ability of species to adapt to ecosystem change, how ecosystem resiliency can be maintained, or how degraded ecosystems can be restored.

\section{Major Challenges}

- Accelerate learning about how ecosystems and their components (species, populations, communities, and habitats) are organized spatially, how changes in land use and biogeochemical processes influence ecosystem functions, and how spatial organization affects ecosystem and landscape processes.

- Identify and map current species distributions through sustained monitoring and biogeographic modeling.

- Enhance knowledge of how ecosystems and their components function, how they have varied over time, and how that variability affects ecosystem functions and the communities they support.

- Identify key environmental factors that regulate biological, physical, and chemical processes and their interactions, including rates and pathways of energy transfer, nutrient dynamics, gene flow, and ecosystem change.

- Advance knowledge of how ecosystem processes influence attributes such as biodiversity, sustainability, resilience, and species-level carrying capacity.

- Enhance understanding of how ecosystem attributes respond to interacting effects of system variability, operating at multiple spatial and temporal scales.

- Identify nonlinear thresholds that affect biological and ecological structure and function. 


\section{Invasion of Asian Carps in the Great Lakes}

Asian carps, especially bighead and silver carp, are aggressive, invasive fish that have become abundant throughout much of the Mississippi River basin. These species now threaten to invade the Great Lakes, potentially putting a $\$ 7$ billion per year commercial fishery resource at risk. In coordination with partners, the USGS is assessing habitats of the lakes and rivers of the Great Lakes region for their capacities to support Asian carps and are developing information on control strategies. Related studies also include understanding Asian carp reproductive biology and food requirements; quantifying early life-stage habitat needs; using environmental DNA as a new monitoring tool; modeling population dynamics; developing toxicants and pheromone attractants and repellents; and using seismic water guns as barriers to prevent carp advancement.

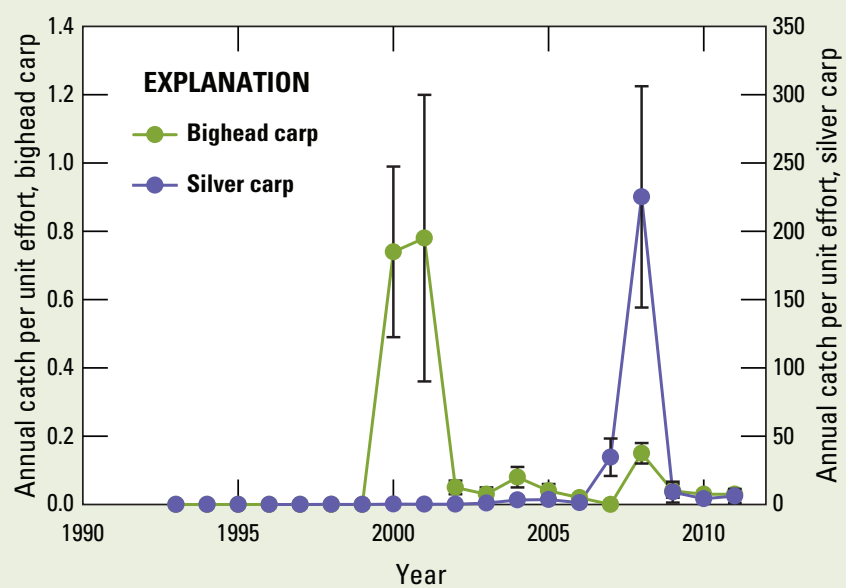

Average annual catch per unit effort (plus/minus one standard deviation) for invasive Asian Carps in the LaGrange Pool of the Illinois River, showing pulses of rapid increase and decrease in catch rate among years, indicative of dynamic population changes. Data are standardized to daytime electrofishing. Data from the U.S. Army Corps of Engineers' Upper Mississippi River Restoration-Environmental Management Program, Long Term Resource Monitoring Program (LTRMP) element, as distributed by the U.S. Geological Survey, Upper Midwest Environmental Sciences Center, La Crosse, Wisconsin (http://www.umesc. usgs.gov/data_library/other/ltrmp_monitoring.htm/).

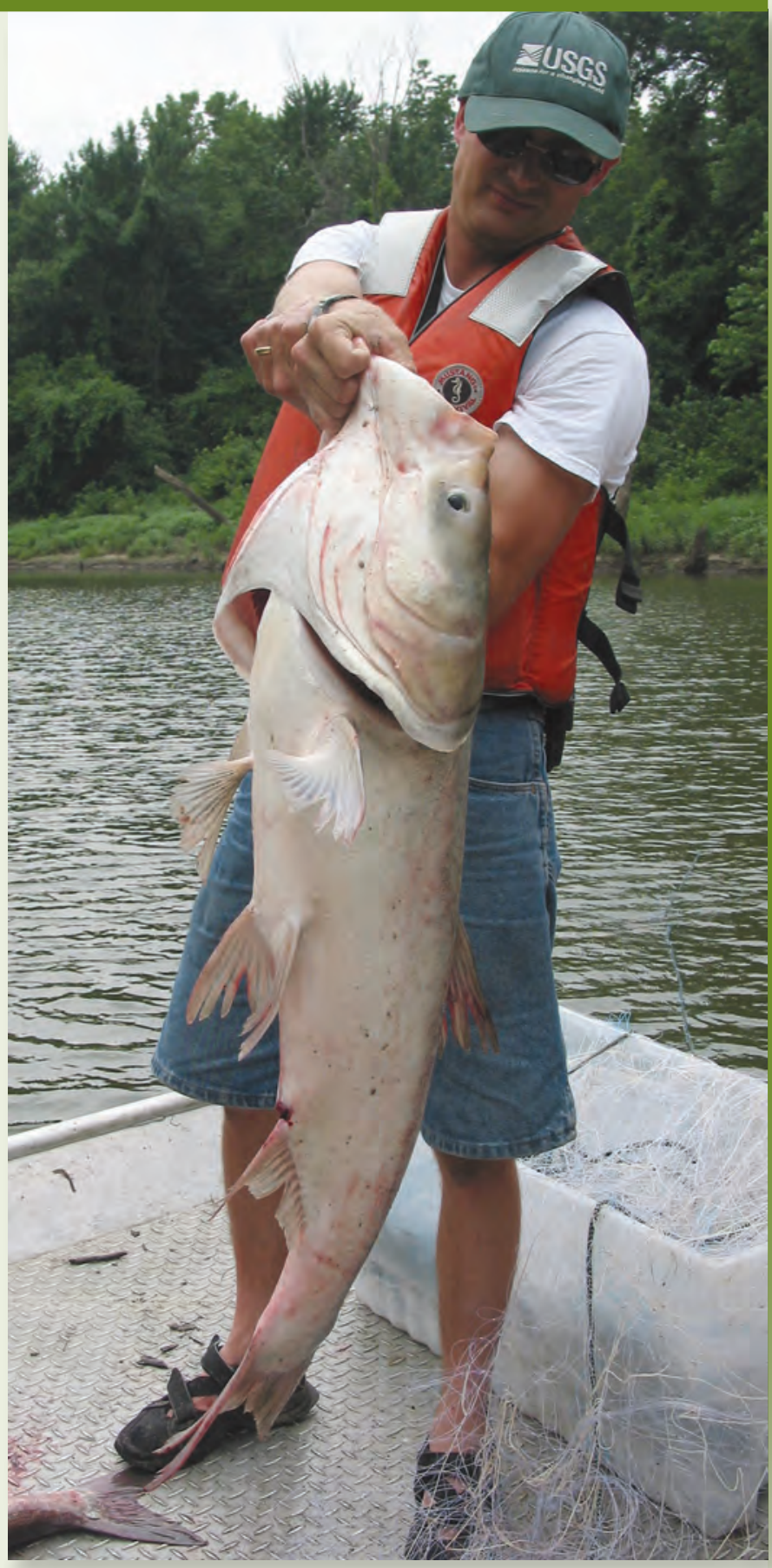

Facing page: USGS scientists test seismic water guns as a potential deterrent to carp movement in the Illinois River system, September 2010. Photograph by Jackson Gross, USGS.
Above: USGS researcher holds large bighead carp on the Missouri River, July 2003. Photograph by Duane Chapman, USGS. 


\section{Goal 2: Advance Understanding of How Drivers Influence Ecosystem Change}

\section{Justification}

Ecosystems are defined in part by the climatic, geologic, biogeographic, and cultural context in which they exist. A key scientific challenge is to recognize patterns and consequences of change in external drivers. Understanding their influences on ecosystem processes, such as the flow of energy, the flux of nutrients, and interrelationships among species, is fundamental to determining ecosystem resilience and sustainability in the face of future changes. Ecosystem management decisions often depend on discrimination of natural from anthropogenic causes of ecosystem change, and determination of causality is essential to both understanding and managing ecosystem change.

Drivers operate across many scales, and the magnitude, direction, complexity of response, and rate of change vary widely from one ecosystem to another. These factors ultimately influence processes such as population dynamics, speciation, succession, and extinction, which, in turn, influence the value of services provided by the ecosystem. Local-scale drivers, such as construction of a dam, application of prescribed fire, restoration of a wetland, or introduction of nonnative species, often affect ecosystem change over localized areas. Cross-scale drivers can have an immediate effect on local environments while also affecting ecosystems over broader areas and periods. For example, the cumulative effects of urbanization, agricultural land use, carbon dioxide emissions, sea-level rise, ocean acidification, and extraction of energy resources can affect ecosystem dynamics locally and over very large areas (Rice and Herman, 2010). Understanding the interactions within and among drivers, the dynamic responses of components of ecosystems, and the feedback loops among the different levels of organization is essential for informed management of ecosystems and the services they provide.

\section{Major Challenges}

- Identify and quantify the important drivers of ecosystem change.

- Determine the feedback mechanisms between the influence of drivers on ecosystems and the influence of ecosystems on drivers.

- Understand the interaction and cumulative effects of multiple drivers, acting over different scales, on ecosystem change.

- Investigate potential future changes in drivers and forecast how species and ecosystems are likely to respond.

- Quantify the uncertainties in forecasting change in drivers and ecosystem trajectories.

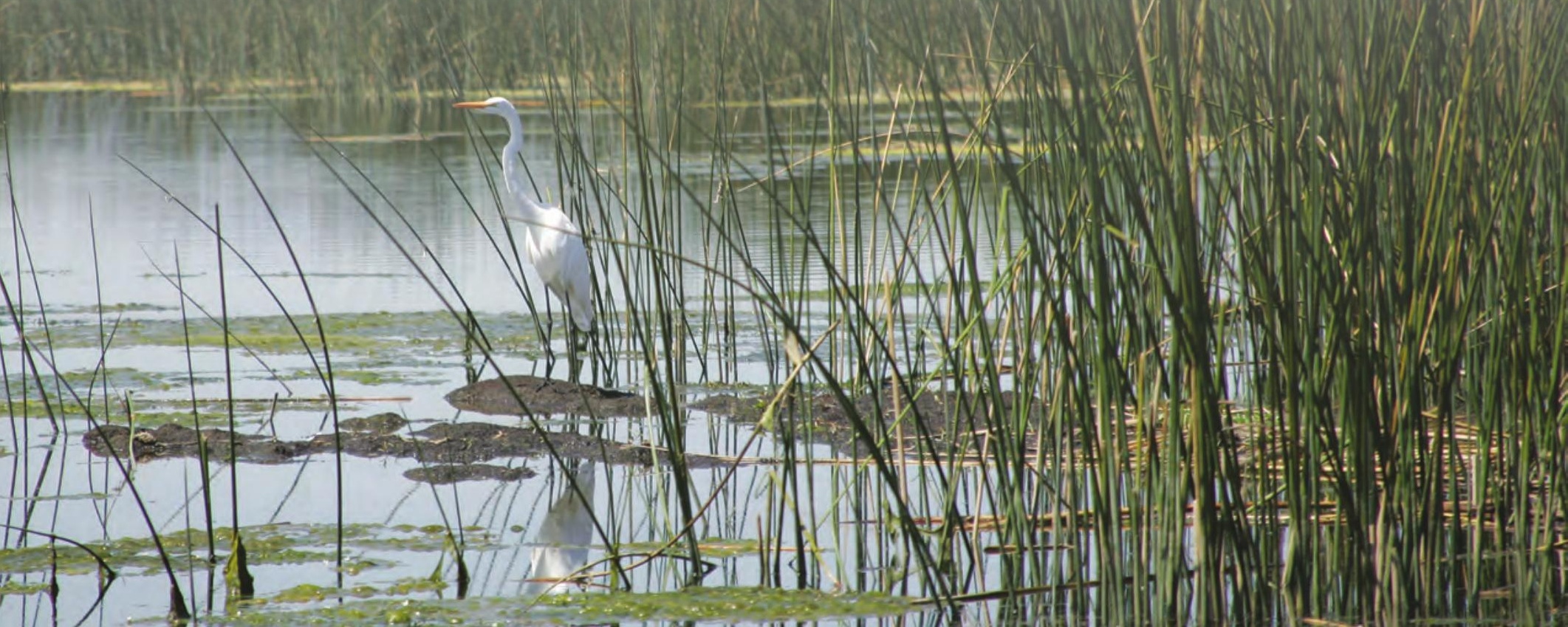




\section{Stressors to the Sacramento-San Joaquin Delta}

California's Sacramento-San Joaquin River Delta is a massively transformed landscape, hub of the State's water-delivery system, and habitat for 14 imperiled species of fish. Resource managers have struggled to identify the stressors responsible for population collapses of these species. USGS studies provide compelling evidence that loss of native species is the result of many stressors, including exotic species, contaminants, water exports, habitat fragmentation, and the damming of rivers. The Department of Interior is contributing to design and implementation of an ambitious Bay Delta Conservation Plan to ensure "a sustainable water supply for California and a healthy Delta ecosystem." The plan is based on the principle that recovery of native biota requires actions to reduce impairments by all the stressors identified in the USGS studies.

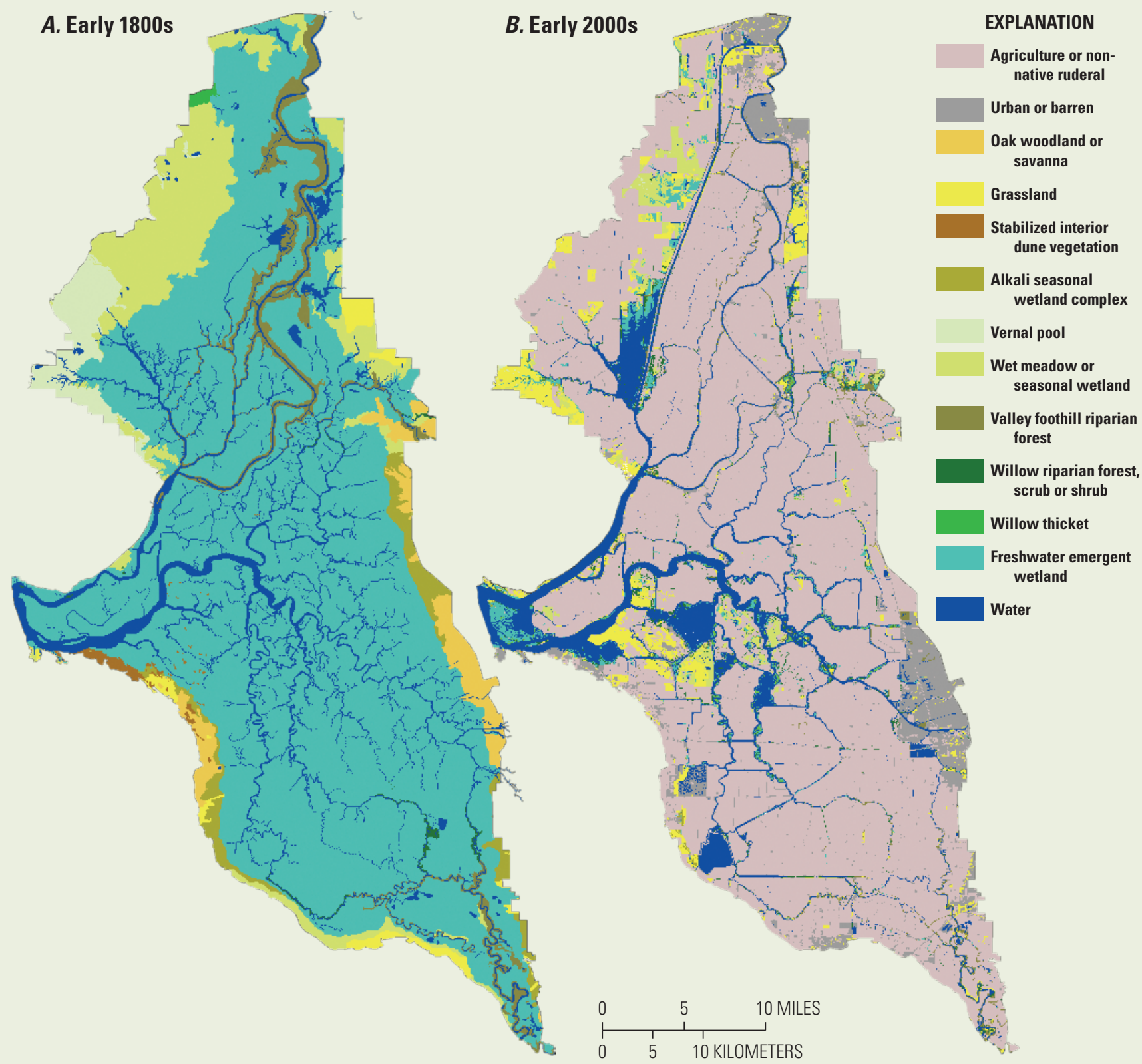

The Sacramento-San Joaquin Delta of the early 1800s $(A)$ was dominated by freshwater emergent wetlands (green), but the Delta in the first decade of the 21 st century $(B)$ is characterized by agriculture (pink) and urban development (gray). USGS scientists are partners in research to understand how the historical Delta supported native species and use that understanding to develop landscape-scale ecosystem restoration plans. Historical reconstruction from Whipple and others, 2012; early 2000s data from Hickson and Keeler-Wolf, 2007. Map courtesy of the San Francisco Estuary Institute-Aquatic Science Center. 


\section{Goal 3: Improve Understanding of the Services that Ecosystems Provide to Society}

\section{Justification}

Ecosystems and the biodiversity they embody are the environmental capital on which human well-being depends, and this capital is the source of ecosystem services. Here, the phrase ecosystem services refers to a wide range of benefits that people obtain from ecosystems, including soil fertility and water-holding capacity; pollination of plants; production of fish, game, and natural resources; and recreational, aesthetic, and existence values from unspoiled landscapes. Recognition of ecosystem services as valuable natural assets that sustain human well-being has become widespread in scientific and policy communities (Daily and Matson, 2008; Carpenter and others, 2009), but the value of these services is often not incorporated into management decisions (Larigauderie and Mooney, 2010; Sukhdev and others, 2010). In the absence of their recognition and valuation, important ecosystem services may be unexpectedly degraded, with substantial monetary and nonmonetary costs to society.

In this rapidly growing field of research, the USGS needs to play a critical role in providing information to managers and stakeholders who are facing complex real-world decisions that require evaluation of tradeoffs in a range of future scenarios. The USGS and other federal agencies need to increase understanding of the production of ecosystem services and enhance capabilities for their valuation with the intent of incorporating ecosystem services into planning and management decisions. USGS research will complement efforts by other governmental, nongovernmental, and academic organizations to understand and predict the potential impacts of external drivers on biodiversity and other important components of our Nation's natural wealth.

\section{Major Challenges}

- Enhance methods to identify, measure, and value ecosystem services.

- Understand the biophysical processes necessary for ecosystems to provide services of value to humans, including energy flows and nutrient cycling.

- Explain how external drivers such as climate change, land use, and resource use - including energy development, mineral extraction, and agriculture - affect the capacity of ecosystems to continue to provide services.

- Assess the associations among multiple ecosystem services.

- Evaluate critical thresholds at which ecosystem change can result in large reductions in the production of services.

\section{Valuing Ecosystem and Economic Services across Land-Use Scenarios in the Prairie Potholes}

The USGS is collaborating with Colorado State University to assess the environmental and economic tradeoffs under different land-use scenarios over a 20-year time period in the Prairie Pothole Region of North and South Dakota. The investigation of ecosystem services has focused on the biophysical and economic values for carbon sequestration, reduction in sedimentation, and waterfowl production in croplands and native prairie grasslands, including lands enrolled in the Conservation Reserve and Wetlands Reserve Programs. By quantifying ecosystem and economic tradeoffs of future landuse scenarios, this study and future USGS research can help policymakers and natural resource managers make more informed, efficient, and defensible decisions.

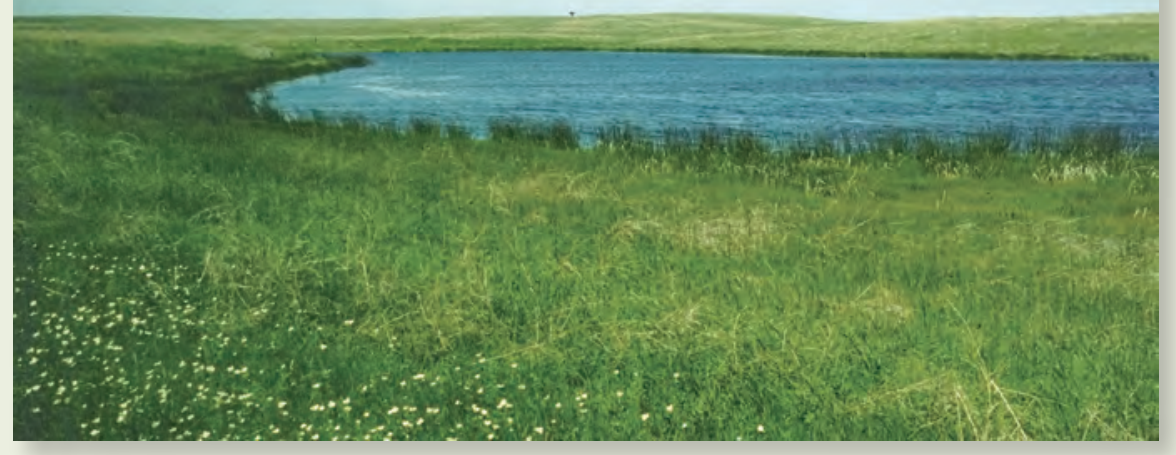

Prairie wetland at The Nature Conservancy's Samuel H. Ordway Memorial Preserve, South Dakota. The Prairie Pothole Region of North American covers more than 444,000 square miles, extending from Alberta to lowa. The highly productive prairies are important for wildlife and for agriculture and USGS scientists and cooperators are studying the ecosystem services provided by the Prairie Potholes and the consequences of alternative land uses. Photograph by W. Carter Johnson, USGS. 


\section{Goal 4: Develop Tools, Technologies, and Capacities to Inform Decisionmaking about Ecosystems}

\section{Justification}

Resource managers are facing complex decisions that require new ways to collect, analyze, and use scientific data. At the same time, theoretical and technological innovations are providing new opportunities to connect science and its application in natural resource management. Rapid advances in remote sensing, development of new GIS tools, genetics and genomics, data management and display, and other new technologies offer USGS scientists new ways to collect, manage, analyze, and display data. Enhanced tools and technologies are required to address the next generation of information management and decision-support systems for ecosystembased, adaptive resource management for restoration, mitigation, and adaptation.

Given the rapid changes in both technology and the drivers that affect ecosystems, the USGS must increase its competency to understand, model, map, and forecast the spatial and temporal dynamics of ecosystem drivers and ecosystem responses to management decisions. Strong collaborations within the Bureau and with partners will be required to integrate knowledge of changing ecosystem conditions and the consequences of these changes into decisions involving terrestrial, freshwater, and marine systems. Efforts under this goal have the potential to change the very nature of ecosystem science in ways that can extend the scope, efficiency, and effectiveness of ecosystem investigations.
"There is clear value in aligning research in the natural and social sciences more closely with the information needs of decisionmakers." (Rudd and others, 2011)

\section{Major Challenges}

- Develop tools, technologies, and standards to observe, map, analyze, and model current and future dynamics of populations and ecosystems.

- Refine methods such as adaptive management and structured decisionmaking to integrate social and ecological sciences into management decisions.

- Improve methods to analyze and use multiscale data from ecosystem observation networks to project the effects of changes in the drivers of natural resource systems.

- Develop and test decision processes that account for uncertainty in decision science applied to support environmental policy and management.

- Increase the capacity of the USGS and partners to fill existing data gaps and develop emerging scientific methods and tools to support decisions.

\section{Everglades National Park. Alligators and wading birds concentrate in watering holes during dry season as resources diminish, January 2011. Photograph by G. Lynn Wingard.}




\section{Everglades Restoration}

An essential component of the Greater Everglades Ecosystem Restoration is to restore more natural patterns of freshwater flow through south Florida wetlands and into the estuaries. A critical question for the U.S. Army Corps of Engineers, National Park Service, U.S. Fish and Wildlife Service, and other agency managers responsible for setting targets and performance measures is how to determine historical freshwater volume. Paleoanalyses of biotic remains in shallow cores collected throughout south Florida have established changes to the hydrologic conditions over the last few centuries. The paleoecologic results were used to hindcast historical stage and flow in the wetlands, and salinity in the estuaries. USGS research in collaboration with our partners has estimated that before canal construction, the Everglades contained approximately 2.5 times more freshwater flow than the current regime. These projections are being used to set targets and performance measures for restoration of the Greater Everglades Ecosystem.

Right: 2001 satellite image of south Florida (including the urban area of Miami, and Everglades and Biscayne National Parks) with superimposed salinity patterns for three time intervals. Historic salinity patterns are based on assemblages of organisms in sediment cores collected throughout the region. $A$, Reconstructed scenario for minimum extent of freshwater environments, indicating that freshwater habitats extended out into northern Florida Bay approximately 2000 years ago. $B$, Typical estuarine salinity patterns characterized Florida Bay around $1900 \mathrm{AD}$. C, Present day assemblages indicate loss of the typical estuarine zones, most likely because of the combined effects of diverted freshwater and sea-level rise.

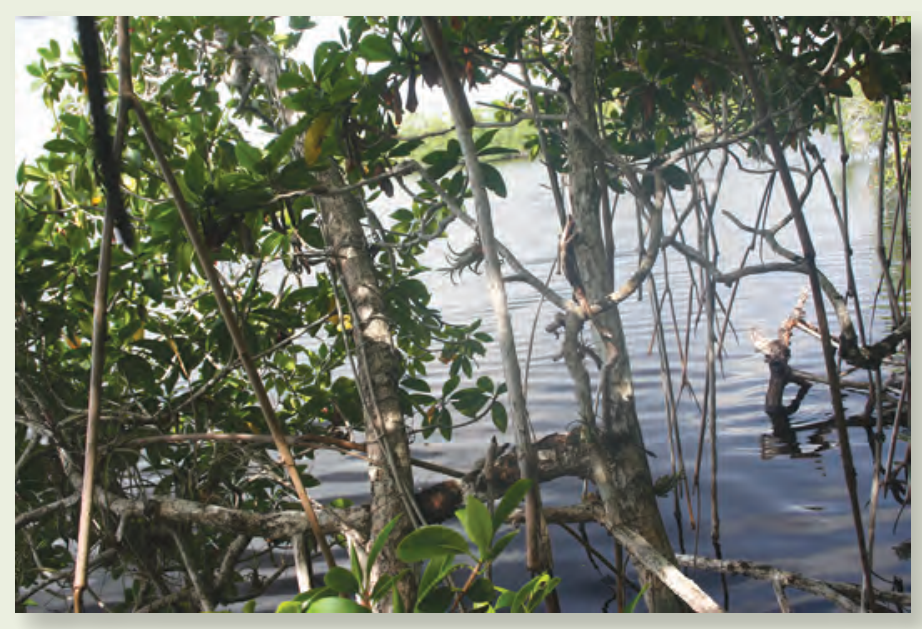

Mangrove forests border the coastline of Everglades National Park. Photograph by G. Lynn Wingard, USGS.
A

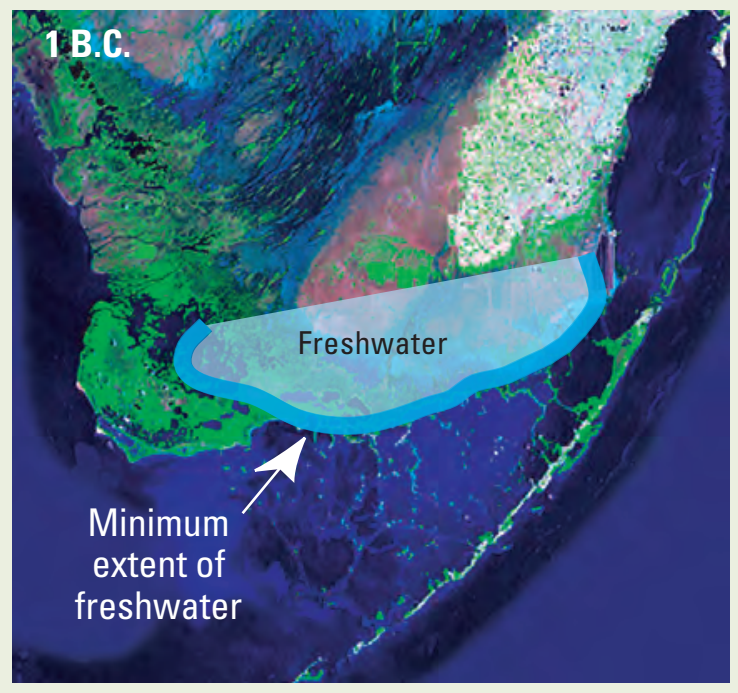

B

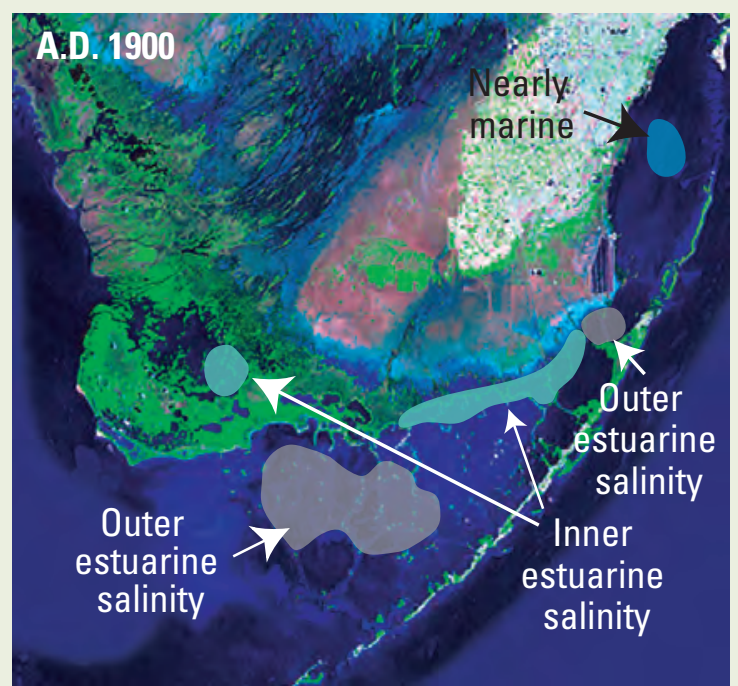

C

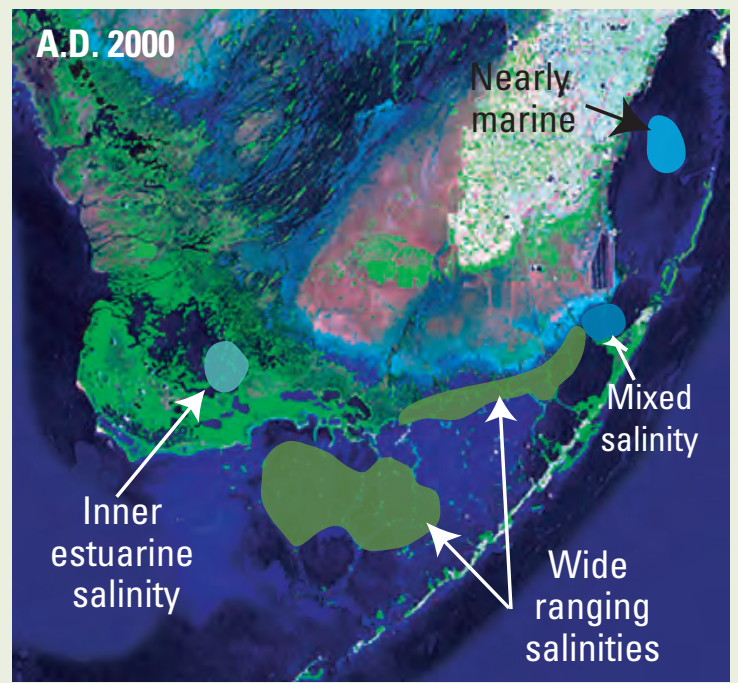




\section{Goal 5: Apply Science to Enhance Strategies for Management, Conservation, and Restoration of Ecosystems}

\section{Justification}

As managers and policymakers are confronted by unprecedented challenges to protect and manage resources in the face of multiple, often conflicting demands, the need for effective collaboration between managers and scientists has never been greater. Goal 5 focuses on the integration of science directly into the management framework, with scientists working closely with managers to ensure that science informs policy and management and leads to decisions that are defensible, transparent, and objective driven. Conversely, managers will be encouraged to work closely with scientists to ensure that management helps to focus science activities, leading to relevant and useful scientific results. Ecosystems respond to management decisions and it is important to use these responses as learning opportunities to reduce uncertainty for future decisions. The integration of scientific discovery and application can be useful at different scales and in different decision environments. It is the full integration of science and management that distinguishes the approach described here from past efforts to simply supply information. The new emphasis will be on science and information that are of most use to managers and their decisionmaking.

Of special importance is engagement of stakeholders through the entire research process, beginning with problem identification, agreement on objectives, development of science-based models, and examination of the consequences of different management actions. A partner-based approach that accounts for scientific knowledge as well as uncertainty holds promise for improving decisions by DOI and other resource managers. More generally, such an approach can help transform the way science is integrated in wildlife management, conservation biology, and other natural resource management disciplines. The USGS can play an important role in helping to integrate human dimensions and technical assessments in resource decisionmaking.

\section{Major Challenges}

- Advance the application of science to address complex resource management problems by integrating scientific discovery and adaptive resource management frameworks.

- Enhance the incorporation of stakeholder values and the transfer of scientific knowledge into the public domain through engagement of stakeholders.

- Develop models along with monitoring and assessment programs that are designed to inform management decisions and assess their utility.

- Use increased knowledge of species of concern, including threatened, endangered, and invasive species, to clarify management objectives and decision options for the Nation's trust resources.

- Use ecological and decision sciences to guide strategies for achieving management, conservation, mitigation, and restoration objectives in the face of continuing climate and land-use change.

- Increase USGS capacity for scientific decision support through training and strategic recruitment of new scientists.

\section{Science to Enhance Management of the Chesapeake Bay}

Chesapeake Bay is the Nation's largest estuary, with a watershed that encompasses six States and the Nation's capital, and includes nearly 17 million inhabitants. The USGS provides critical interdisciplinary science that addresses the major restoration goals of the President's Executive Order and the Chesapeake Bay Program (CBP), a Federal-State partnership working to restore, protect, and manage the bay. USGS scientists conduct monitoring, modeling, and research in conjunction with partners in an adaptive management framework. These efforts focus on restoring water quality, recovering habitat, sustaining fish and wildlife, and conserving vital lands. The USGS has the lead responsibility, in collaboration with NOAA, to strengthen science to support the CBP. It collaborates with 13 different national programs to bring our full capabilities on the science issues in the Chesapeake Bay.

Left: Mosaic of six Landsat 5 thematic mapper scenes of the Greater Chesapeake Bay region acquired in 2009 and 2011. Landast imagery can be used to produce high resolution maps of land-use type, vegetation, and other ecosystem attributes. 


\section{Integrating Ecosystem Science across the USGS}

"...it is evident that the innovative and transformative science that leads to breakthroughs often happens at the intersections of disciplines." (Smithsonian Office of Policy and Analysis, May 2009)

The goals and challenges described in the Ecosystem Science Goals Section represent a systematic framing of issues for ecosystem science. The goals are all mutually reinforcing, in that each is best understood in the context of the others, and combined they form our vision of providing science that becomes the foundation of natural resource policy and decisionmaking. Similarly, the challenges within and among goals are designed to be reinforcing, each providing context and focus for the others. The goals and challenges in the strategy can be seen as synergistic concepts in a framework that integrates discovery and application of ecosystem science for all USGS science. Figure 2 illustrates the placement of the five goals of this strategy along a continuum between discovery and application, while showing the essential interaction between resource management and science that must occur.

The conceptual model in figure 2 indicates linkages to the other USGS science mission areas. The report "Facing Tomorrow's Challenges" (U.S. Geological Survey, 2007) states that ecosystem science "is itself an essential direction for the USGS to pursue in order to meet pressing national and global needs." The report also emphasizes that "ecosystembased approaches underpin" the other mission areas, "which all require ecosystem perspective and tools for their execution." The framework presented here promotes the integration of science across the USGS mission areas.

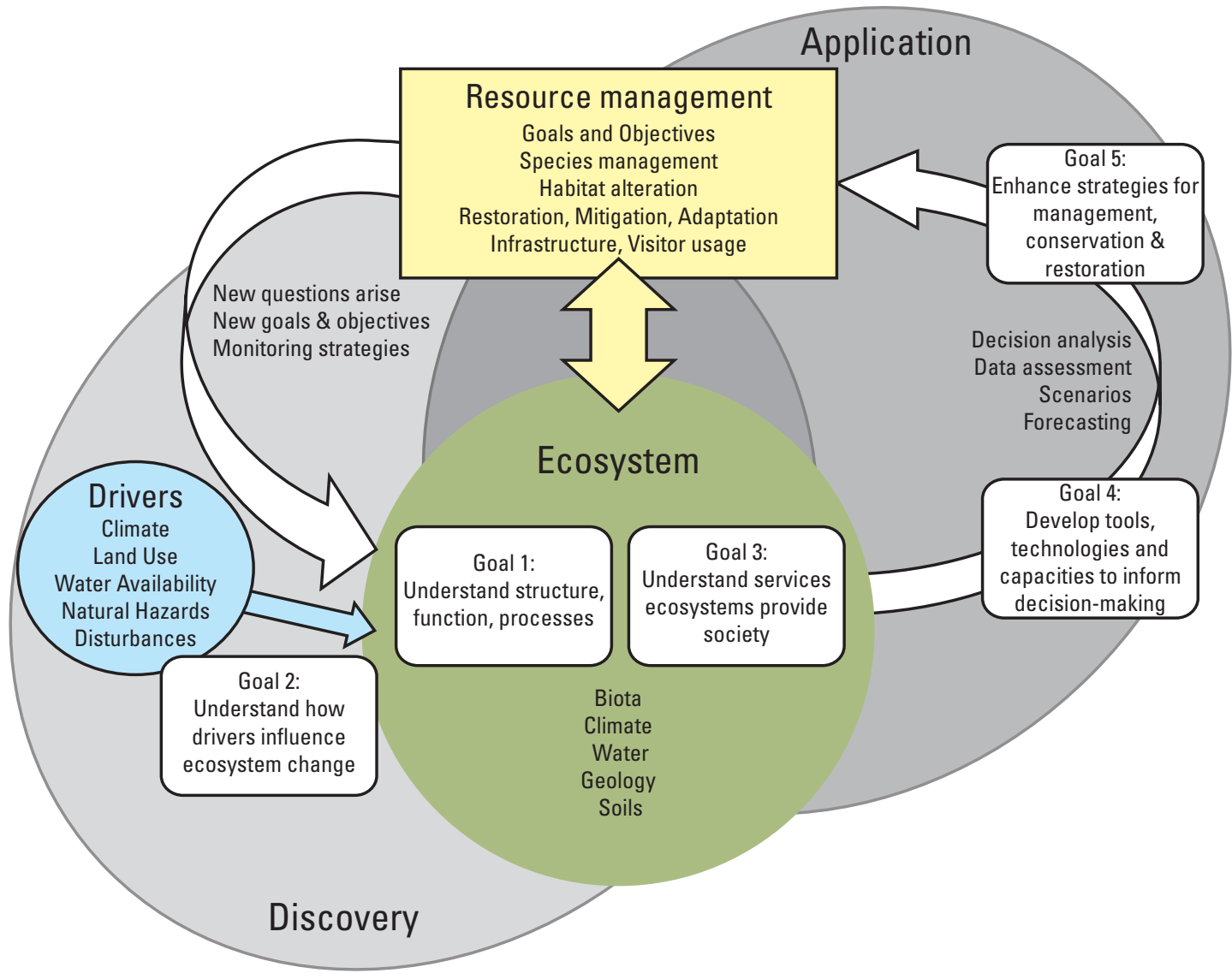

Figure 2. USGS ecosystem science must incorporate the study of an ecosystem and the drivers influencing the system while fully engaging and integrating resource management in the process. Strategic goals, shown in white, are placed along the continuum between discovery and application. Links to certain USGS mission areas are highlighted as drivers (Natural Hazards, Water, and Climate and Land Use Change). Disturbances include such factors as contaminants, pollutants, invasive species, pathogens, and resource extraction, which link Ecosystems Science to Energy and Minerals, and Environmental Health Mission Areas. Understanding the components of an ecosystem - the biota, climate, water, geology, and soils that characterize the ecosystem-links Ecosystem Science to Water, Climate and Land Use Change, and Core Science Systems Mission Areas. 


\section{Phenology and Climate}

Earlier springtime warming since the late 1970s, attributed to greenhouse gas buildup and climate variability, is driving far-reaching physical and biological phenomena throughout the United States and the world. USGS studies have documented trends in earlier breakup of stream, lake and ocean ice, increases in rainfall and decreases in snowfall, declining snowpack, earlier snowmelt and streamflow, more frequent fires, earlier leafing and flowering, and responses of animals to these changes. These trends in seasonal timing (phenology) are having cascading effects throughout managed and unmanaged ecosystems, but are poorly understood. The USGS is leading interdisciplinary research focused on seasonal timing in ecosystem dynamics; the management and monitoring of plant and animal phenology; and its influence on population dynamics, species interactions, and ecosystem fluxes and services. The USGS also has taken the lead in developing collaborative efforts such as the USA National Phenology Network (NPN), which includes citizen scientists, students, educators and other government agencies to increase our observations of change.

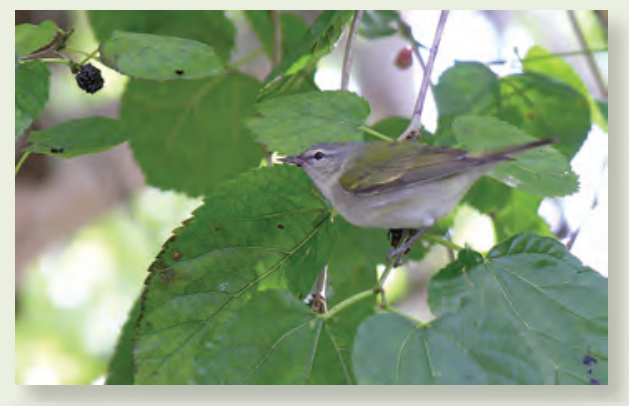

Tennessee Warbler, Grand Isle, Louisiana, 2005. Photograph by Dennis Demcheck, USGS.

The charts at right compare the 2011 and 2012 timing of Tennessee Warbler spring migration through the Northeast and Great Lakes regions of the United States with the timing (phenology) of flowering of six deciduous trees (white oak, northern red oak, sugar maple, red maple, American elm, American beech, and black walnut). Because of early warm temperatures in 2012, mean and peak flowering advanced by 19 to 20 days. However, timing of Tennessee Warbler migration did not advance, resulting in a greater than 25-percent decrease in overlap (blue-green polygons) between the flowering event and the bird migration. Because the plants serve as a food resource (the plants themselves and the insects attracted by the flowers), there was a significant loss of potential food resources for birds during migration stopover in 2012. Advanced plant phenology along migration routes could thus influence duration of birds at stopover sites, and ultimately influence nesting success on the northern breeding grounds.

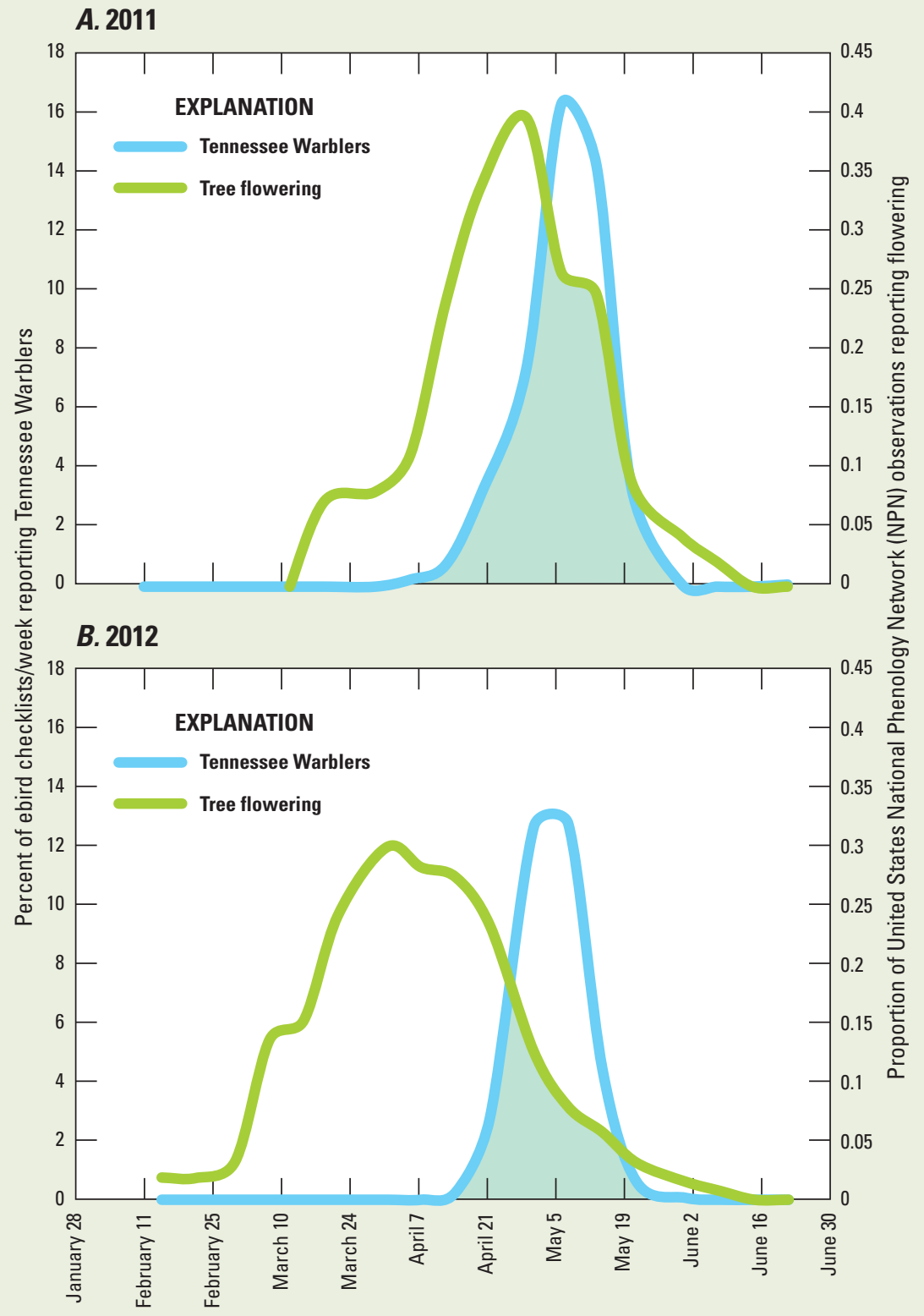


The Climate and Land Use Change Mission Area plays a role in ecosystem science by examining key natural and anthropogenic drivers that influence ecosystem change and feedbacks among those drivers as they influence structure, function, and processes of ecosystems and their associated services. Science pursued under the Climate and Land Use Mission Area will improve understanding of the global carbon cycle and land-use and land-cover changes, including rates, causes, and consequences and will improve understanding and prediction of coastal response to sea-level rise and climate change. The Water Mission Area will predict changes in the quantity and quality of water resources in response to changing climate, population, land use, and management scenarios. Water is a fundamental component of ecosystems, a dominant mechanism of transporting energy, nutrients, and contaminants through ecosystems, and a potential driver of change. The

Natural Hazards Mission Area will assess and guide decisions that minimize risk from hazards such as fire, volcanoes, and floods. An understanding of the magnitudes and frequencies of hazards that also may operate as ecosystem disturbance and regulating mechanisms will be provided. Ecosystem processes also are highly relevant to Natural Hazards science because they influence the impacts of disturbances. The Energy and Minerals Mission Area will provide accurate, unbiased inventories of the location, nature, and quantity of geologically based energy and mineral resources and conduct applied research needed to understand costs and benefits associated with energy and minerals development, and these costs include impacts on ecosystems. The Environmental Health Mission Area will identify and improve understanding of the effects of emerging contaminants and infectious agents in the environment. The Hazards, Energy and Minerals, and Environmental Health Mission Areas share common domains in the conceptual model, related to questions about how environmental and socio-economic drivers alter distributions of energy, materials, contaminants, water, pathogens, and nutrients in ecosystems, including the human dimension of the ecosystems. The Core Science Systems Mission Area provides a framework for organizing information on the geology, geomorphology, and soils, along with other physical and biological components of an ecosystem. Core Science will develop methods and systems to access and integrate disparate biogeochemical and socio-economic datasets. Finally, all the USGS mission areas have the potential to link to decision-analytic approaches and applications. These linkages will allow USGS scientists to examine the interactions that occur within and between ecosystems across spatial and temporal scales and the effects that ecosystems have on other earth processes.

In some cases, the USGS mission areas share similar research goals and approaches. Close coordination and leveraging of resources among the mission areas will be required to effectively and efficiently address the environmental challenges that are outlined above. Where proposed activities overlap among the mission areas, future implementation plans can incorporate decisions about which mission areas will lead or contribute to interdisciplinary research efforts. There are many opportunities for such collaborations. USGS ecosystem science will rely on the resources, information, expertise, tools, and technologies from each mission area. Potential areas for integration and coordination between Ecosystems Science and other mission areas include the following.

\section{Waterfall, El Yunque National Forest, Puerto Rico. Photograph by G. Lynn Wingard.}




\section{Climate and Land Use Change}

- Evaluations of effects of past and present conditions and changing patterns of air and water temperatures, precipitation, ocean acidification, and land use.

- Assessments of rates and magnitude of past ecosystem change, and projections of future change.

- Understanding of impacts of various climate-change scenarios on ecosystem services.

- Development of models and forecasts of how organisms and populations will respond to changing climate and land use.

- Improvements to tools and techniques to assess global- to local-scale responses to climate and land-use change.

- Sharing of knowledge of climate, land use, and ecology to provide comprehensive, holistic understanding of past, current, and future ecosystem change and to provide decisionmakers with options for mitigation and adaptation.

- Use of climate forecasting models to examine the effects of climate change on the structure and function of ecosystems.

- Identification of vulnerable ecosystems and patterns in ecosystem change that will be driven by climate and land-use change.

\section{Water}

- Assessment of status and trends of water quality, water use, and water availability and forecasting of changes in water supplies in response to climate change.
- Development of ecological flow science - explain and model how changing hydrological water cycles affect biological and ecological systems.

- Assessment of relationships between changes in water quality and quantity on the availability of other ecosystem services.

- Evaluation of strategies for sustaining the biological diversity and vital functions of aquatic ecosystems.

\section{Natural Hazards}

- Assessment of the frequency, magnitude, and likelihood of extreme/rare events (earthquakes, volcanic eruptions, tsunamis, floods, wildfires, and others), which act as disturbance mechanisms and drivers of ecosystem change, and the impact of these natural stressors on ecosystem processes.

- Assessment of resilience of ecosystems to natural hazards and the potential impact of natural hazards on the provision of ecosystem services, and development of a better understanding of the services that ecosystems provide to mitigate or reduce the effects of a hazard.

- Rapid response planning and modeling for anticipating threats from natural hazards and extreme events.

- Description and modeling of remediation and restoration strategies to minimize long-term impacts of hazards to human societies while maximizing benefits to ecosystems and people.

- Identification and prediction of hazards risks to ecosystems, and development of adaptive management strategies that account for hazard risks and uncertainties. 


\section{Energy and Minerals}

- Assessment of conditions of energy and mineral resources, chemical concentrations, and their transformation, degradation, and flux, with coordination on joint efforts on the environmental consequences of changing conditions.

- Assessment and models of the impacts of past, present, and future mineral and fossil fuel extraction on ecosystems.

- Evaluation of resource life cycles and the impacts of energy and mineral development on ecosystem services and sustainability.

- Rapid responses to environmental disasters associated with energy and mineral extraction.

- Modeling and decision support for remediation and restoration strategies to reduce environmental impacts of energy and mineral resource extraction and use.

- Provision of mineral and contaminant information on abandoned mine lands for restoration of ecosystem services disrupted by mineral extraction.

\section{Environmental Health}

- Evaluation of past and present conditions and changing patterns of fish and wildlife health and the population dynamics of the wildlife host species.

- Assessment of occurrence and exposure pathways for contaminants, infectious disease transmitted by animals to humans, parasites, and microbial ecology.

- Understanding of interrelationships among contaminants and infectious agents and ecosystem services.
- Modeling of environmental health threats to fish and wildlife populations and humans.

- Development of models, decision support, and adaptive management approaches to prevent, control, and manage pathogens and infectious diseases.

\section{Core Science Systems}

- Development of new methods for synthesizing, integrating, mapping, and modeling data related to ecosystem drivers.

- Enhanced retrieval and analysis of relevant data on abiotic ecosystem components (for example, rainfall, atmospheric temperature, population demographics, land use, potential hazards) and the packaging of ecological information into useful products such as GIS maps and databases.

- Development of models and provision of spatial representations of the flow of ecosystem services to beneficiaries.

- Development of techniques and standards for habitat classification and biogeographic mapping.

- Development of methods to link and merge terrestrial, aquatic, coastal, and marine data and habitat maps.

- Access to databases to evaluate and map patterns of land use and land change.

- Development of software and technology to manage and display ecological data. 


\section{United States-Mexico Border}

The Santa Cruz River Watershed (SCW) is located in the United States-Mexico border region, where surface water is scarce during much of the year. Groundwater is the primary water source for industrial, agricultural, and domestic use in the region. The USGS is investigating ways to identify risks to water resources and the potential consequences to riparian ecosystems and, ultimately, human health. To understand impacts of various management scenarios on ecosystem services in the SCW, the USGS is developing decision-support tools that will permit scientists to evaluate how changes in climate and land use will impact ecosystem services of flood regulation, erosion control, and habitat provision, and determine the distribution of the burdens associated with these impacts. This United States-Mexico collaboration illustrates the importance of interdisciplinary continental-scale studies.

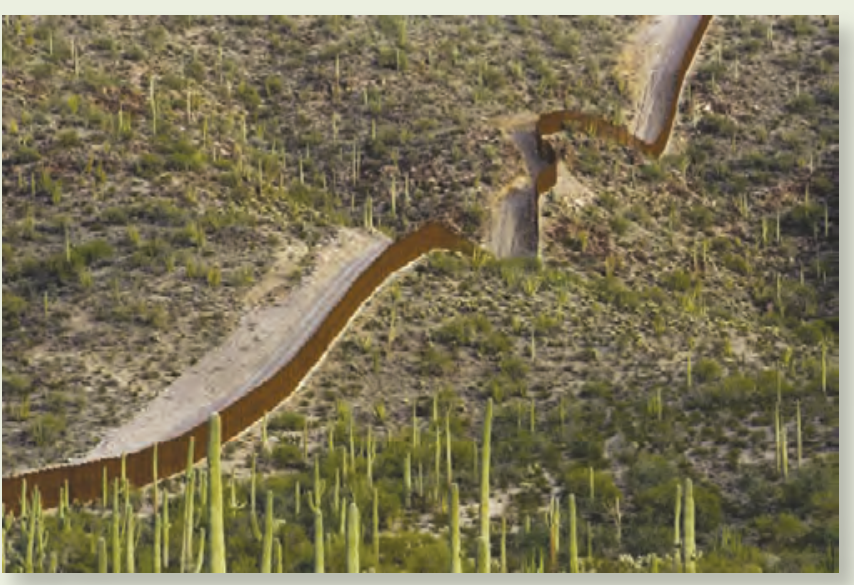

The United States-Mexico border fence cuts through a forest of saguaro cactus on the Sonora Mexico and Arizona border, 2012. Photograph courtesy of Jack William Dykinga, CDykinga Photography. research designs in areas like Chesapeake Bay (see highlight, p. 20), Mojave Desert, Platte River, Colorado River (see highlight, p. 28), Puget Sound, San Francisco Bay (see highlight, p. 15), and south Florida (see highlight, p. 19). By fully supporting these regional partnerships, priority ecosystem issues can be best identified and refined by multiple stakeholders and thus lead to more collaborative research and more effective application to management problems. Key geographic areas, species, and ecosystems will be identified where USGS contributions to research, monitoring, assessment, mapping, and modeling can provide important information on ecosystem structure, function, process, and change.

This strategic approach will ensure that the USGS and its partners are effectively communicating, planning, and implementing science on a regional basis to address the highest priority information needs and resource management decisions. Collaborations to identify and address restoration issues and anticipate and respond rapidly and effectively to environmental disasters will be promoted. USGS scientists and DOI management agencies will work together to determine priority science needs. Engagement with stakeholders as they identify specific management objectives and available management actions will promote science that is oriented toward the consequences of actions. This science focus serves as a filter for hypotheses that are directly relevant to decisionmaking and leads to an effective prioritization of science needs.

Through these interactions, funding and other resources will be leveraged among multiple partners. Sustained investment in a diverse portfolio of field- and laboratory-based ecosystem science will yield high returns in fundamental understanding of ecosystem dynamics through interdisciplinary collaborations, development of fundamental biological and ecological knowledge, and applications of system modeling and analytical frameworks. Hypothesis-based research, monitoring, and assessment will focus on selected taxa and representative ecosystems under a strategic, collaborative planning process, thereby optimizing investment of USGS and other bureau resources. These focused efforts will strengthen ecosystem science and increase linkages between science and its application in resource management decisions.

\section{Canyonlands National Park, Utah, July 2006. Photograph by Robin P. White, USGS.}




\section{Colorado River Management}

The Colorado River is one of the most highly regulated and heavily used river systems in the world. Two principal reservoirs, Lakes Powell and Mead, along with 49 other large reservoirs, store and release water for more than 30 million people who depend on Colorado River water and the ecosystem services the river provides. USGS scientists are working with managers and stakeholders to conduct river and riparian monitoring and experimentation of hydrological flows to evaluate physical, biological, and cultural responses to different management techniques. The results are being used to inform management decisions about water releases and ecosystem management.

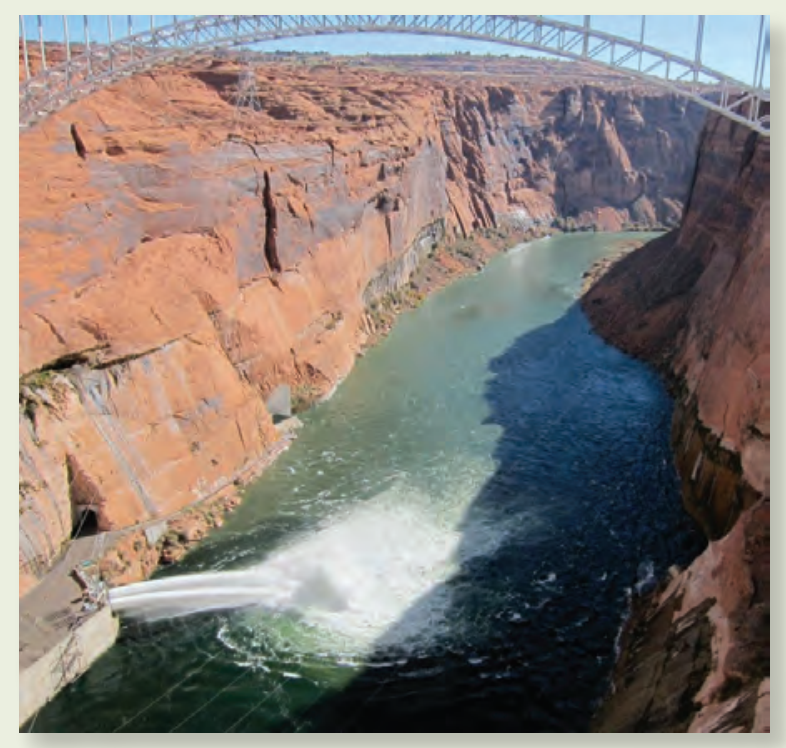

Release of water into the Colorado River through Glen Canyon Dam's powerplant and bypass tubes at approximately 41,500 cubic feet per second. This 2008 high-flow experiment lasted for 60 hours and was designed to enhance wildlife habitat and to learn more about complex natural river systems. The USGS and cooperators studied the influence of the high flows along the 277-mile stretch of the Colorado River that runs through Grand Canyon National Park to understand the responses of the river system to the experimental high flow.

\section{Strategic Approach 2. Promote the Use of Interdisciplinary Ecosystem Science}

- Encourage and support interdisciplinary ecosystem research among the USGS mission areas.

- Develop information from interdisciplinary processoriented research within ecosystem science in collaboration with other agencies and partners.

- Design and conduct interdisciplinary research to understand ecosystem variability across temporal and spatial scales that is important to management decisions.

The USGS bureau science plan (U.S. Geological Survey, 2007) emphasized that ecosystem science requires the full power of an integrated systems approach. Ecosystem science provides a context to take advantage of the multiple capabilities and strengths of all USGS mission areas to develop a more comprehensive understanding of coupled socio-ecological systems. The focus of this strategic approach is on finding common ground among mission areas to identify priority issues, leverage budgetary and intellectual resources, and collectively inform pending and future resource management decisions through improved scientific understanding.

Solutions to complex problems with coupled socio-ecological systems will require knowledge gained from integrated, interdisciplinary studies that span the mission areas. As a result of these activities, the USGS will develop ways to field teams of interdisciplinary scientists to address information needs of DOI agencies and other resource management organizations. The result will be a more holistic understanding of socio-ecological systems and more applicable ecosystem science for management, conservation, and restoration of 
ecosystems. Interdisciplinary expertise will be used to explain ecosystem functions, outputs, and services that are valued by the American people. These values will be incorporated into goals and challenges for decisionmaking that are science based and adaptive. Synthesizing approaches from other disciplines will produce innovations to help evaluate the benefits that resilient, diverse ecosystems provide to people.

\section{Strategic Approach 3. Enhance Modeling and Forecasting}

- Design conceptual models of ecosystems for which there are pressing needs for management decisions.

- Build quantitative models to forecast ecosystem changes and their implications under a range of future scenarios, including alternative management strategies.

- Use comparisons of GIS data layers and model forecasts against observations to advance understanding and improve forecasting.

- Identify critical data gaps, design and implement new monitoring and process measurements, and use the resulting data to reduce forecasting uncertainties.

This strategic approach involves the implementation of research and monitoring to support and advance modeling, mapping, and forecasting of species, ecosystem services, and other key indicators in selected terrestrial, freshwater, and marine systems. Observations and research, together with models and forecasts, help scientists and managers understand environmental variability, explain vulnerabilities and risk, and evaluate management options. Models can help integrate disparate social, cultural, economic, and ecological data, enabling the evaluation of how different management options impact resource use and sustainability. By testing and improving the accuracy of models - for example, using adaptive management strategies - tradeoffs between resource use and sustainability can be better quantified for managers and stakeholders.

Forecasts of ecosystem change from climate, land use, and other drivers and their impacts on ecosystems services are vital to managers for evaluating alternative scenarios and management options. Developing these forecasts requires knowledge of current and past ecosystem dynamics, the impacts of external drivers and stressors, and potential synergistic and cumulative effects. A key focus of modeling and forecasting will be to facilitate decisionmaking to meet objectives while reducing uncertainty and thereby improving future decisions. Model-based forecasts can be compared against new monitoring data to refine understanding of model parameters and processes, which, in turn, can be incorporated into decisionmaking in the form of better model forecasts.

These activities will provide systematic analyses of past, present, and future ecosystem dynamics in key ecosystems. Decisionmakers will benefit from predictive models of future ecosystem conditions under various scenarios of changing climate, water use, and land use. Ecosystem modeling and forecasting will lead to quantitative decision-support tools, with important benefits in prioritizing investments in restoration strategies and options for mitigation, adaptation, and conservation. Modeling and forecasting techniques are common to all USGS mission areas, and we anticipate many practical opportunities for cross-mission collaboration. The data framework and modeling techniques used to forecast ecosystem changes will build on collaborative work and knowledge produced within the other mission areas.

\section{Glen Canyon National Recreational Area, July 2012. Photograph by Christopher Wingard.}




\section{Strategic Approach 4. Support Decisionmaking}

- Develop quantitative approaches, tools, and capacity to evaluate success of adaptation, restoration, and other conservation decisions.

- Use output from forecasting models to assess the consequences of management actions and evaluate the services provided by selected ecosystems under a range of future scenarios and management options.

- Provide managers with information to identify ecosystems, habitats, and species that are particularly vulnerable to ongoing and anticipated changes, and collaborate with managers in assessment of potential actions.

\section{Golden Eagles in Denali Park}

Denali National Park is a popular venue for visitors and for nesting golden eagles. The key tradeoff in park management is between the dual National Park Service objectives of public use and healthy natural systems, with the possibility that one form of use, hiking near golden eagle nest sites, may reduce eagle occupancy and nesting success. Management involves closure of areas to hiking during the nesting season, with closure decisions derived as a function of eagle population status and snowshoe hare (key eagle prey item) abundance. Adaptive management of hiking activity in the proximity of golden eagle nests at Denali National Park is an example of successful collaboration between scientists and managers to meet multiple resource objectives.

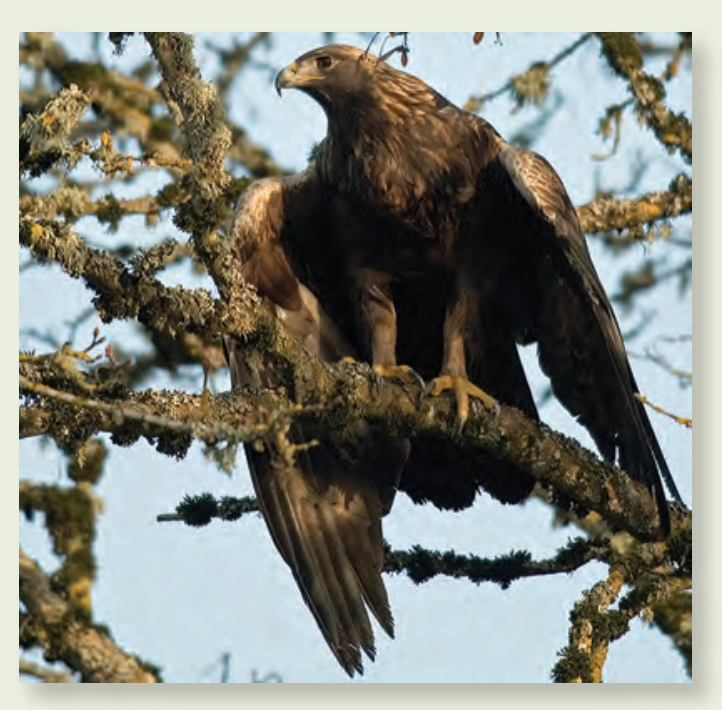

Golden eagle, February 2009. Photograph by

George Gentry, U.S. Fish and Wildlife Service.
This strategic approach is at the heart of our vision for USGS ecosystem science. It involves collaboration with partners to expand capacity, leverage resources, and apply stateof-the-art mapping and decision science to manage natural resources in key terrestrial, aquatic, and marine ecosystems. These collaborations will build on expertise in all USGS mission areas and partner agencies in ecosystem science, monitoring, data collection, decision analysis, and socio-economic systems. The tools and approaches of decision assessments will be developed and applied to ecosystem management in a context of structured decisionmaking. USGS scientists will work with partners to design monitoring protocols and determine data gaps for use in evaluating ecosystem responses to decisions, determining patterns of ecosystem change, and improving understanding of ecosystem structures, functions, and processes. Working with partners, the USGS will promote the development and use of new technologies for tracking ecosystems, investigating ecosystem processes, and evaluating ecosystem services.

The principal outcome of these activities will be to strengthen ecosystem management and increase the linkages between science and its application in resource decisionmaking. Depending on the ecosystems and issues under investigation, decision analysis will focus on specific interactions with the other mission areas. USGS expertise in decision science will serve a critical function in integrating interdisciplinary concepts in the framing of ecosystem decisions. Decisionanalytic frameworks will be developed that allow for adaptive decisionmaking, with the learning from assessment of ecosystem responses used to inform subsequent management actions.

Denali National Park, Alaska. Photograph courtesy of National Park Service. 


\section{Proposed Actions}

The following proposed actions are presented as examples of specific activities that address the most pressing environmental information needs of our Nation and that illustrate the depth and breadth of USGS ecosystem science. They highlight our vision of bringing science to the forefront of decisionmaking and they emphasize the alignment between societal needs and the goals, challenges, and strategic approaches outlined in this report. These actions range across a spectrum from ongoing mission-critical activities to long-term strategic activities. Each action focuses on interdisciplinary science and its application to decisionmaking. No attempt has been made to prioritize or categorize these actions because all are seen as key to meeting the science needs of the Nation. These actions are steps that can advance the USGS science strategies and help to identify priorities for future implementation plans. Flexibility will be necessary in the timing and pace of implementation.

Proposed action.-Establish a USGS Ecosystems Science Forum. The USGS Ecosystems Mission Area needs to coordinate closely with DOI and other stakeholders on regional and national scales to maximize

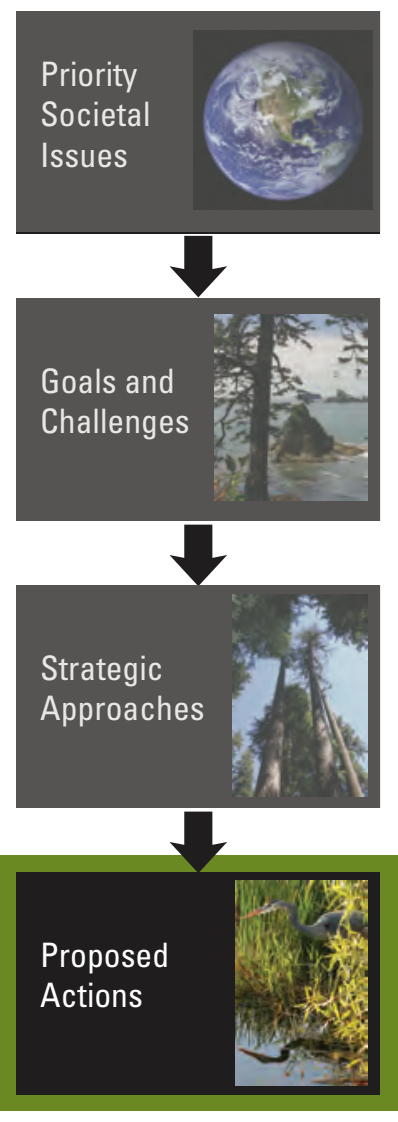

contributions to ecosystem science. One method to accomplish better science coordination is to establish a body for consultation and communication, a "USGS Ecosystems Science Forum (EcoForum)." The EcoForum would be a standing committee coordinated by the USGS and would include participants from interested groups within the DOI bureaus. The EcoForum would be charged with ongoing broad-scale evaluation of direction, integration, and quality of USGS ecosystems science and with formulating recommendations for how USGS ecosystems science can be better positioned to contribute integrated USGS science to meet partner needs. Early tasks of the EcoForum would be to recommend strategies for integrating multiscale investigations of ecosystems and exploring the feasibility of a national ecosystem assessment.

Proposed action.-Collaborate with partners to monitor responses of endangered species to environmental change. Federal mandates require the protection of endangered species, but it is difficult to determine the best management strategies under rapidly changing environmental conditions. Agencies responsible for the management of endangered species

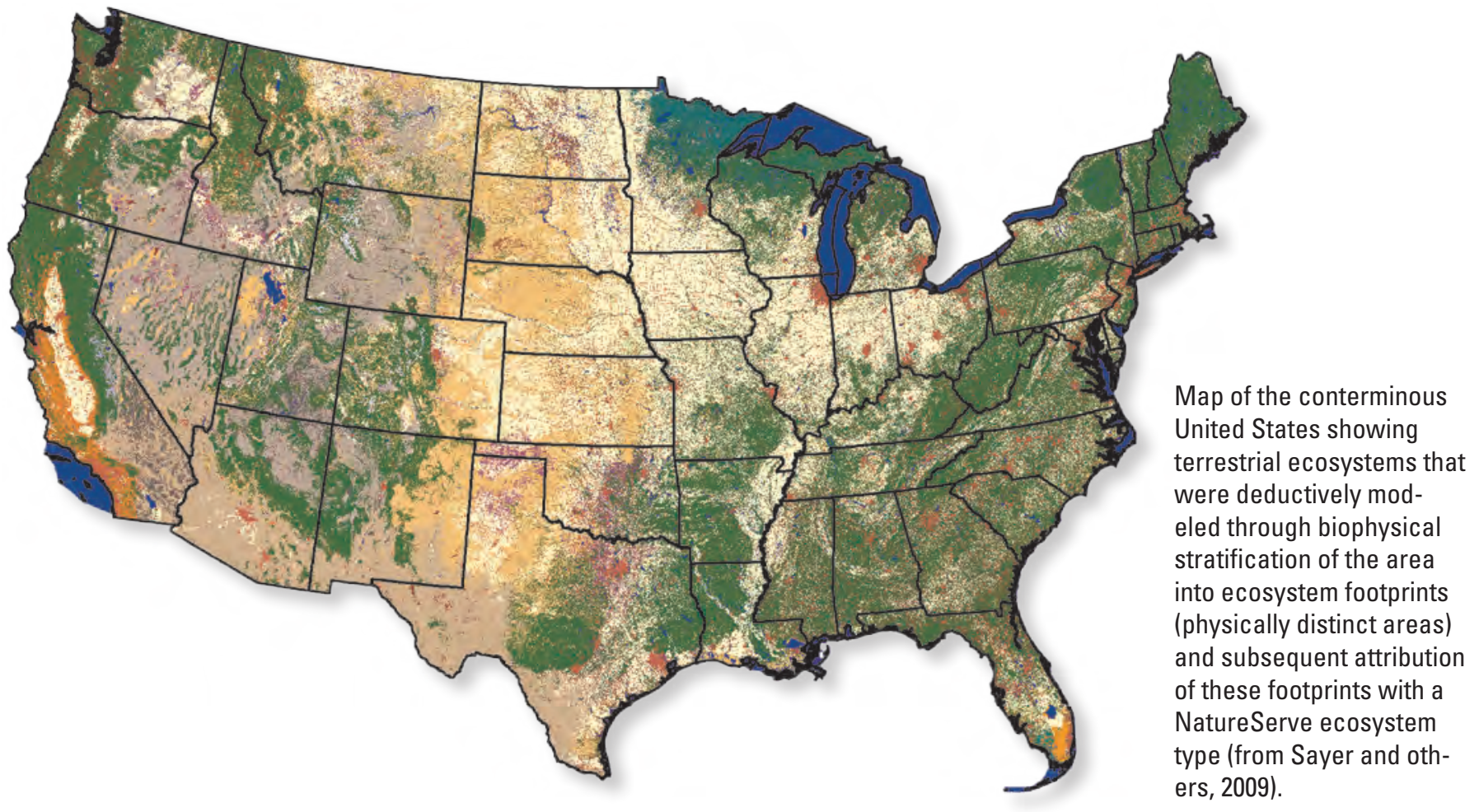




\section{Integration of Science from Local to National Scale}

Many studies conducted by USGS scientists are used to answer specific questions from local to regional scales. Integration of results from these studies across the Nation can begin to move us toward a better understanding of the complex natural interactions across ecosystems with respect to issues such as migration patterns, invasives, shifting climate, ecological flows, and a myriad of other natural resource issues. By combining data from these studies we may be better able to accomplish the following:

- Understand the nature, rates, and underlying causes of environmental changes detected across the Nation's ecosystems.

- Measure the social and ecological costs and benefits of these changes.

- Project future ecosystem changes as drivers, such as climate change, alter existing patterns of response.

- Inform policies to sustain ecosystems and the services they provide in a rapidly changing world.

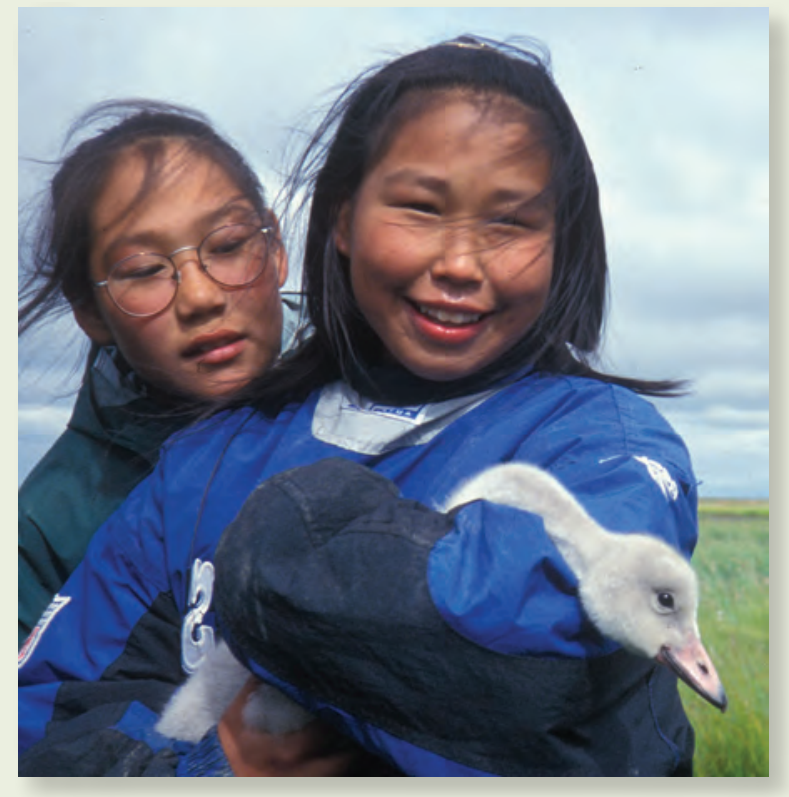

Yupik Eskimo students, holding a tundra swan cygnet (juvenile), assist with annual USGS bird banding program along the Kashunuk River in Alaska. Citizen scientists and volunteers are essential to conducting science across the Nation's vast landscapes. Photograph by Craig Ely, USGS. need tools for understanding the impacts of future changes on these sensitive populations. The ability to visualize current distributions and potential range shifts as a consequence of global climate change is an important component of effective management of listed species. Range shifts will likely span land-management and political boundaries, so it is important to develop consistent and comparable datasets to track species distributions and populations. The USGS, in collaboration with our partners, can compile and standardize existing data on ranges of endangered species, identify information gaps, and develop a coordinated plan for monitoring changes in the species distributions. This compiled information can be used as input for models forecasting movement and population changes of endangered species in response to environmental change.

Proposed action.-Improve understanding of the impacts of alternative energy development on ecosystems. Renewable energy alternatives that will reduce the Nation's dependence on foreign energy resources are receiving increasing attention. Although these alternatives have been viewed as relatively harmless by some people, there are environmental consequences that need to be considered. For example, wind turbine development has affected bird and bat migrations and caused increased mortality. As new alternative energy technologies are developed and older technologies are improved, managers will need to understand the consequences and tradeoffs of these technologies to ecosystems. USGS interdisciplinary perspectives are well situated to provide science for selecting sites for energy development that minimize impacts to species and habitats, evaluate the consequences of various management alternatives, and provide managers with tools that they can use to improve their decisionmaking.

Proposed action.-Incorporate understanding of past patterns of environmental variability into forecasting efforts. Environmental changes are occurring across the United States at unprecedented rates, with implications for the sustainability of ecosystem services and the Nation's well-being. A vast amount of information recording these changes exists in isolated datasets and reports. There is a critical need to synthesize, compare, and analyze this existing information and develop integrated assessments of how and why human actions and natural events interact to bring about changes in biodiversity, nutrient cycling, energy flow, and ecosystem services. Such syntheses would help answer important questions 
about which processes of environmental change are most important, which are changing most rapidly and where, and how these altered processes interact to affect life-supporting functions of terrestrial, freshwater, and marine ecosystems. These assessments would contribute to the development of models of ecosystems' responses to drivers and would lead to better forecasts of change, including strategies for mitigation and adaption.

Proposed action.-Improve the ability to predict the occurrence and consequences of fire across the landscape. Fire has the ability to substantially alter an ecosystem, yet our understanding of the potential and consequences of fire remains limited. The probability of fire at a given location depends on a number of variables including ignition sources, vegetation types, and available fuels. Severe and intense fires may cross a threshold for the ecosystem that impacts the resilience of successional cycles and may lead to completely new patterns of succession. The resulting ecosystem following such a fire can represent a completely new situation. The USGS can work with land-management agencies to develop fire management plans that are based on an understanding of potential outcomes. In addition, fires frequently originate in unmanaged lands, and they spread across jurisdictional boundaries. The USGS has the capacity to provide information on the variability of vegetation and fuels in space and time without regard to boundaries. This information is critical to understanding the hazards to people and property associated with the risk of wildland fire. Fires also affect carbon sequestration, water availability, and fish and wildlife habitat. Knowledge of interactions between ecosystem structure and wildland fire is critical to modeling and forecasting the future probability and consequences of fire across the landscape in response to changing climate and land use.

Proposed action.-Investigate the impacts of acidification on ecosystems. Anthropogenic activities are causing acidification of the Earth's oceans, primarily from the combustion of fossil fuels, smelting of ores, mining of coal and metal ores, and application of soil fertilizers. Key issues are the magnitude of anthropogenic acidification and connections to the degradation of terrestrial, freshwater, and marine systems at regional to global scales, and specifically the impact of more acidic ocean waters on carbonate-secreting organisms, such as corals and other invertebrates. Cost-effective mitigation efforts will require a better understanding of the capacities for communities and ecosystems to adapt to increasingly acidic environments. In addition to understanding the biological responses, it is essential to understand the compounding effects of multiple drivers of change. The USGS should develop collaborations with other governmental and academic efforts to understand how and why alterations in biogeochemical properties and processes like acidification are affecting the provision of goods and services that sustain human health, societal well-being, and national security.

Proposed action. - Work with resource managers to develop science-based restoration performance measures and targets. A priority for the USGS is to provide science to our partner land management agencies in areas that have been targeted for restoration and rehabilitation. The challenge for restoration/rehabilitation of ecosystems is to integrate a strong scientific understanding and institutional commitment to highly interactive, collaborative decisionmaking involving scientists, managers, and stakeholders. Resource managers often are required to develop performance measures and targets (specific goals) for restoration, yet they are managing landscapes that have already been altered. In addition, the resources they manage do not occur in isolation of surrounding landscapes. USGS science can provide an understanding of the ecological processes, past patterns of ecological variability, and drivers of change across the regional landscape that lead to the development of scientifically defensible performance measures and targets for restoration of the resources.

Proposed action.-Develop teams to investigate the scale and effects of environmental disasters. Unforeseen natural and manmade disasters affect ecosystems as well as human lives, property, and infrastructure. In some cases, ecological effects may exacerbate disasters, for example by increasing the potential for subsequent floods, landslides, or coastal flooding until the ecosystem recovers. The USGS should develop interdisciplinary and collaborative response teams in coordination with other mission areas to evaluate effects of environmental disasters on ecosystems and improve forecasts of their consequences. Following initial evaluation, the disaster response team could establish a coordinated monitoring effort to document the subsequent changes to the ecosystem, in order to provide basic scientific information on ecosystem processes and functions, response to drivers, and impacts of disasters on ecosystem services. The results of these coordinated and focused studies of disaster response can be applied

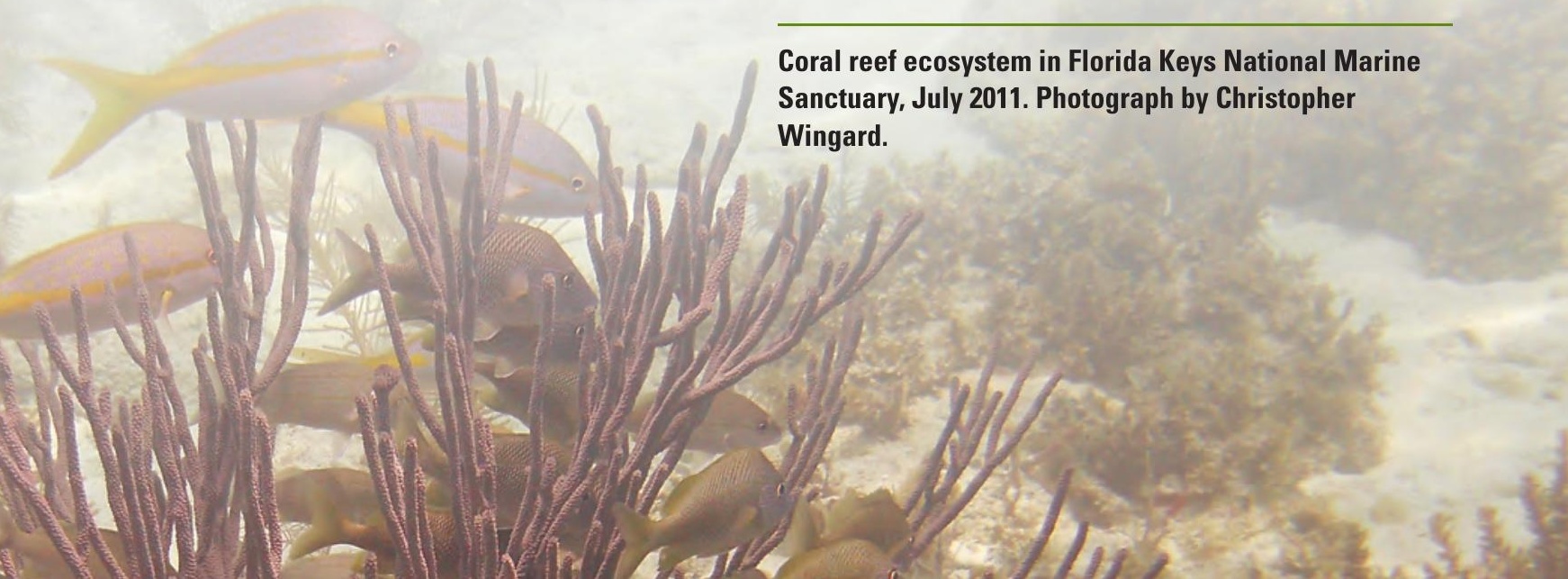


to modeling efforts and will provide resource managers with tools to anticipate and respond rapidly and effectively to future environmental disasters.

Proposed action.-Incorporate environmental thresholds and resiliency in the assessment of ecosystem dynamics. USGS research should recognize and address more explicitly the complex issues involving environmental thresholds and the prospect of large, potentially irreversible changes in ecosystem behaviors. Nonlinear trajectories, thresholds that separate them, and complex patterns of change in system dynamics often characterize large and interconnected ecosystems. As the scope and scale of issues grow with climate change, land-use change, and other factors associated with increasing human populations, the need to describe, model, and assess nonlinear attributes in the context of sustainable resources is becoming increasingly urgent. The USGS has the opportunity to expand its science capacity and infrastructure to better understand these issues and to integrate that understanding into the Bureau's science portfolio.

Proposed action.-Develop integrated models for forecasting the consequences of climate change to ecosystems. Forecasts of changes in ecological systems rely on models that include the dynamic components of an ecosystem. Though many existing models include ecosystem responses to change, they are based on dynamic ecological processes that are stationary through time. A substantial challenge in accounting for climate change in ecological models is to recognize that environmental variation is not stationary. To improve our ability to forecast the impacts of climate change on ecosystems, the USGS will need to develop new approaches to modeling that incorporate nonstationary change. In addition, models will need to simultaneously examine ecosystem characteristics and environmental drivers of change in those characteristics. Such models will provide managers with a better understanding of the consequences of land-use decisions and climate change on ecosystems. The applications of this integrated modeling range from endangered species management to large-scale changes in species distribution patterns. The USGS should expand its capacity to develop these integrated models through interdisciplinary collaboration and building on existing efforts.

Proposed action.-Evaluate factors that contribute to the establishment, spread, and control of invasive species. Invasive species are a leading threat to native species and their ecosystem services. The magnitude of impact from invasives on native species assemblages hinges on site-specific characteristics and other drivers of population decline, such as habitat degradation and climate change. A priority for the USGS is to understand the movement of invasive species across national boundaries. The USGS also needs to investigate how invasives affect key ecosystem processes, to predict which systems are most likely vulnerable to new invasions, and to develop innovative approaches to control or eliminate the spread of invasives. Cost-effective rehabilitation efforts will require a better understanding of how invasive species affect ecosystems and their communities.

Proposed action.-Build capacity and expertise to quantify the costs and benefits of ecosystem services. An important research thrust for the USGS during the next decade will involve defining, measuring, and valuing ecosystem services. A key research challenge is to describe and assess the linkages between ecosystem structures and functions, and the production of ecosystem services. A second research challenge will be to evaluate the ecosystem services thereby produced, using both market and nonmarket valuation methods. This research will fold directly into a science framework for sustainable management of natural resources and will contribute to a more complete accounting and assessment of the resulting ecosystem services. USGS investment in ecosystem services science will include investigations by USGS scientists and cooperative interactions with academic and agency partners at the forefront of this developing field of science.

Proposed action. - Investigate and evaluate the effects of fossil fuel development on ecosystems. The demand for fossil fuels and expanded exploration of new energy sources has placed unprecedented pressures on selected ecosystems across the country. Though much of the recent expansion has occurred in the Western United States, exploration is now occurring in the Midwest and East, as well as coastal areas. There is an urgent need to provide managers with information to understand ecosystem effects, predict where those effects may occur, and develop new mitigation strategies if impacts do occur. In addition, the development and dissemination of decision-support technologies are urgently needed as managers cope with evaluating tradeoffs of various development alternatives and try to understand the consequences to the resources they manage. Close coordination with the Water, Energy and Minerals, and Environmental Health Mission Areas will be critical to addressing these issues.

Proposed action.-Develop innovative approaches to ecological flow science. The growing demands for water resources will increase the already urgent need for sciencebased decisionmaking in water management. The interdisciplinary science of ecological flows, linking aquatic and riparian ecosystems directly to water, will be required to inform those decisions. Although originally focused on low flows in regulated rivers, management needs have grown
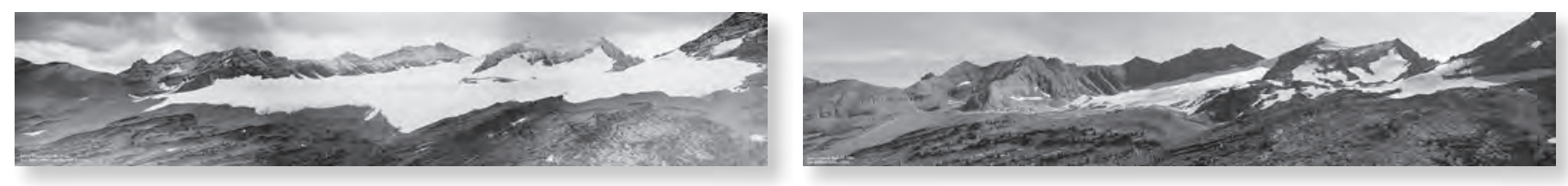

Glacier National Park, Montana. Photograph at left taken 1913. Photograph at right taken 2008. 
into the broader scope of how species are affected by a wide range of factors involving water quantity and quality, as influenced by multiple stressors including dams, diversions, land-use change, and climate change. Progress in ecological flow science will require the USGS to demonstrate the utility of approaches that address how hydrologic alterations affect food webs, population processes, biotic interactions (predation, competition), disturbance processes, water quality, and contaminants.

Proposed action.-Develop robust approaches to natural resource decisionmaking in the face of climate change. Climate change is expected to exacerbate uncertainties facing resource managers and to affect all of the major components of an informed decision process (objectives, actions, models, monitoring, and alternative assessments). Multidisciplinary teams of USGS scientists can work with our partners to address questions of how agencies and societies will (1) continue ongoing management of natural resources in the face of climate change and (2) initiate new efforts to mitigate or adapt to climate change. USGS scientists will be encouraged to work with agency managers to develop fundamental scientific understanding and robust approaches to decisionmaking in the face of the increased uncertainty that will attend climate change. A key component is an increased emphasis on decisionmaking that incorporates an understanding of dynamic change and moves away from the concept of equilibrium.

Proposed action.-Develop and use new tools and methods in the management and conservation of at-risk populations. USGS science can play a pivotal role in understanding susceptibility and resistance of species to disease and other natural or anthropogenic stressors such as habitat change, contaminants, and genetically engineered crops. Newly developed genetic and genomic techniques, for example, will play increasingly important roles in the management of wild populations, as well as in the investigation of issues in environmental toxicology, epidemiology, and potential threats from genetically engineered organisms. Genetic and genomic techniques will be important in identifying demographic trends, determining effective population sizes of species at risk, and recognizing species and even individuals from environmental DNA, often by unobtrusive sampling. New technologies such as these are growing rapidly, and that growth presents an opportunity for USGS science during the next decade.

Proposed action.-Develop capacity to engage USGS scientists in design and execution of adaptive management projects. A priority for the ecosystems strategy is to integrate science discovery and science application in natural resource conservation and management. To accomplish this, the USGS needs to engage partners and stakeholders in a process of learning-based adaptive decisionmaking that increases understanding of natural resources and better informs future decisionmaking. Adaptive management recognizes uncertainty as to the mechanisms of ecosystem change and the influence of management on them. It focuses on the reduction of uncertainty through integrated efforts involving scientists, managers, and other stakeholders in an iterative process of learning through management and adjustment of management actions based on what is learned. USGS scientists have made important contributions in characterizing and measuring uncertainties, in the comparative assessment of potential consequences of management actions, in the design of monitoring programs that target relevant information for management decisions, and in the development of approaches to engage managers and stakeholders in a collaborative process of structured, adaptive decisionmaking. However, the demand for these skills by partners and stakeholders far exceeds the Bureau's capacity to meet that demand. This action would build USGS capacity to both conduct adaptive decision science and contribute decision support to Federal and State agencies and other organizations that are engaged in adaptive management projects for ecosystem restoration, adaptation, and management.

The actions discussed above are not intended to be the exclusive focus of ecosystem science in the USGS. Rather, they represent steps that can advance the USGS science strategies and help to identify priorities for future implementation plans. Efforts by the USGS and partners to observe, understand, map, and model ecosystems will vary in response to unexpected events and priorities at regional as well as national and global scales.

We emphasize that implementation of the strategic approaches and the proposed actions will depend on partners, collaborators, and stakeholders to help identify and prioritize the scientific information that they need to enhance the conservation and management of natural resources. This is in keeping with the vision of science that is deeply integrated with applications (figs. 1 and 2), such that science is framed, conducted, and applied by working directly with those who ultimately use and advance that science. Future actions and priorities will be identified and refined through multiple feedbacks within the USGS and from working with collaborators. The overall goal is to provide opportunities for scientists and managers to simultaneously advance scientific understanding and meet management's information needs.

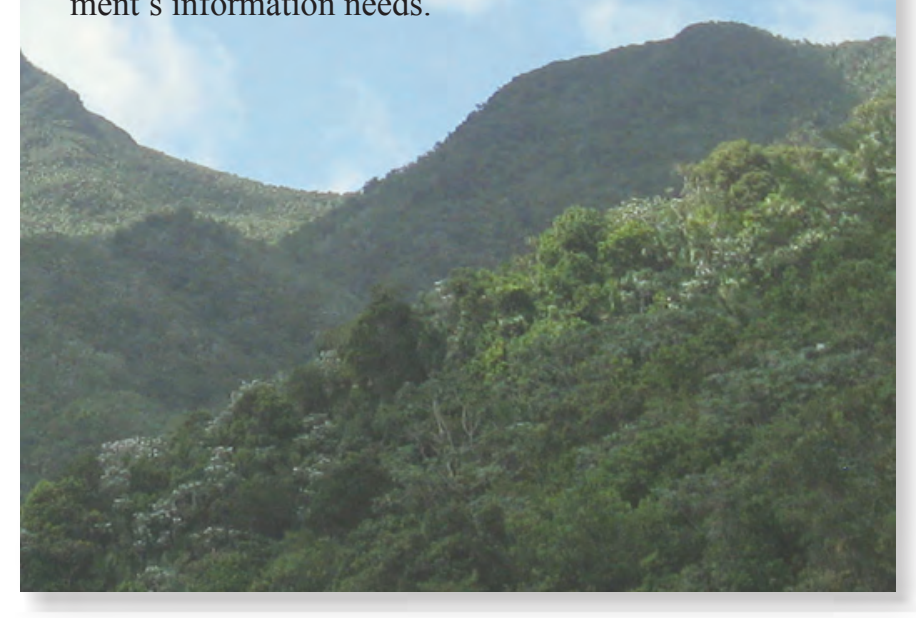




\section{Summary and Future of Ecosystem Science for the USGS}

The Nation faces complex and urgent environmental and social challenges that weigh heavily on the future security and well-being of society. Ecosystem science will be critical in meeting these challenges, and we envision the USGS as a leader in bringing unbiased scientific information to the forefront of decisionmaking processes that impact the Nation's natural resources and human well-being. In coordination with DOI partners and other Federal, tribal, State, territorial, and local institutions and nongovernmental collaborators, the USGS will accomplish the following:

- Identify priority issues that concern the use and sustainability of the Nation's natural resources.

- Invest in research, observations, monitoring, assessments, mapping, and modeling of biological, ecological, and social systems.

- Discover, understand, map, and describe the structures, functions, and drivers that influence fundamental ecosystem processes.

- Explain the distribution, abundance, and dynamics of the Nation's natural resources.

- Clarify the causes of change in biological and ecological systems over multiple spatial and temporal scales, including alterations in the Nation's environmental capital of ecosystem goods and services.
- Develop assessments, models, maps, and forecasts that deal explicitly with uncertainty to inform resource managers about natural hazards; resource extractions; land, water, and energy use; climate; and invasive species, pathogens, and disease.

- Provide decisionmakers with tools and techniques to explore policy and management options, including the investigation of tradeoffs in the costs and benefits of conservation, mitigation, adaptation, and restoration strategies.

- Implement adaptive, ecosystem-based resource management protocols and standards involving scientists and stakeholders who collaborate early and often to inform decisions within a decisionmaking framework that effectively integrates scientific discovery with applications.

By working proactively with stakeholders, building on USGS's broad scientific foundation, and integrating our portfolio of ecosystems science with the other mission area portfolios, the USGS will accelerate the understanding needed to manage biological and ecological systems. In so doing, our Bureau will provide information of fundamental importance in sustaining the Nation's natural resource heritage for future generations.

Volunteers planting marsh grass at Big Branch National Wildlife Refuge, Louisiana, as part of a multiyear land-reclamation project, which is designed to test the feasibility of larger scale coastal restoration efforts. Photograph by Steve Hillebrand, U.S. Fish and Wildlife Service.

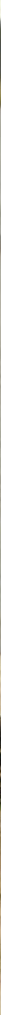




\section{Important Next Steps}

This strategy presents a broad, strategic vision of USGS ecosystem science for the next decade and represents the first step in a process that will include a more detailed implementation strategy for the ideas outlined here. Before the initiation of the implementation phase, we will need to coordinate closely with other mission areas, agencies, and organizations in the science community to understand where USGS efforts can provide added value to existing research efforts and to identify promising new directions consistent with the goals and approaches in this strategy. In addition, the USGS will need to collaborate closely with resource agencies in the DOI to address their needs for species and ecosystem management. The establishment of a USGS science forum (see first proposed action p. 25) provides an opportunity to foster such collaboration. Additional working groups like this may be necessary to include other partners that do not fall under the DOI umbrella. The important message is that there is still much work to do to ensure that our implementation strategy recognizes important ecosystem science that is being conducted by our partners and that USGS efforts include the priorities of our partners and stakeholders, while fundamentally advancing ecosystem science. Working with these partners and stakeholders, the USGS will play a key role during the next decade in developing the science foundation for sustaining the natural resources that diverse, productive, resilient ecosystems provide.

\section{A red wolf in the Alligator River National Wildlife Refuge, North Carolina, July 2009. The endangered red wolf once roamed the southeastern United States, but today the species is limited to the Outer Banks of North Carolina, a habitat threatened by sea-level rise. Despite their protected status, red wolves are frequently shot by hunters. Researchers studying the red wolf diet are demonstrating that wolves are not a threat to domestic animals. Photograph by Steve Hillebrand, U.S. Fish and Wildlife Service.}
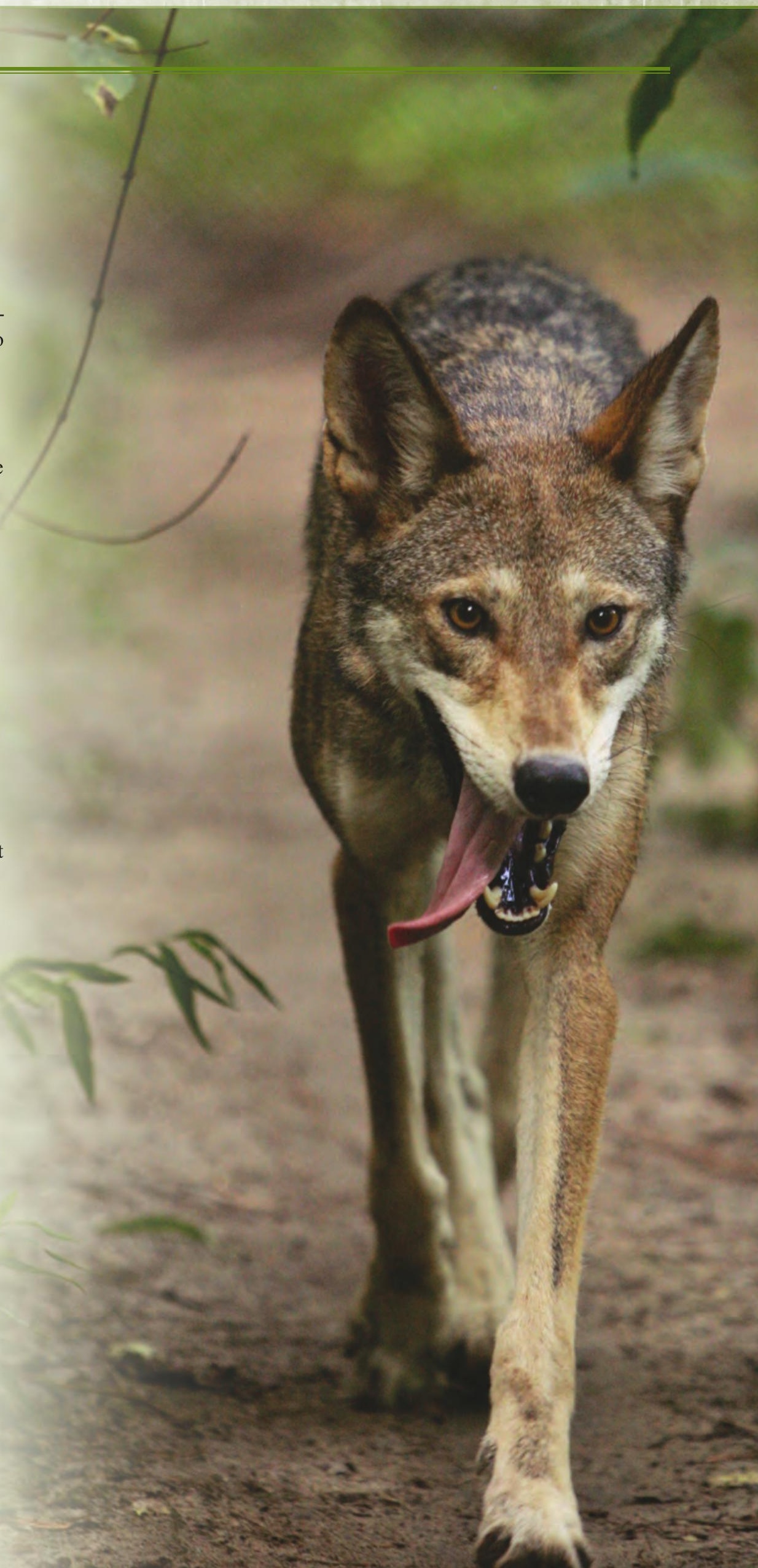


\section{References Cited}

Carpenter, S.R., Mooney, H.A., Agard, John, Capistrano, Doris, DeFries, R.S., Díaz, Sandra, Dietz, Thomas, Duraiappah, A.K., Oteng-Yeboah, Alfred, Pereira, H.M., Perrings, Charles, Reid, W.V., Sarukhan, José, Scholes, R.J., and Whyte, Anne, 2009, Science for managing ecosystem services-Beyond the Millennium Ecosystem Assessment: Proceedings of the National Academy of Sciences, v. 106, no. 5 , p. 1,305-1,312.

Costanza, Robert, d'Arge, Ralph, de Groot, Rudolf, and others, 1997, The value of the world's ecosystem services and natural capital: Nature, v. 387, p. 253-260.

Daily, G.C., and Matson, P.A. 2008, Ecosystem servicesFrom theory to implementation: Proceedings of the National Academy of Sciences, v. 105, no. 28, p. 9,455-9,456.

Fleishman, Erica, Blockstein, D.E., Hall, J.A., and others, 2011, Top 40 priorities for science to inform US conservation and management policy: BioScience, v. 61 , no. 4, p. 290-300.

Hickson, D., Keeler-Wolf, T., 2007, Vegetation and land use classification and map of the Sacramento-San Joaquin River Delta. California Department of Fish and Game.
Intergovernmental Panel on Climate Change (IPCC), 2007, Climate Change 2007-Synthesis Report-Contribution of Working Group I, II, and III to the Fourth Assessment Report of the Intergovernmental Panel on Climate Change (IPCC AR4) [Core Writing Team, Pachauri, R.K., and Reisinger, A., eds.]: Geneva, Switzerland, IPCC, 104 p.

Jackson, S.T., 2007, Looking forward from the past-history, ecology, and conservation: Frontiers in Ecology and the Environment, v. 5, no. 9, p. 455.

Larigauderie, Anne, and Mooney, H.A., 2010, The Intergovernmental science-policy Platform on Biodiversity and Ecosystem Services-moving a step closer to an IPCC-like mechanism for biodiversity: Current Opinion in Environmental Sustainability 2010, v. 2, no. 1-6.

National Energy Policy Development Group, 2001, Report of the national energy policy development group: Washington, D.C., U.S. Government Printing Office, 169 p.

President's Council on Science and Technology (PCAST), 2011, Sustaining environmental capital-Protecting society and the economy: Executive Office of the President, 145 p.

Rice, K.C., and Herman, J.S., 2010, Acidification of Earth-An assessment across mechanisms and scales: Applied Geochemistry, v. 27, p. 1-14.

Rockstrom, Johan, Steffen, Will, Noone, Kevin, and others, 2009, A safe operating space for humanity: Nature, v. 461, p. $472-475$. 
Rudd, M.A, Beazley, K.F., Cooke, S.J., and others, 2011, Generation of priority research questions to inform conservation policy and management at a national level: Conservation Biology, v. 25 , no. 3 , p. 1,523-1,739.

Sayre, Roger, Comer, Patrick, Warner, Harumi, and Cress, Jill, 2009, A new map of standardized terrestrial ecosystems of the conterminous United States: U.S. Geological Survey Professional Paper 1768, 17 p. (Also available at $h t t p: / /$ pubs.usgs.gov/pp/1768/.)

Smithsonian Office of Policy and Analysis, 2009, Addressing complexity-Fostering collaboration and interdisciplinary science research at the Smithsonian, Volume I-Summary Study Report: Report prepared for the Smithsonian under Secretary for Science by the Smithsonian Office of Policy and Analysis, 84 p.

Stokes, D.E., 1997, Pasteur's quadrant-Basic science and technological innovations: Washington, D.C., Brookings Institution Press, 196 p.

Sukhdev, Pavan, Wittmer, Heidi, Schroter-Schlaack, Christoph, and others, 2010, The economics of ecosystems and biodiversity-Mainstreaming the economics of nature-A synthesis of the approach, conclusions and recommendations of TEEB: United Nations Environment Programme, $36 \mathrm{p}$.

U.S. Census Bureau, 2008, (NP2008-T1) Projections of the population and components of change for the United States-2010 to 2050: Washington, D.C , Population Division, U.S. Census Bureau, Department of Commerce.
U.S. Fish and Wildlife Service, 2012, Adaptive harvest management—2012 hunting season: U.S. Department of Interior, Washington, D.C., 58 p. (Also available online at z.)

U.S. Geological Survey, 2007, Facing tomorrow's challengesU.S. Geological Survey science in the decade 2007-2017: U.S. Geological Survey Circular 1309, 70 p. (Also available at http://pubs.usgs.gov/circ/2007/1309/.)

Vitousek, P.M., Mooney, H.A., Lubchenco, Jane, and Melillo, J., 1997, Human domination of Earth's ecosystems: Science, v. 277, p. 494-499.

Whipple, A.A., Grossinger, R.M., Rankin, D., Stanford, B., and Askevold, R.A., 2012, Sacramento-San Joaquin Delta Historical Ecology Investigation: Exploring Pattern and Process: Richmond, CA, San Francisco Estuary InstituteAquatic Science Center Historical Ecology Program, Report, Publication \#672, Richmond, CA. (Available at http://www.sfei.org/node/4118).

Williams, B.K., and Brown, E.D., 2012, Adaptive management-The U.S. Department of the Interior Applications Guide: Washington, D.C., Adaptive Management Working Group, U.S. Department of the Interior.

Williams, B.K., Szaro, R.C., and Shapiro, C.D., 2007, Adaptive management-The U.S. Department of the Interior Technical Guide: Washington, D.C., Adaptive Management Working Group, U.S. Department of the Interior.

\section{Glacier National Park, Montana, August 2005. Photographs by G. Lynn Wingard, USGS. Right: Mountain goat. Background: Hidden Lake.}

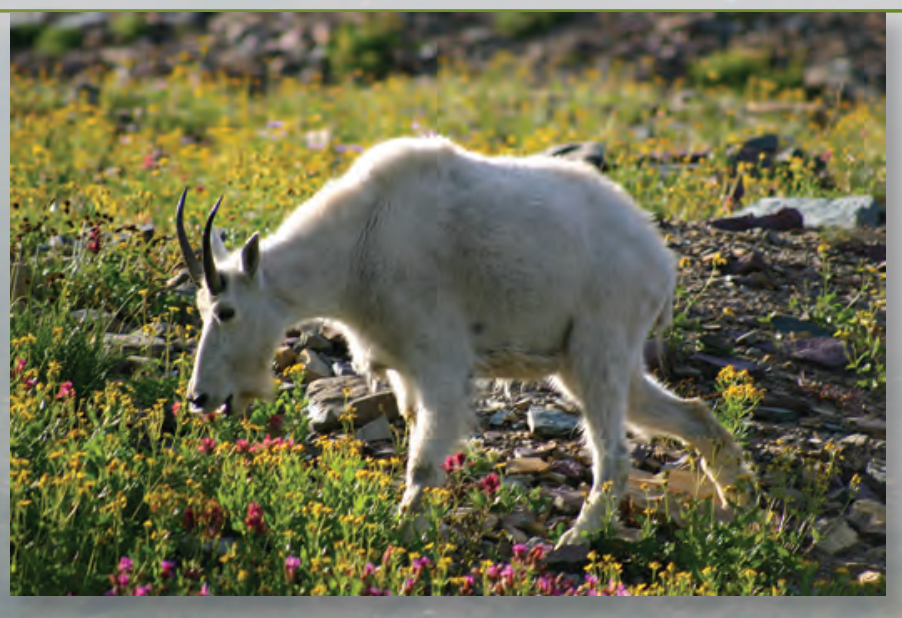




\section{Appendixes}

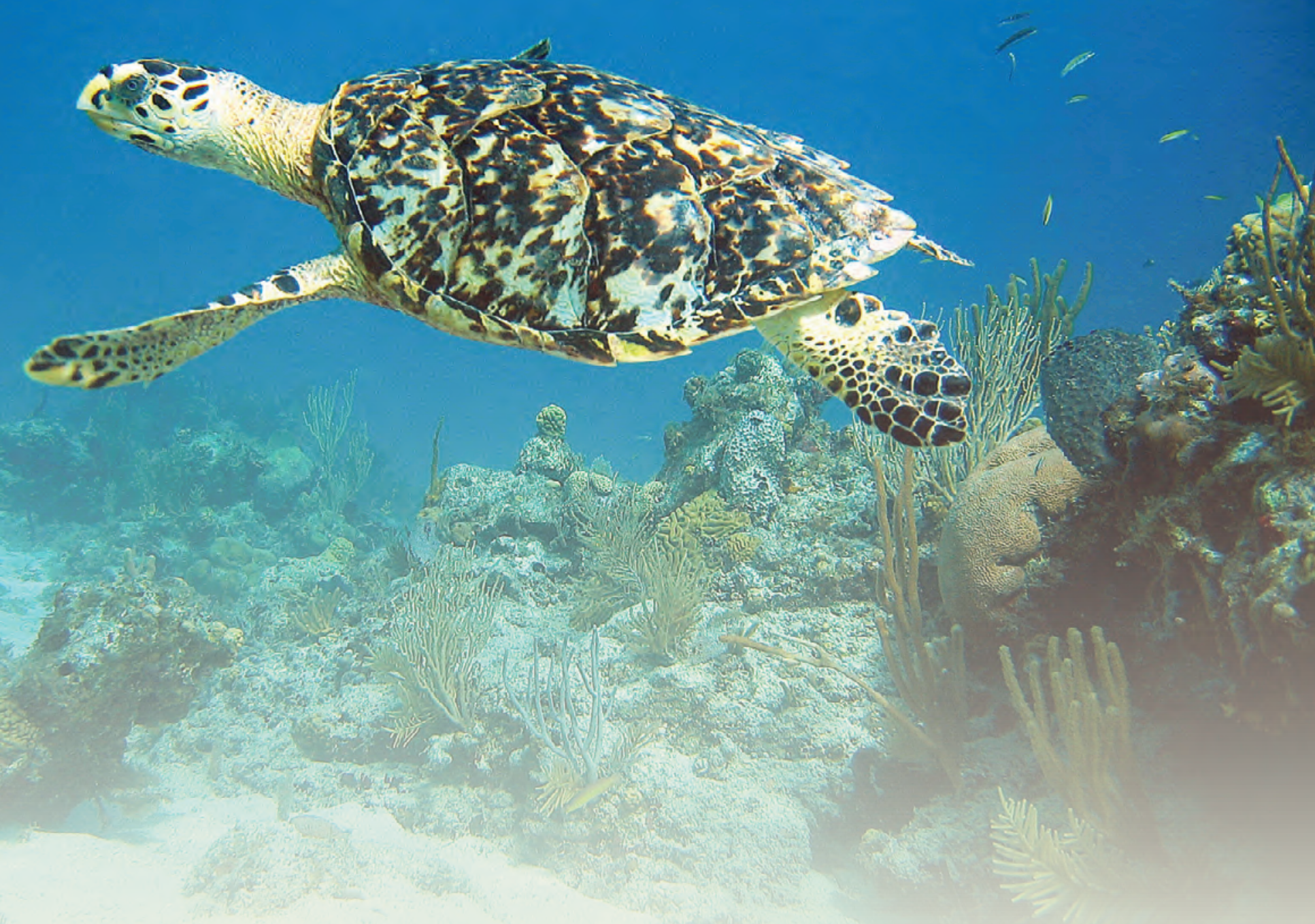

Hawksbill Turtle. Photograph by Gary Brewer, USGS. 


\section{Appendix 1. Author Affiliations and Acknowledgments}

The U.S. Geological Survey Ecosystem Science Strategy Planning Team is composed of the following individuals:

\begin{tabular}{ll}
\multicolumn{1}{c}{ Name } & \multicolumn{1}{c}{ Title/affiliation } \\
\hline Dr. Gary Brewer (co-chair) & Ocean Science Coordinator, Coastal and Marine Geology Program \\
\hline Dr. Byron K. Williams (co-chair) & Chief, Cooperative Research Units and Co-Director, Science and Decisions Center \\
\hline Dr. G. Lynn Wingard (co-chair) & Research Geologist, Eastern Geology and Paleoclimate Science Center, Northeast Region \\
\hline Dr. James E. Cloern & Senior Scientist, National Research Program, Western Branch \\
\hline Dr. Guy Gelfenbaum & Oceanographer, Coastal and Marine Geology, Pacific Region \\
\hline Dr. Robert B. Jacobson & Supervisory Research Hydrologist, Columbia Environmental Research Center, Midwest Region \\
\hline Dr. Jeffrey L. Kershner & Center Director, Northern Rocky Mountains Science Center, Northwest Region \\
\hline Dr. Anthony D. McGuire & Assistant Unit Leader, Alaska Cooperative Fish and Wildlife Research Unit, Alaska Region \\
\hline Dr. James D. Nichols & Senior Scientist, Patuxent Wildlife Research Center, Northeast Region \\
\hline Dr. Carl D. Shapiro & Economist and Co-Director, Science and Decisions Center \\
\hline Dr. Charles van Riper III & Senior Scientist, Southwest Biological Science Center, Southwest Region \\
\hline Dr. Robin P. White & Bureau Approving Official, Office of Science Quality and Integrity \\
\hline
\end{tabular}

${ }^{1}$ Gary Brewer served as co-chair from October 2010 until his retirement December 30, 2011. G. Lynn Wingard, a team member from October 2010, was appointed co-chair in January 2012.

The team appreciates the support and guidance provided by Anne Kinsinger, U.S. Geological Survey (USGS) Associate Director for the Ecosystems Mission Area and our Science Strategy Planning Team (SSPT) champion. Sarah Gerould (USGS) assisted with coordinating the team's activities and provided other valuable services and knowledgeable insight. We thank Julio Betancourt (USGS) and Jayne Belnap (USGS) for their careful reviews of an earlier version of the report. Scott Phillips (USGS) contributed the text box on the Chesapeake Bay to the document. We thank the many USGS scientists and external stakeholders who shared their knowledge of biological and ecological science with the team and contributed thoughtful comments on-line, during listening sessions, and in reviewing draft material.

Arctic National Wildlife Refuge, Alaska. Photograph by Steven Chase, USFWS.
We would especially like to thank the Federal agencies who provided formal written comments during an inter-agency review of an earlier draft in January 2012: Bureau of Land Management (BLM), Bureau of Ocean Energy Management (BOEM), Bureau of Reclamation (USBR), Federal Aviation Administration (FAA), Environmental Protection Agency (EPA), National Geospatial-Intelligence Agency (NGA), National Institutes of Health (NIH), National Oceanic and Atmospheric Administration (NOAA), National Park Service (NPS), U.S. Army Corps of Engineers (USACOE), U.S. Fish \& Wildlife Service (USFWS), and the U.S. Department of Agriculture (USDA) Animal and Plant Health Inspection Service and Agricultural Research Service. 


\section{Appendix 2. Key Terms}

Adaptation The adjustment of natural or human systems to a new or changing environment. Adaptation to climate change refers to adjustments in natural or human systems to reduce vulnerability to actual or anticipated climate change, or to exploit opportunities arising from that change.

Adaptive management Management that accounts for uncertainty about the processes that control natural resource behavior and the influence of management on resource changes. Adaptive resource management involves iterative decisionmaking along with resource monitoring to reduce this uncertainty through time and thereby improve resource management.

Collaborator In the context of USGS ecosystem science, a collaborator is a person, institution, or agency that participates in a collaborative scientific endeavor. Collaboration is used as an umbrella term to include peer-to-peer scientific relations, interactions with management agencies, and information exchanges with stakeholders (see stakeholder). A partner (see partner) is considered a specific type of collaborator.

Decision analysis In natural resources management, an investigation of decisions that can influence resource conditions or processes or both. Decision analysis may focus on a single decision made at a particular time, or iterative decisionmaking with the opportunity to learn through time and adjust management strategies based on what is learned.

Driver A factor that causes a change in an organism, community, ecosystem, or other ecological component of the landscape. An ecological driver may be biotic (for example, an invasive plant species that causes a decrease in the biological diversity of a forest) or abiotic (for example, a fire that causes a decrease in the biological diversity of a forest).

Ecosystem rehabilitation Recovery of ecosystem structure and function, but not necessarily to a pre-disturbance condition.

Ecosystem restoration The process of assisting the recovery of an ecosystem that has been degraded, damaged, or destroyed. The end state or reference condition for ecosystem restoration is rarely a pristine, natural state and, in most cases, recovery is defined as a condition that returns the ecosystem to a socially acceptable level of natural structure, function, and process.

Ecosystem science The study of systems of organisms interacting with their environment, and the consequences of natural and human-induced change on those systems.

Ecosystem services Goods and services that create value for human users and are derived from ecosystem processes such as nutrient recycling, climate regulation, and maintenance of biodiversity. Examples of ecosystem services include provision of clean drinking water, flood risk reduction, pollination of crops, and decomposition of wastes.

Existence value The value of an ecosystem attribute that accrues whether or not the attribute is ever experienced.
Examples are the Caribou breeding grounds in the Arctic wilderness or the mangrove wilderness of southwest Florida. Many people never experience these places in person but value their existence.

Feedback A mechanism, process, or signal that is looped back to control a resource system within itself. In systems containing an input and output, feeding back part of the output so as to increase the input is positive feedback; feeding back part of the output in such a way as to partially oppose the input is negative feedback.

Partner In the context of USGS ecosystem science, a partner is an individual, agency, or other group whose participation in a collaborative scientific endeavor includes investment of resources.

Resilience The ability of a system to absorb disturbances and still retain the same basic structure and functions. A resilient system is flexible and forgiving of external shocks. As resilience declines, the magnitude of shocks from which the system cannot recover gets smaller and smaller. Management for resilience seeks flexible system behaviors that can deliver desired ecosystem goods and services on a sustained basis.

Stakeholder An individual or organization (for example, a manager, scientist, private citizen, nongovernmental organization) with a vested interest in a shared enterprise. Interests can include an expectation of received benefit, a perceived threat, a prior investment of time or resources, or values shared with others associated with the enterprise. Partners are distinguished from stakeholders in that partners bring to the discussion table funds or resources (such as in-kind labor). Collaborators are referred to in this report as an equivalent to scientific peers in developing studies and conducting research.

Stressor An agent, attribute, or event that induces stress in a resource system. The factor that triggers the stress response may be a chemical or biological agent, environmental condition, external stimulus, or event.

Structured decisionmaking An organized approach to identifying and evaluating options and making choices in complex decision situations. The goal is to inform difficult choices and to make them more transparent and efficient through the integration of technical analysis with value-based deliberations.

Sustainability The capacity to endure over an extended time. Sustainable resource systems retain their structure, function, and ability to provide ecosystem services, and sustainable management is conducive to such retention. Sustainability is closely tied to the concept of system resilience (see resilience).

Threshold The limiting value of a resource attribute that triggers a change in management actions. Management strategies often include thresholds, such that one action is specified for resource values less than the threshold and a different action is specified for resource values greater than the threshold. 


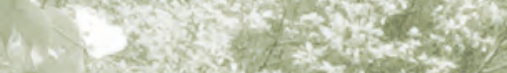

(4.5) (x) (n)

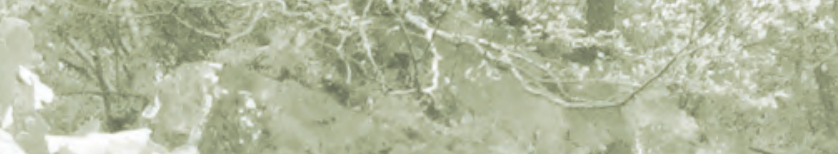
3. $k 31$

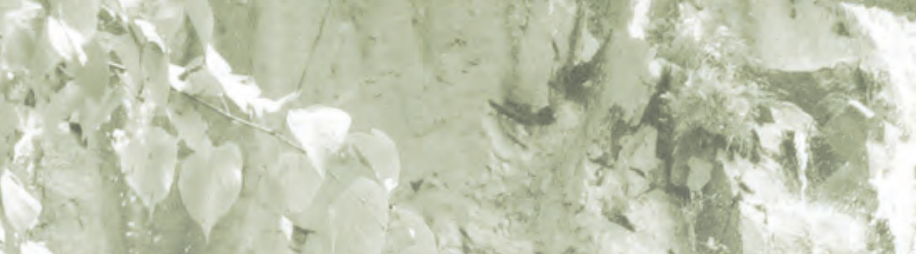

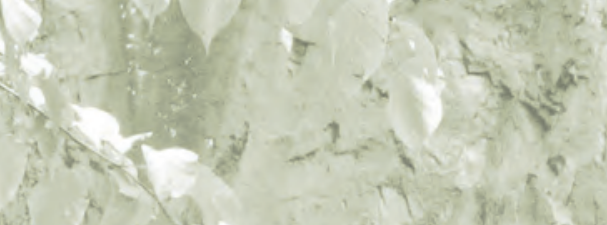

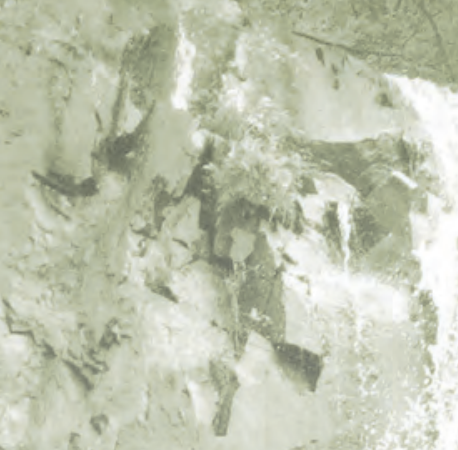

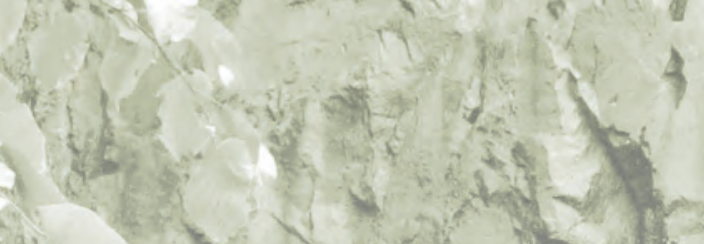

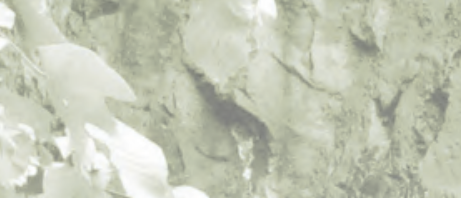

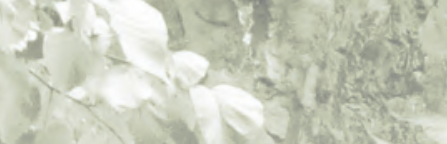

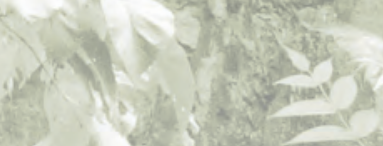

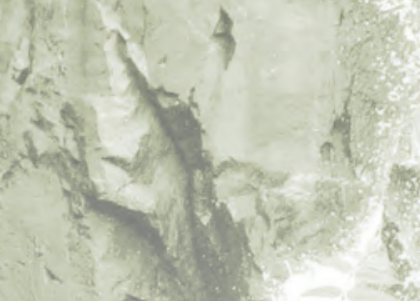

$\frac{3}{3}$

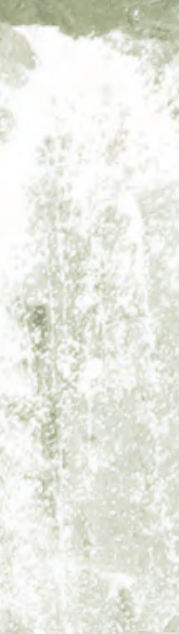

$x^{2}+x^{2}+x^{2}$
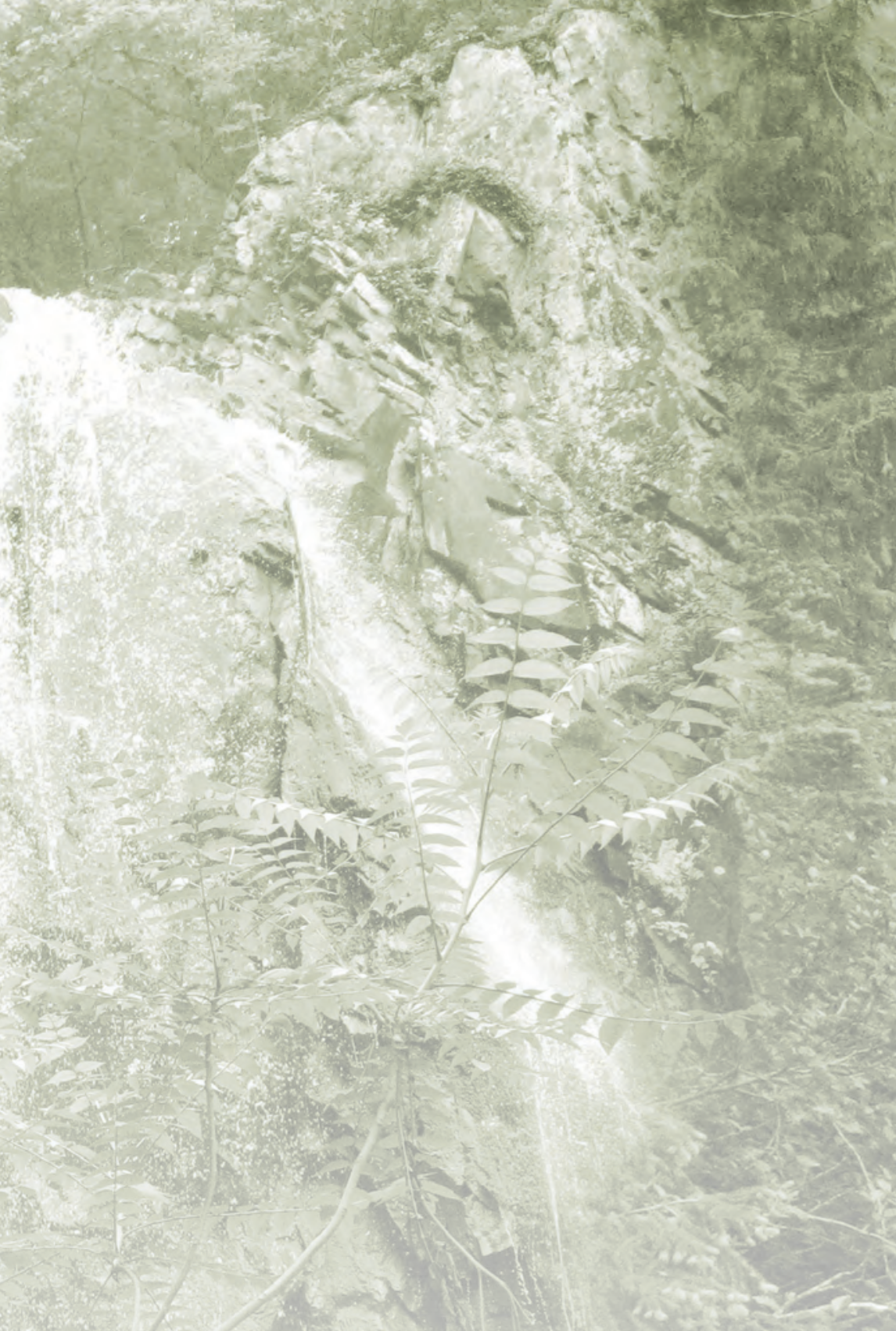

7. 

